\title{
Technical and environmental efficiency of grapevine producers in Mendoza, Argentina
}

\author{
Dissertation \\ to obtain the doctoral degree Dr. rer. pol. \\ in the International Ph. D. Program for Agricultural Sciences in Göttingen (IPAG) \\ at the Faculty of Agricultural Sciences, \\ Georg-August-Universität Göttingen, Germany
}

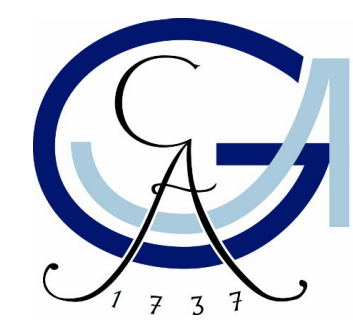

presented by

Félix Sebastián Riera

Born in Mendoza, Argentina

Göttingen, October 2018 
D7

1. Name of supervisor: Prof. Dr. Bernhard Brümmer

2. Name of co-supervisor: Prof. Dr. Stephan von Cramon-Taubadel

3. Name of 2nd co-supervisor: Prof. Dr. Alejandro Gennari

Date of dissertation: 02.11 .2018 


\section{Summary}

Throughout the past years, the exploitation of natural resources has gained relevance in the global development agenda, and the agricultural sector has thus been put under considerable pressure to improve efficiency in production systems. While producing more with less has seemed to be right direction, the resilience capacity of agroecosystems calls for responsible exploitation of natural

resources. Agricultural systems in semi-arid areas present a good example of the challenges of sustainable development, where the climatic conditions are suitable for the high-value crops with relatively low water needs. Grapevine production fits into this scenario providing the main input for the high-value product wine. Due to the continuing economic development, the demand for natural resources could increase creating frictions among demanding sectors of the economy. In light of this, a clear legal framework and institutional hierarchy are desirable to regulate exploitation. However, weak or static institutional settings could enable predatory behavior by stakeholders with privileged access.

As the Argentinean grapevine production systems have gained global visibility, the wine industry has been revitalized with a greater focus on enological quality, technology adoption, and export orientation. Although grapevine production has decreased $36 \%$ in a decade nationwide, the province of Mendoza accounts for $66 \%$ of grapevine production and $73.3 \%$ of the wine making (INV 2018a). These changes are explained by relatively more technologically advanced production systems with a focus on quality and a higher decrease of vine hectarage in other provinces of Argentina. However, even after qualitative improvements, the export value has not increased substantially in the last years; simultaneously small and medium size producers face scale limitations, financial constraints, and uneven access to quality irrigation water. There is a concern that vineyards fall short on their potential and that they are not optimizing their resources. While local farmers face a shrinking supply of water due to the high competition for the resource, different extension programs contributed to farmers' organization but have not improved their economic performance, maybe due to inaccurate planning and baseline information.

The contribution of this dissertation is to unveil the underlying political and economic factors that affect the performance of vineyards and their effects on water resources. This dissertation departs from previous empirical applications by shedding light on the efficiency determinants of grapevine production and simultaneously accounting for agroecosystem characteristics and plot level information including irrigated water volumes in Mendoza, Argentina.

The second chapter of the document analyzes through a conceptual framework the economic and political forces that influence stakeholders' decision on public support to agriculture. Natural resource policies in Latin America are rarely identified as long-term consistent and power independent. The province of Mendoza could achieve both characteristics with the exception of groundwater management were policy flaws are visible on ensuring quality and availability. Energy subsidies for agricultural irrigation have relied too long on permanent policy subject to political maneuvers every time their stability is at risk. Following a tripod framework to review the institutional settings of 
the water-energy nexus, we review the policy effectiveness and analyze their outcome in light of the water-energy policies. Although the majority of policy tools were demand oriented during the last 25 years, they have not provided consistent economic incentives for agricultural producers to consider environmental degradation of groundwater resources. The economic tools designed for the agricultural sector aimed to sustain a level of profits by influencing the market conditions rather than improving farm level efficiency. A relation between grapevine prices and groundwater table levels was found, which suggests the over exploitation of the Carrizal aquifer under the energy subsidy scenario. In order to employ the resources in a sustainable manner and further save energy and money, subsidy effectiveness shall be reconsidered.

The third chapter considers the economic performance of small and medium farmers, whose profitability is compromised and is sensible to the economic framework and local markets. This group of producers could be trapped in a declining spiral of water availability, vine production quality, and economic profitability. Although the public sector creates policies oriented to small-scale producers, most of them aim at solving urgent needs rather than fostering performance. Technical efficiency is assessed utilizing an unique dataset of 647 plots that includes, soil characterization, water volumes, and dummy variables for technology adoption and enological practices. To further enhance better understanding of the vineyards' performance, this chapter analyses technical efficiency for two subgroups: viticulturists $(n=444)$ and wine growers $(n=203)$. The former commercializes their output with wineries; while the latter elaborates their own wine. The stochastic analysis is performed allowing for external and managerial variables to affect the economic performance in relation with their benchmark; whose effect can be overall assessed with the estimation of marginal and partial effect of the average.

Although the mean technical efficiency of both subgroups is similar, $82.9 \%$ and $81.9 \%$ for viticulturists and winegrowers respectively, their mean yield production is significantly different. Moreover, winegrowers' production process is more dependent on capital, while viticulturists rely on all production inputs significantly. The focus on quality of winegrowers is tangible through the employment of machine and craft management practices. The energy subsidy for groundwater irrigation contributes to efficiency performance but only for viticulturists. While, the technical advice of agricultural extensionists translate into efficiency gains.

The fourth chapter continues with parametric techniques but employs directional distance functions to jointly estimate technical and environmental efficiency of grapevine producers. The research considers that farmers jointly produce a desired output (grapevines) and an undesired output (saline hazard), both are dependent on the farmers' location as well as their production systems and practices. The framework allows for estimation of the directional distance function following the most fair direction; that is, increasing grapevine production while decreasing salinity hazard. Results of the estimation confirm an existing trade-off relationship between grapevine production and saline hazard. The mean economic environmental efficiency is 0.869 corresponding a mean inefficiency of 0.131. Furthermore, production systems are performing at decreasing returns to scale and there are significant differences in some indicators according to the water source and 
market orientation. Each plot has an irrigation need that varies according to the agroecosystem and crop management, the results confirm that irrigation beyond a certain threshold does not improve performance. While vineyard density and the advice of agricultural extensionists do diminish the gap with the benchmark. The chapter also includes the calculation of the shadow price for each kilogram of saline content; the average price is USD 3.09 and also varies across districts.

General conclusions of the analysis calls for greater involvement in the decision process of the sector specific policies while jointly fostering accountability of policy-makers on their decisions. Vineyards that rely on groundwater for irrigation perform relatively well considering their limitations, governmental support should focus on strengthening managerial practices and technology adoption that will minimize their losses against environmental threats. The technical advice from agricultural extensionists is a desirable contribution to improve technical-environmental efficiency performance. In particular, the energy subsidy contributes to efficiency gains for small and medium viticulturists but when economic and environmental efficiency are jointly estimated, the effect of subsidy only diminishes uncertainty at the expense of more inefficiency. Moreover, significant technical and environmental performance could be achieved if joint programs of technology adoption and extension services are fostered. The funding for these programs could come from gradual reassignments of the annual budget for subsidizing energy. To envisage greater development of the industry, the edition of a new joint strategic development plan would realign efforts towards quality while ensuring economic earnings for producers. 


\section{Acknowledgements}

Doing a Ph.D. is a life experience and, certainly, a life-long lesson. And it would be completely unfair not to look back and greet all the people that have supported me in this brief but challenging chapter of my life. Göttingen is a wonderful place to accomplish many things but doing a Ph.D. surrounded by wonderfull people is priceless.

Firstly, I would kindly like to thank Prof. Dr. Bernhard Brümmer for providing your continuous support, guidance and empathy with my professional and personal objectives. I honestly considered it a privilege to count on your trust and your invaluable insights on my work, ideas and projects. I would also like to thank Prof. Dr. Stephan von-Cramon Taubadel for his support not only during my doctoral studies but also since I did my master with the joint program. I have always benefited from our talks and I enjoyed our discussions. Also, I would like to thank Prof. Dr. Alejandro Gennari, who was the first person that suggested me pursue a Ph.D. and his support and feedback has been very important in the interpretation of water and grapevine management. Personally, I would also like to thank Dr. Sebastian Lakner, who acknowledged my willingness to pursue a doctoral degree and assisted me in the application process. Without his support I would not have returned so quickly to Göttingen.

Pursuing a Ph.D. in Germany would have not been possible without the scholarship provided by the German Academic Exchange Service (DAAD). They facilitated me and my wife with numerous benefits and opportunities. This research has also been funded by the Chair of Agricultural Market Analysis of the Agricultural Economics Department.

Also, I would like to thank the institutions that assisted me in the field work and data collection planning. The coordination with the General Department of Irrigation (DGI) and the Statistics Bureau of the province (DEIE) allowed a detailed planning for fieldwork execution. Furthermore, DEIE advised me on how to assess socio-economic characteristics of producers and supported the logistic planning to collect the data. Also, Lic. Javier Castillo from the Provincial Energy Regulator Entity (EPRE) who facilitated me with the energy data for groundwater estimation, and Leonardo Insegna from the Agricultural Direction of Climate Contingencies (DACC) for their initial support.

Life would not be complete without friends and memorable times. Göttingen has gone beyond my expectations and provided me with strong life-long friendship bonds. I am deeply thankful to all my friends and colleagues that supported and enriched my Ph.D. roller coaster. In particular, to the maes Luis \& Gloriana, the garotinhos Caetano \& Sabrina and, mi querido Atlético Chingones. To my dear colleagues from the Chair, I am really thankful for the opportunity to meet you, and share numerous amount of laughs, theoretical knowledge and asados. In alphabetical order, Bernhard, Claudia, Dela-Dem Do, Enrique, Gabriel, Jurij, Malte, Mareike, Marwan, Oliver, Tim, Yashree; your support has been invaluable at all times and I am deeply thankful that our paths have crossed.

Last but not least, to my lovely wife Lucia who has always trusted in me and provided me with advice, support and containment. I deeply thank you. Also, I would like to thank my family for all the support and empathy with my objectives. I love you infinitely. 


\section{Contents}

Summary ......................... i

1 General introduction $\quad 1$

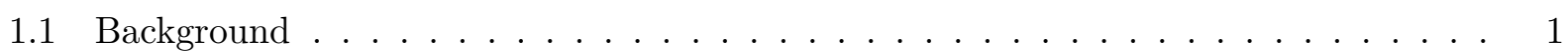

1.1.1 Viticulture in Argentina . . . . . . . . . . . . . . . . . . 2

1.1.2 Water scarcity and challenges in the wine sector . . . . . . . . . 3

1.2 Research gaps . . . . . . . . . . . . . . . . . . . 4

1.2.1 Interactions of political and economic factors in water management under pollution threat and scarcity . . . . . . . . . . . . . 4

1.2.2 Economic performance of grapevine producers and efficiency determinants . . 5

1.2.3 Environmental performance of grapevine producers . . . . . . . . . . . . 6

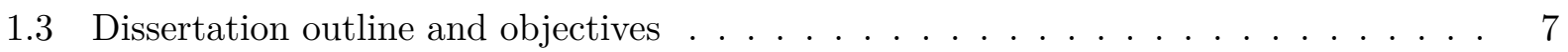

2 Political economy of energy subsidies for groundwater irrigation 9

2.1 Introduction . . . . . . . . . . . . . . . . . . . . . . 9

2.1 .1 Study area . . . . . . . . . . . . . . . . . . 10

2.1 .2 Water resources . . . . . . . . . . . . . . . . . . 11

2.2 Materials and methods . . . . . . . . . . . . . . . . . . . 11

2.2.1 General water law, principles, and institutional organization . . . . . . . . . 11

2.2.2 Energy and subsidy information . . . . . . . . . . . . . . . . 15

2.2.3 Agricultural and economic tools . . . . . . . . . . . . . . . . 17

2.2 .4 Framework . . . . . . . . . . . . . . . . . . . 19

2.3 Results and discussion . . . . . . . . . . . . . . . . . . 20

2.4 Conclusions . . . . . . . . . . . . . . . . . . . 23

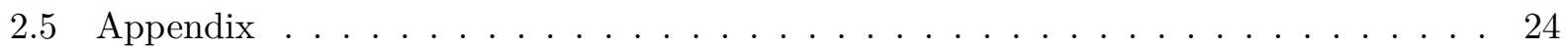

3 Determinants of technical efficiency 26

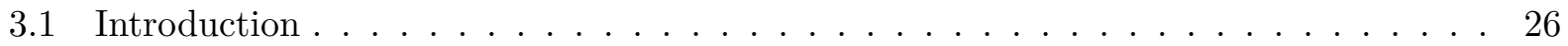

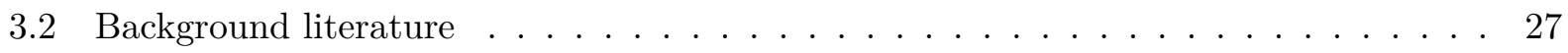

3.3 Methodology . . . . . . . . . . . . . . . . . . 29

3.3.1 Valuation of capital services . . . . . . . . . . . . . . . . . 29

3.3 .2 Model specification . . . . . . . . . . . . . . . . . . . 30

3.3.3 Marginal and partial effects of the average . . . . . . . . . . . 31 
3.4 Data . . . . . . . . . . . . . . . . . . . . . 32

3.4.1 Sample data and variable selection . . . . . . . . . . . . . . 34

3.4.2 Data validation and interpretation . . . . . . . . . . . . . 34

3.4.3 Analysis and imputation techniques . . . . . . . . . . . . 35

3.5 Results and discussion . . . . . . . . . . . . . . . . 36

3.5.1 Functional form and efficiency determinants . . . . . . . . . . . . . 37

3.5.2 Marginal and average partial effects . . . . . . . . . . . . . . . . 41

3.6 Conclusions . . . . . . . . . . . . . . . . . . . . . . . . 42

4 Environmental efficiency of grapevine production 44

4.1 Introduction . . . . . . . . . . . . . . . . . . . . . . . 44

4.2 Methods and materials . . . . . . . . . . . . . . . . . 45

4.2 .1 Theoretical model . . . . . . . . . . . . . . . . . . . 45

4.2 .2 Empirical specification . . . . . . . . . . . . . . . . 48

4.2 .3 Data . . . . . . . . . . . . . . . . . . . 50

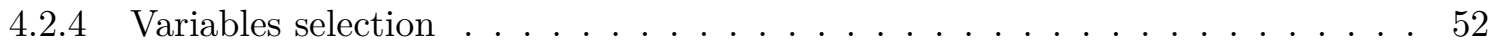

4.3 Results and discussion . . . . . . . . . . . . . . . . . 55

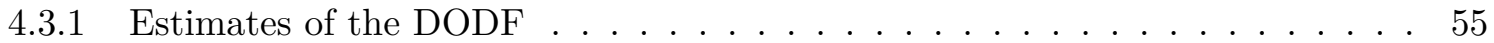

4.3 .2 Efficiency determinants . . . . . . . . . . . . . . . . 57

4.3.3 Shadow price of saline hazard . . . . . . . . . . . . . . . . 60

4.4 Conclusions . . . . . . . . . . . . . . . . . . . . . . 61

5 General conlusions $\quad 63$

5.1 Main findings . . . . . . . . . . . . . . . . . . . 63

5.2 Policy implications . . . . . . . . . . . . . . . . 66

5.3 Limitations and suggestions for future research $\ldots \ldots \ldots \ldots$ 


\section{List of Figures}

2.1 Land entitlement over the Carrizal aquifer . . . . . . . . . . . . . . 10

2.2 Characterization of institutions . . . . . . . . . . . . . . . . . 12

2.3 Annual changes in the storage of the aquifer $(1979-1999) \ldots \ldots \ldots$

2.4 Energy consumed for agricultural irrigation (Mendoza) . . . . . . . . . . . . . 16

2.5 Trimestral energy tariffs for irrigation. Low and high demand prices . . . . . . . . 17

2.6 Grapevine prices, energy subsidy and groundwater table . . . . . . . . . . . 21

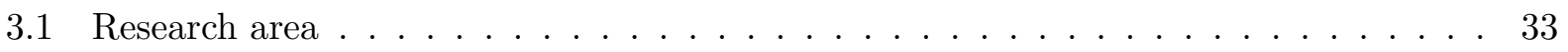

3.2 Grapevine yield per hectare . . . . . . . . . . . . . . . . . 35

3.3 Histograms of TE scores . . . . . . . . . . . . . . . . . . . . . . . . . 39

4.1 Geographical location of the research area and water sample points . . . . . . . . 51

4.2 Salinity hazard and yield relation . . . . . . . . . . . . . . . 54

4.3 Histograms of EE scores and trade-off visualization . . . . . . . . . . . . . . 59 


\section{List of Tables}

2.1 Comparison of irrigation systems . . . . . . . . . . . . . . . . 14

2.2 Basin characteristics . . . . . . . . . . . . . . . . . . . 15

2.3 Subsidy scheme including fix costs of energy provision $(2012) \ldots \ldots$. . . . . 17

2.4 Current policy tools on water management . . . . . . . . . . . . . 22

2.5 Record of political disputes in the last 20 years $\ldots \ldots \ldots . \ldots \ldots$

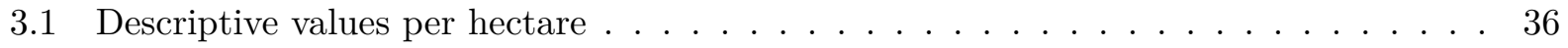

3.2 Estimation coefficients of production function . . . . . . . . . . . 38

3.3 Estimation coefficients for external variables . . . . . . . . . . . . . . . . 40

3.4 Mean efficiency scores per district . . . . . . . . . . . . . . . . . . . . . . 41

3.5 Marginal and average partial effects of external variables . . . . . . . . . . . 42

4.1 Descriptive values per hectare . . . . . . . . . . . . . . 51

4.2 Estimation coefficients of environmental efficiency . . . . . . . . . . . . 56

4.3 Summary elasticities . . . . . . . . . . . . . . . . . . . 57

4.4 Estimated coefficients and marginal effects of external variables . . . . . . . . . . 58

4.5 Mean differences in alternative subgroups . . . . . . . . . . . . . . . . . . . 59

4.6 Mean efficiency and shadow price per district . . . . . . . . . . . 60 


\section{List of acronyms}

\begin{tabular}{ll}
\hline AE & Allocative efficiency \\
APE & Average Partial Effect \\
ARS & Argentinean Pesos \\
BCM & Mendoza Stock Exchange \\
COVIAR & Argentine Viticultural Corporation \\
DDF & Directional Distance Functions \\
DEA & Data Envelopment Analysis \\
DEIE & Statistics and Economic Research Direction \\
DGI & General Irrigation Department \\
DODF & Directional Output Distance Function \\
EC & Electro-conductivity \\
EPRE & Provincial Electric Regulator Entity \\
FAO & Food and Agriculture Organization of the United Nations \\
GDP & Gross Domestic Product \\
HLPM & Honorable Legislature of Mendoza Province \\
IERAL & Institute of Studies of the Argentinean and Latin American Reality \\
INA & National Institute of Water \\
INTA & National Institute of Agricultural Technology \\
INV & National Institute of Viticulture \\
IWMI & International Water Management Institute \\
kWh & Kilowatt hour \\
MAGyP & Ministry of Agriculture, Livestock and Fisheries \\
ME & Marginal Effects \\
ML & Maximum Likelihood \\
OECD & Organization for Economic Cooperation and Development \\
OEI & Ibero-American States Organization \\
OIV & International Organisation of Vine and Wine \\
OVA & Argentine Viticultural Observatory \\
PEVI & Argentina Viticultural Strategic Plan \\
pH & Acidic Levels \\
PROSAP & Provincial Agricultural Services Program \\
SAGyP & Secretariat of Agriculture, Livestock and Fisheries \\
SDGs & Sustainable Development Goals \\
SFA & Stochastic Frontier Analysis \\
SH & Salinity Hazard \\
SSPE & Undersecretary of Economic Planning \\
TDS & Total Disolved Solids \\
TE & Technical efficiency \\
UN-WATER & United Nations Water \\
USD & United States Dollar \\
WEF & World Economic Forum \\
WWAP & World Water Assessment Programme \\
YPF & Fiscal Oilfields \\
\hline & \\
\hline & \\
\hline
\end{tabular}


Para Valentina 


\section{Chapter 1}

\section{General introduction}

\section{$1.1 \quad$ Background}

As climate changes and human interactions with ecosystems increase, access to natural resources is becoming a strong limitation in some areas, in particular water resources in arid and semi-arid environments (OECD/FAO 2018; OECD/FAO 2012). Global institutions had envisioned the threat of inefficient water management and sought to increase social awareness through the promotion of the Sustainable Development Goals (SDGs), the water governance indicators by OECD (2011) and eliciting the interlinkages between water and other value generating sectors of the economy (WEF 2011a; FAO/IWMI 2018; WWAP/UN-Water 2018). Although technology and management improvements have a great potential of saving water by making irrigation more efficient (Speelman et al. 2008; Karagiannis et al. 2003), the resulting programs that foster technology adoption have not met all their objectives (Berbel et al. 2014; Ward and Pulido-Velazquez 2008). Potential gains from advances in irrigation systems do not necessarily contracts the demand for water. Therefore, the integrated management of water resources recalls for research of water systems at a broader scale, which is impossible without improving water accounting, volume estimations, and hydro-geological knowledge of the basins (Grafton et al. 2018). Some efforts have been documented in this line (Scott et al. 2014; Sun et al. 2016; Bowmer 2011; Rosegrant et al. 2000).

Evidence shows that it is possible to improve water management and subsequently progress towards a better-off situation for agricultural development (OECD 2015; Brozović et al. 2006; Oster and Wichelns 2003). However, an important question is: what are the limitations for these achievements to succeed in practice? Most likely, flaws in the policy implementation that do not account for changes in the behavior of stakeholders ( $\mathrm{Li}$ et al. 2018; Grafton et al. 2018) and inconsistent policy coherence, as it is relatively difficult for governments to maintain strict rules for longer periods of time (Lankoski et al. 2018; World Bank 2008; Donoso et al. 2014).

Since Aigner et al. (1977) and Meeusen and van Den Broeck (1977) simultaneously acknowledged the possibility to analyze production processes decomposing the former statistical error into an efficiency measure and stochastic noise, efficiency analysis has become a relevant branch of empirical economics 
with several approaches and techniques to improve the performance assessment of different economic sectors. The agricultural sector has become an important recipient of research studies and applied theoretical developments. Nevertheless, evidence of applications in grapevine production is scarce, which is surprising considering the spill-over effects of wine grape production (Giraud-Héraud and Pichery 2013) and the potential increase in areas suitable for wine grape crops due to increments in temperature (PwC 2009).

This dissertation seeks to address these general issues to further decouple the implications for the grapevine producers at the right bank of the Mendoza river in Mendoza, Argentina. Where the production and quality potential is acknowledged but is still restricted (Stein 2007; Farinelli 2007).

\subsubsection{Viticulture in Argentina}

Historically the wine industry has been representative of intensive agricultural systems in Argentina, a country that can count on relatively high consumption in the regional markets. The country is the $7^{\text {th }}$ largest in the world producing 1,174 million liters, where approximately $76 \%$ is consumed locally (INV 2018a; OIV 2018). The total value of the industry represented USD 4,242 million or Argentinean Pesos (ARS) 72,100 million; which only accounts for $0.4 \%$ of the national GDP (COVIAR/OVA 2018). However, the industry stimulates other sectors of the economy by generating 279,000 jobs indirectly plus the commercialization of inputs such as agrochemicals and machinery. Generally, the production process is labor intensive and demands management crafts to be performed throughout the year, such as pest control, pruning, leaf removal, among others. At the end of last century, sector specific organizations drafted the strategic medium-term plan (PEVI 2020) to further innovate and develop the industry with a clear orientation to international markets and global consumption trends (Ruiz and Vitale 2011; Jofré 2010). The favorable agricultural and enological conditions contributed to catalog Argentina as a New World wine country (Fleming et al. 2014). Economic and financial crises justified currency devaluation that boosted foreign direct investments in the sector; which fostered technology adoption and the exploration of new global markets (IERAL 2011). Turbulent economic years of adjustments and infrastructure development did not impede the wine industry to continue developing. During 2017, the country exported 223 million liters valued USD 953.65 million (INV 2018b).

Nationwide, the total grapevine production was valued at USD 930 millions (ARS 15,822 millions) from which Mendoza province accounted for 89.6\% (INV 2018a). Although some organizations have gained power along the value chain, within the province, a significant share of vineyards are affiliated with wine cooperatives (20-28\%) that purchase their grapevine and elaborate according to the expected quality (Hartt Kentnor 2012; Jofré 2010; Richard-Jorba 2007). Non-affiliated vineyards may have contract agreements with other wineries or may produce their own wine and commercialize it accordingly (Codron et al. 2013). Despite the invigorating growth of the wine industry, several sector specific policies have not achieved success upon implementation or their tools have been undermined by other macroeconomic aspects, e.g., micro-devaluations failed to increase competitive gains for the sector since input suppliers adjusted their prices quicker. 
As the harvest season approaches, farmers face uneven commercialization scenarios of price fluctuations and bargaining power from wineries, even those that are affiliated with cooperatives (Codron et al. 2013). Generally, provincial government have engaged in negotiations, providing support in wine purchasing or withdrawing wine stocks from the market in order to indirectly invigorate prices (Ferreyra and Vera 2018). In a fluctuant macroeconomic context, vineyards may face the financial constraints of unprofitable business with a production system that is continuously demanding resources for management tasks and activities.

\subsubsection{Water scarcity and challenges in the wine sector}

In the province of Mendoza, access to natural resources is uneven considering the infrastructure conditions required by the heterogeneous terrain and the rural urbanization phenomenon (HLPM 2017). Water management is critical and relies on the oldest water law in the continent (Bermejo 1884), this legislation set the principles in the usage of the resource to human and economic development. Currently, the share of water used in agriculture is $85-90 \%$ in Mendoza (Puebla et al. 2005), exceeding the global average of $70 \%$ (WWAP/UN-Water 2018), other sectors in the economy demand a greater share of water resources.

In addition to resource competition, the scarcity context and climate variability raises questions whether farmers are using the resource efficiently or performing below their potential and not fully benefiting from their water supply (Agosta et al. 2012). Higher water productivity in economic terms also contributes to resource competition, in particular if the perception is that farmers are not using water efficiently. In Latin America, the agricultural use of water is among the less productive, generally less than USD $1 / \mathrm{m}^{3}$, while industrial use of water in Argentina yields USD $80 / \mathrm{m}^{3}$ (Donoso et al. 2014).

In 1999 the General Irrigation Department (DGI), the local water authority, acknowledged the deficit of $34 \mathrm{hm}^{3}$ of irrigation water and the 3.5 meter decrease in the groundwater levels and imposed the zoning restriction under the resolution 220/99 that still remains active (Llop et al. 2016; Foster and Garduño 2006; Álvarez et al. 2009). The Carrizal aquifer is sensible to resource pollution from two sources. A local pollution source was discovered at the petrochemical complex located in the area, which forced farmers to seek more reliable irrigation water from the deeper confined aquifer (Foster and Garduño 2005; Altamirano et al. 2005; Reta 2005). This led to excess pressure from water overdraft that incite saline intrusion and further extended the period for aquifer recovery (Hernández et al. 2012; Diaz Araujo and Bertranou 2004; Lohn et al. 2000).

Although several technological improvements have been developed to save water though irrigation practices (Trentacoste et al. 2015), there is a growing evidence that policy implementation unfolds in the opposite direction of increasing consumption instead of decreasing it (Grafton2018; Qureshi et al. 2010; Ward et al. 2008). In agriculture, the concept of efficient irrigation can be misperceived with similar concepts of water productivity or allocation efficiency (Donoso et al. 2014). To a great extent, water institutions in Mendoza have focused on forecasting and modeling at a greater water scale than farm, mainly Instituto Nacional del Agua (INA) and Departamento General de Irrigacion 
(DGI) through their reports on the northern basin and hydric balance (Hernández et al. 2012; Salomón et al. 2008). But policy decisions are not fully addressing these approaches (Castex et al. 2015; Hurlbert and Mussetta 2016). There is a significant need to improve water accounting and water productivity measures that will contribute to the formulation of water policies to a broader scale.

\section{$1.2 \quad$ Research gaps}

\subsubsection{Interactions of political and economic factors in water management under pollution threat and scarcity}

The complexity of political decisions under changing economic circumstances increases significantly if environmental pollution is affecting stakeholders. Economic policy is a broad highway with different lanes of political implications, lobbyist groups and stakeholder involvement; the heterogeneity of water, food, and energy policies requires a broader perspective of interactions to design tailored interventions (Dinar 2000; Scott et al. 2014). Local pollution is sector specific and most likely accidental, while diffuse pollution, is commonly related with common-pool resources (OECD 2017), where individuals are prone to adopt unilateral utility maximization behavior without considering the (detrimental) effects of their actions (Ostrom 2012; Bertranou et al. 1983).

Subsidizing energy for groundwater irrigation has been interpreted as an ill conceived (Bailis 2011) or harmful policy (OECD 2003). In developing countries, subsidies for groundwater pumping reached USD 45,000 million annually (Dinar 2018). The province of Mendoza maintains the economic tool of subsidizing energy for groundwater irrigation and several attempts to modify or withdraw these tax benefits faced political constraints and justification not based on empirical studies but on political maneuvers (Severino 2016; Severino 2005).

The political will to reform water or energy pricing may not be adequate under local and diffuse pollution circumstances (World Bank 2008). Considering that aquifer characteristics are heterogeneous and difficult to assess (OECD 2015; Theesfeld et al. 2010), pollution threat may unleash regional disputes under a relatively high uncertainty conditions. The general consensus in literature is that institutions should track water volumes and discipline users to make them accountable of their deviations in water-logging in order to achieve water savings and minimize diffuse pollution risks (Ward et al. 2008; Khanna and Farnsworth 2006). Since water rights are fixed in the area of research, possible solutions imply the analysis of the role of stakeholders and their political involvement, as well as pricing alternatives for water and energy.

The use of economic tools that directly influence farmers to pump water has largely been documented in developing countries (OECD 2015; Foster et al. 2016; Margat and Gun 2013; Scheierling et al. 2006), where there is a disproportionate willingness to withdraw subsidies and the general conception is that decisions are politically driven (Gruère et al. 2018; Shah et al. 2012). While several studies that address the water governance scheme in Mendoza were found (Hurlbert and 
Montana 2015; Castex et al. 2015; Foster and Garduño 2012), unfortunately, no record was found for a joint analysis of the political and economic tools that assess the environmental threat of water management implications. Therefore, it is desirable to highlight the underlying political constraints that affect the adoption of more comprehensive policies towards responsible use of natural resources minimizing environmental threats.

\subsubsection{Economic performance of grapevine producers and efficiency determi- nants}

The Argentinean wine industry drafted a strategic plan (PEVI 2020) to effectively redirect efforts towards international wine markets (Ruiz et al. 2011). This led to international support to promote technical advice by agricultural extensionists and technology adoption programs. While some interventions were successful by improving output growth and managerial performance (Maffioli et al. 2011; Gibbons et al. 2016), other cases did not succeed as expected (World Bank 2017; Cerdán-Infantes 2008). Potential waves of strategic planning require empirical applications that address the underlying heterogeneity in production decisions of vineyards.

The analysis of technical efficiency can provide an overall assessment of the wine region and the relative performance of vineyards with respect to best practices. Parametric approaches allow for the decomposition of the statistical noise into random noise and inefficiency, that can be further modeled with the external variables or inefficiency determinants. Accounting for the demise of the Argentinean strategical plan, the stochastic frontier analysis (SFA) is a potential methodology to derive impactful implications with respect to farmer performance. While the assessment of economic performance in the agricultural sector through technical efficiency frameworks is extensive (Battese 1992), the share of empirical applications of these methodologies to wine grape production is scarce. Within the literature, the SFA framework is the most employed, Conradie et al. (2006) and Piesse et al. (2018) both for South Africa utilizing cross-sectional and panel datasets respectively. Ma et al. (2012) estimated the technical efficiency for 24 Chinese provinces; while Manevska-Tasevska (2012) analyzed allocative and economic efficiency for Macedonian vineyards.

Generally, vineyards are quality oriented exploitation and they may have several plots with different treatment; due to the heterogeneous management, data collection is a possible limitation. Considering these difficulties, most of the winegrape efficiency estimations are carried at the vineyard level. Moreira et al. (2011) is the only study that has recorded the efficiency performance of farmers at the plot level. They estimated plot efficiencies and an average farm performance of $77.2 \%$ employing the cross-sectional. The assessment could be challenged to account for water use in the vineyard, agroclimatic conditions could be considered as an alternative (Urso et al. 2018; Coelli and Sanders 2012; Moreira et al. 2011).

Yet, there is a gap to effectively address the vineyards' performance accounting for their use of natural resources, plot management heterogeneity and agroclimatic characteristics that determine their production decisions. With some observations on their estimation of applied water volumes, only a few studies account for water consumption as an input (Coelli and Sanders 2013; Andrieu 
et al. 2014; Elhag 2017). This is a challenge itself considering that fewer studies have addressed water productivity in agriculture (Scheierling et al. 2016; Azad et al. 2015). Within the literature accounting for water productivity, the transition from farm-level to a broader scale like sub-basin has not been documented (Bravo-Ureta et al. 2015).

\subsubsection{Environmental performance of grapevine producers}

While environmental threats have stimulated the focus on natural resources and competition for water grows fiercely across economic sectors (Rodriguez et al. 2013; Donoso et al. 2014), grapevine producers in Mendoza have come into focus because of their privileges with regards to water resource distribution irrespective of their level of efficiency in management (Christ and Burritt 2013; Wagner 2010).

As stated by Ancev, M. S. Azad, et al. (2017), trade-offs between the environmental and economic effects of water use go beyond the value generated from the resource use. The further development of current frameworks should focus in the assessment of the social optimum for economic performance and environmental effects; environmental adjusted efficiency measures provide a framework to evaluate the undesired effects of desired production processes.

Among the studies that measured environmental adjusted productivity and efficiency, the initial estimation attempts embedded the undesired output as an input in the production process (Reinhard et al. 1999; Hailu and Veeman 2001). This approach was argued by Färe et al. (2005) through the acknowledgement that undesired output is a consequence of the production process imposed by the strong disposability between the desired and undesired outputs. Since then, many studies have employed productivity and ecological indicators, such as Luenberger, Malmquist or alternatives of these indexes in their environmental adjusted estimations. The meta-study of Ancev, M A Samad Azad, et al. (2017) constitutes a recent overview of environmental efficiency applications.

Although the applications of distance functions (DF) employing parametric techniques treating detrimental effects as undesired output have increased over time (Cuesta et al. 2009; Feng and Serletis 2014; Njuki et al. 2016; Holtkamp 2017), considerations of water resources are scarcely documented. While Wang (2010) found that wheat production in China could save water up to $70 \%$ of the current used volume; Azad et al. (2015) found fairly efficient use of water in Australia but following a non-radial distance function approach.

The joint estimation of technical environmental efficiency allows for the identification of determinants, such as managerial decisions or other external factors, that can effectively improve the performance in a given direction. The empirical application constitutes an adaptable tool to further value economic activities and gain insights into viable policy measures to shape a responsible use of resources. In the current scenario, the application of this approach could provide substantial knowledge of the current practices of grapevine production and their interactions with the agroecosystem in Mendoza. 


\subsection{Dissertation outline and objectives}

The main objective of this dissertation is to analyze the joint performance of grapevine producers and derive implications from the frontier with respect to their input usage, in particular water resources, to address the aforementioned research gaps through the case study of the grapevine production of Mendoza in Argentina. The second chapter seeks to disentangle the intrinsic effects of political economy of water reforms in the context of water scarcity and groundwater pollution threat in Mendoza. A critical analysis is offered to further understand how the status quo was unaltered after all the political discussions and maneuvers took place. To achieve these objectives, the tripod policy analysis approach was selected to analyze the effectiveness of economic tools to improve farmers' profitability and access to resources (Sadoff et al. 2015; OECD 2015; Meinzen-Dick 2007). To some extent, problems of common-pool resources with distorsive taxes are similar but the magnitude of the effects can vary substantially across regions (Sun et al. 2016).

In the third chapter, the focus is on the estimation of the production frontier for grapevine producers in the Carrizal aquifer. The objectives are to estimate and analyze the determinants of technical efficiency accounting for agroclimatic conditions and water management practices and to disentangle the effects of water management according to production objectives. A unique primary dataset of 647 grapevine plot observations from 177 farmers is utilized. The analysis estimates a Stochastic Frontier (SF) for the complete sample and later tests the feasibility of sub-setting the total observations according to their production objectives. Analysis at the plot level has only been documented by Moreira et al. (2011) in a smaller data base for a broader research area. The analysis also estimates the marginal effects of external variables to assess the direction of the effects on the technical inefficiency (Kumbhakar and Sun 2013) and also provides a more concise measure the Average Partial Effects (APE) (Parmeter 2014).

The fourth chapter acknowledges the existence of an undesired output, namely salinity hazard, and moves forward into the environmental efficiency estimation of grapevine producers. This chapter hypothesizes about the joint economic and environmental performance of grapevine producers and explores whether their practices are influencing diffuse pollution through potential groundwater overdraft. The research questions are addressed with the empirical application of the DDF approach that will contribute to understand the feasibility of expanding grapevine production while decreasing the saline content of irrigation water. During fieldwork, water were collected to perform a quality analysis of the irrigation water, this option was voluntary for the farmers. From the total dataset, only 420 wine grape plots with information on water quality were considered. Joint efficiency determinants include the constructed variable of water balance, which seeks to improve the estimation of the difference between the reported irrigation volumes and the water demanded by the crop, according to their agroclimatic context and other management variables. Here, marginal effects of the covariates were estimated and discussed, along with some mean differences of alternative subgroups. Furthermore, in this chapter an estimation of the shadow price is performed to support the interpretation of the environmental trade-off circumstances at the frontier.

The dissertation follows with chapter 2 that presents the political economy analysis. Chapter 3 
continues with the technical efficiency paper accounting for agroclimatic conditions, plot management decisions, and discrimination according to the destination of the production. In chapter 4, the environmental efficiency analysis takes place, here the joint efficiency estimation seeks to expand the grapevine production, while reducing the saline content in irrigation water. Lastly, the general conclusions will provide a selective overview of the main results that endows the policy implications, acknowledging the limitations of the current research but not without considering future steps forward. 


\section{Chapter 2}

\section{Political economy of energy subsidies for groundwater irrigation}

\section{$2.1 \quad$ Introduction}

In the area of agriculture and resource economics, challenges for optimization are continuously updated. ${ }^{1}$ Facing an increasing demand to provide food with limited resources, imply a more efficient production under changing environmental conditions (FAO/IWMI 2018). The reinvigorated interest on the water-food-energy nexus increases public concern for a responsible and efficient use of natural resources (Allan et al. 2015).

In the arid province of Mendoza, groundwater irrigation is vital for agricultural activities in certain areas. Political will to improve the profitability of small producers has distorted economic incentives and led to the creation of power asymmetries among stakeholders and decision makers. Jointly, a political and economic analysis is carried below to unmask the reform arena of public policies that link water and energy in the agricultural sector.

Local governments are responsible for designing solid policies that contribute to the responsible use of natural resources and, at the same time, that coincide with public preferences. Institutional settings, lack of information, policy implementation time-frames, and political influence may obstruct the optimizing path of social welfare, providing wrong signals to stakeholders (Foster et al. 2016; Dinar 2000; Shah et al. 2012). When it comes to water demand, the institutional settings are fundamental to empower stakeholders and set economic incentives. As a multi-purpose resource, water is demanded as a production input or consumption good. Globally, the agricultural sector employs near $70 \%$ of the total water supply (Dagnino and Ward 2012). Groundwater use for agriculture is

\footnotetext{
${ }^{1}$ This chapter is co-authored by Bernhard Bruemmer (BB) and Alejandro Gennari (AG). The contributions of each author are as follows: Sebastian Riera (SR), BB and AG conceptualized and designed the research. SR collected the data with support of AG. SR analysed and interpreted the data. BB and AG assisted in the analysis and interpretation of the results. SR wrote the paper. BB and AG also provided valuable feedback at various stages of the research. This paper has been published as a chapter of the book Agua y Sociedad Riera et al. (2017). Acknowledgements - The authors are grateful for the valuable feedback from two anonymous referees.
} 
desirable due to the ability to face production challenges or scarcity periods. Overexploitation and poor management may lead to irreversible quality degradation (Garduño and Foster 2010). Jointly, energy and water policies determine institutional settings and power spaces of the stakeholders (Azpiazu et al. 2014). Abuse of economic tools to maintain political power could jeopardize the sustainability of the resource sharping incentives of water users (Badiani et al. 2012).

This paper seeks to describe the economic incentives and behavior of local stakeholders towards the exploitation of groundwater resources. The analysis will focus on the economic and political framework of the water-energy nexus. Main research questions to address are: $(i)$ Are the current water and energy policies influencing the agricultural irrigation practices such that the Carrizal aquifer is under threat as a complementary irrigation source? (ii) Do local stakeholders have incentives to consider the environmental effects of groundwater overexploitation for production purposes? The main hypothesis is that energy subsidies for agriculture irrigation drive farmers' behavior towards an over-exploitation of the aquifer.

\subsubsection{Study area}

The province of Mendoza is located in a semi-arid region in the central-west of Argentina. It covers an area of $150,839 \mathrm{~km}^{2}$. It is characterized by its mountainous area, formed by the Andes mountain range that runs from north to south. Rainfall average is $220 \mathrm{~mm}$ per year. It has a desert-dry, continental climate characterized by the level of summer rainfall regime (Morello et al. 2012).

During 2013, the provincial GDP reached USD 2.08 billion. The main economic sectors are commerce, services, and manufacturing industry, which jointly represent $60 \%$ of the province GDP (DEIE 2014). Agricultural activity contributes with USD 132 million to the regional GDP, representing $7 \%$ of the total (Medawar et al. 2011). The irrigation system reaches 267,889 ha, which represents $85 \%$ of the arable land in the province and $25 \%$ of the national irrigated area (Calcagno et al. 2000; FAO/PROSAP 2015).

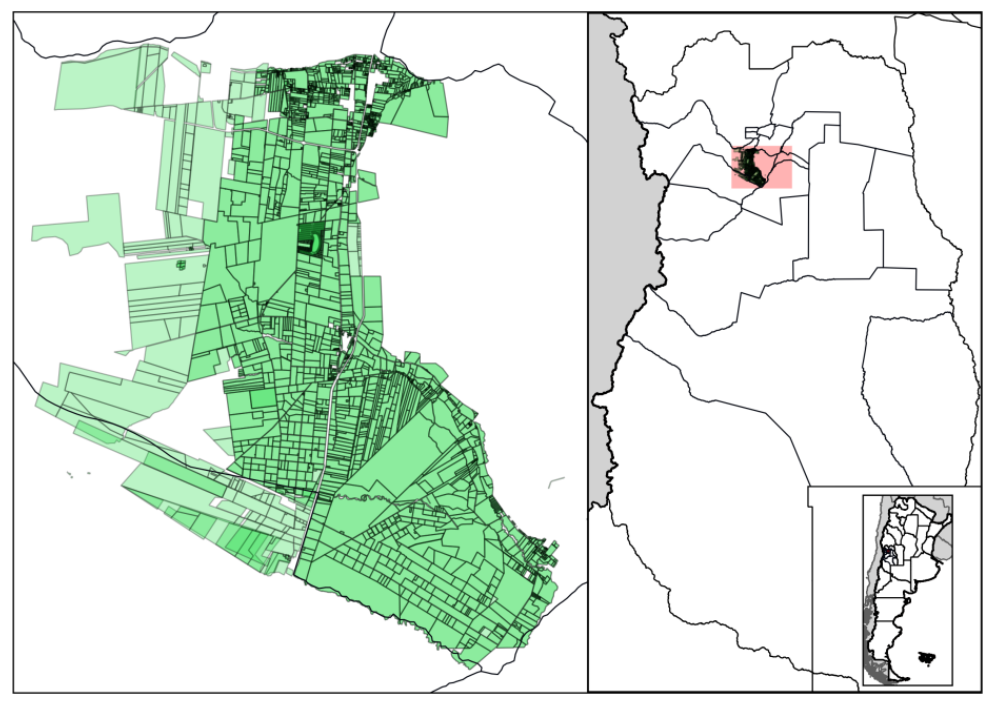

Figure 2.1: Land entitlement over the Carrizal aquifer 
The geographical and environmental characteristics made the province strongly dependant on water resources for economic development. The location at the Andes Mountains allows primary access to surface water in summer through the largest irrigation system in the country, that was originally designed by Inca population. Over the Carrizal aquifer, the coexistence of agricultural activities with oil refineries has evolved with a delicate matter for water users and management institutions.

The extension of the aquifer is nearly $1,000 \mathrm{~km}^{2}$, where most of land depicted in 2.1 is dedicated to agriculture, in particular grapevine production for wine production.

\subsubsection{Water resources}

With the melting of snowpack in the high peaks in the spring and summer, water is provided by five rivers to the region. Precipitation as rain provides little input into rivers and it does occurs mostly in the summertime with high intensities (Maccari 2004). More than $80 \%$ of the water supply is employed in agriculture. In particular, the agroindustry demands nearly $13.51 \mathrm{hm}^{3}$ of water in order to produce processed fruits, vegetables, and beverages (Duek et al. 2013).

In terms of irrigation practices and technology adoption, the current policies have led to the formation of two main groups. Producers with low technological capacity, which consider the irrigation system a valid manner to access quality water at a reasonable cost, and therefore, they welcome discussions to improve the management of the resource as long as the irrigation system remains unchanged. The former is characterized by more traditional practices and less modern systems generally associated with higher age groups. The remaining group is made up for market-oriented vineyards, for which technology adoption does not represent a barrier neither in terms of innovation nor the investment costs (Maffioli et al. 2011).

\subsection{Materials and methods}

The main policies and institutional setting that shape the political economy of the water-energy nexus for agricultural producers are reviewed in this section. Mendoza belongs to the most arid area in Argentina, the use of water it is relevant for every economic activity. The historical relevance of water regulation is represented by the General Water Law (Ley General de Aguas), which was issued in 1884 prior to the provincial constitution. This legislation is the foundation for economic development in the region and further influences the policy design of economic and agricultural tools.

\subsubsection{General water law, principles, and institutional organization}

Considered as the foremost legislation on water management, the law regulates use, distribution rules, payments and quality (DGI 2016; Silanes 2013). Water was declared to be an asset of public domain and three main water-use principles are represented in the water law: inheritance, non-prejudice clause, and specificity. 
The inheritance principle determines the permanent attachment of water rights with the land property, which avoids the potential to divide and commercialize rights individually. Additionally, this water right is perpetual unless it is declined by the owner. The non-prejudice clause looks after the common welfare of water users since it considers the effects on individuals of certain actions or new activities. At last, the specificity principle ensures the nullity of contracts that use water for purposes other than those agreed upon (Bermejo 1884; Pinto et al. 2006).



Figure 2.2: Characterization of institutions

Source: Own based on DGI (2015), Maccari (2004), Severino (2005), OEI/DGI (2006).

Issued in 1916, the provincial constitution rectified the formed water law and constitued the General Irrigation Department (DGI, according to the name in Spanish) as the institutional body to execute the police power. This autonomous body makes their own decisions in terms of administration, resource allocation, and investments.

Representation of stakeholders is promoted within the irrigation system. Watershed Inspections (Inspecciones de Cauce) are 'ministry legis' by law 5302 and law 6405. Their purpose is to engage in the administration and distribution of the waters, maintenance of secondary network and derivatives. Officials within the department are elected democratically, and they have their own budget (Maccari 2004; Pinto et al. 2006).

Ideally, the organization of water management should not be static and respond to the ever evolving interests of farmers determined by agricultural demand (Jofré 2010). Minor changes in the irrigation system directly result in strategic behavior and design of complimentary water-use tools. Therefore, any potential changes should be announced in a clear and transparent manner (Erice 2013).

\subsubsection{Current conditions of irrigation efficiency}

Different definitions of efficiency exist in the field of water management. In general terms, irrigation efficiency is measured as the ratio of the water volume beneficially used with respect to the received volume (Morábito 2005). Generally, a global indicator of irrigation systems measures the efficiency with a combination of effectiveness ratios that qualify the water management performance. Every stage in the irrigation system is important to determine global efficiency, which depends on the 
coating state of the channels, distribution rules, in farm use, and other factors.

In the northern basin, the irrigation system efficiency varies from 28 to $40 \%$. In other words, from 100 liters of water available in the system, the farmer receives between 28 and 40 liters (Bos and Chambouleyron 1999; Jofré and Duek 2012; Morábito et al. 2012). On average, with the methods practiced, irrigation efficiency is low at the parcel level and the DGI estimations ranges between 30 and $50 \%$. At the provincial level, distribution efficiency is between 70 and $90 \%$, depending on the condition of the channels (Morábito et al. 2007; OEI/DGI 2006). The main causes of the low efficiency of irrigation are:

$i$. Reduced percentage of canal lining at the provincial level.

ii. High infiltration due to the prevailing light soils and the phenomenon of clear waters.

iii. Lack of irrigation planning to deliver water according to the actual cropping needs.

$i v$. Inadequate distribution systems that deliver large supply of water in a short period of time, leading to losses and waste.

$v$. Incomplete maintenance of major irrigation and drainage network.

In short, the technological level of irrigation at the provincial level could be markedly improved if changes in irrigation methods are introduced, for example, scheduled rotations according to a crop plan and irrigation are absent today. In addition, infrastructure improvements in irrigation and drainage could be made, among other things (FAO/PROSAP 2015).

\subsubsection{Surface and groundwater irrigation}

In several regions of Mendoza, surface irrigation overlaps with groundwater irrigation. At the expense of increasing exploitation of underground water resources, between 1960 and 1980, the local and national government promoted the expansion of the agricultural frontier into more arid areas (OEI/DGI 2006). The incentives included tax exemptions and subsidized credit lines for farm technology and pumping equipment. 
Table 2.1: Comparison of irrigation systems

\begin{tabular}{|c|c|c|}
\hline Aspects & Surface water & Groundwater \\
\hline Physical access & $\begin{array}{l}\text { Depends on the natural } \\
\text { conditions (seasonal patterns, } \\
\text { rainfall, etc.) but also on } \\
\text { infrastructure for delivery }\end{array}$ & $\begin{array}{l}\text { Higher infrastructure and } \\
\text { operation costs. Less dependent } \\
\text { on natural conditions }\end{array}$ \\
\hline Abstraction costs & $\begin{array}{c}\text { Fix costs normally subsidized } \\
\text { and variable costs according to } \\
\text { farm characteristics and } \\
\text { management }\end{array}$ & $\begin{array}{l}\text { Fix costs for use, pumping costs } \\
\text { (variable according to the state } \\
\text { of the source) }\end{array}$ \\
\hline $\begin{array}{l}\text { Distribution and } \\
\text { equity of the public } \\
\text { domain }\end{array}$ & $\begin{array}{l}\text { Directly visible to users. More } \\
\text { dependence on management and } \\
\text { co-operation }\end{array}$ & $\begin{array}{l}\text { Less cooperative resource in } \\
\text { terms of use. Difficult but } \\
\text { desirable for co-operation }\end{array}$ \\
\hline $\begin{array}{l}\text { Legal access and } \\
\text { entitlements }\end{array}$ & $\begin{array}{l}\text { Managed under specific water } \\
\text { allocation, generally with legal } \\
\text { entitlements }\end{array}$ & $\begin{array}{l}\text { Legal entitlements subject to } \\
\text { zoning restrictions and } \\
\text { availability }\end{array}$ \\
\hline $\begin{array}{l}\text { Asymmetry of } \\
\text { information }\end{array}$ & $\begin{array}{l}\text { Availability and quality easy to } \\
\text { check and review }\end{array}$ & $\begin{array}{l}\text { Regulation more difficult and } \\
\text { costly }\end{array}$ \\
\hline
\end{tabular}

Source: Own elaboration based on OECD (2015), Theesfeld et al. (2010).

As stated in the table above, the irrigation alternatives differ not only in the origin of the resource but also in the physical and institutional management aspects. The conjunctive use of both resources carried out in a responsible manner could lead toimprovements in groundwater quality and better use of the existing systems.

\subsubsection{Characteristics of Carrizal aquifer}

The Carrizal aquifer represents a sub-basin and is the main recharge area of the northern basin. Within this area, the development of oil and petrochemical industries has exploited the natural resources with different uses increasing pressure on the environment (Altamirano et al. 2005).

Overexploitation of groundwater resources leads to quality degradation, which can be divided into local and diffuse pollution (Margat et al. 2013). Saline intrusion is a typical contamination effect of excessive and inefficient irrigation. This quality degradation is provoked by excessive pumping that breaks the harmony of pressure between stratums with standard percolation and infiltration levels (Kupper et al. 2002; Morábito 2005). 
Table 2.2: Basin characteristics

\begin{tabular}{ll}
\hline Northern Basin & \\
Storage capacity & $30,000 \mathrm{hm}^{3}$ \\
Underground extension & $22,800 \mathrm{~km}^{2}$ \\
Renewable resource & $700 \mathrm{hm} 3 /$ year \\
Carrizal aquifer & \\
Groundwater abstraction & $66.7 \mathrm{hm}^{3} /$ year \\
Area above aquiferNorthern Basin \\
Agricultural land served & $5,000 \mathrm{ha}$ \\
Grape for wine production & $3,250 \mathrm{ha}$ \\
Vegetables & $1,300 \mathrm{ha}$ \\
Olives and pastures & $450 \mathrm{ha}$ \\
Irrigation means & \\
$\quad$ Surface only & $1,330 \mathrm{ha}$ \\
Groundwater only & $1,330 \mathrm{ha}$ \\
Conjoint use & $1,330 \mathrm{ha}$ \\
\hline
\end{tabular}

Source: Own based on Foster et al. (2005); Hernández et al. (2012), IDR (2016), OEI/DGI (2006).

After the construction of the Potrerillos Dam during early 2000s, the hydrology of the northern basin has changed. Due to the fact that the river carries fewer types of sediment, carried water is lighter and easier to filtrate on the ground; this phenomenon is known as clear waters. Until 1999, an accurate estimation of the groundwater abstraction in the Carrizal aquifer was $66.7 \mathrm{hm} 3$ per year (Hernández et al. 2012).

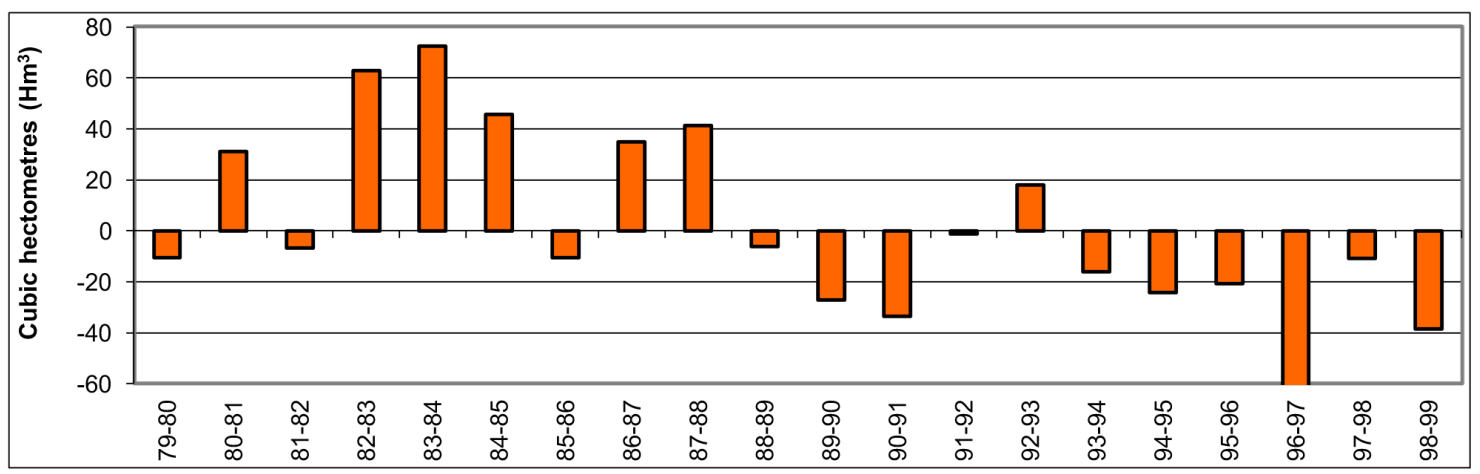

Figure 2.3: Annual changes in the storage of the aquifer (1979-1999)

Source: Hernández et al. (2012).

According to Hernández et al. (2012), between 1979 and 1999 the average pumped water in the Carrizal aquifer was 61.235 cubic hectometres $\left(\mathrm{hm}^{3}\right)$. Due to the increasing public concern over groundwater pollution and delivery of illegal permits for groundwater wells in the past (Conte 2014; Erice 2013; Fernández Rojas 2012), the information about current storage of the aquifer is classified at the moment.

\subsubsection{Energy and subsidy information}

In Mendoza, the energy production increased at lower rates than the total demand. The province does not perform satisfactorily on energy self-sufficiency. Imported energy in total consumption is 
nearly 20\% (EPRE 2013). Since 2008, the water institutions manage the resource under a water scarcity scenario, which means that the snowfalls during winter do not fulfill the expected demand for irrigation during spring and summer seasons. Lower surface water supplied translates into more energy demanded for pumping groundwater.

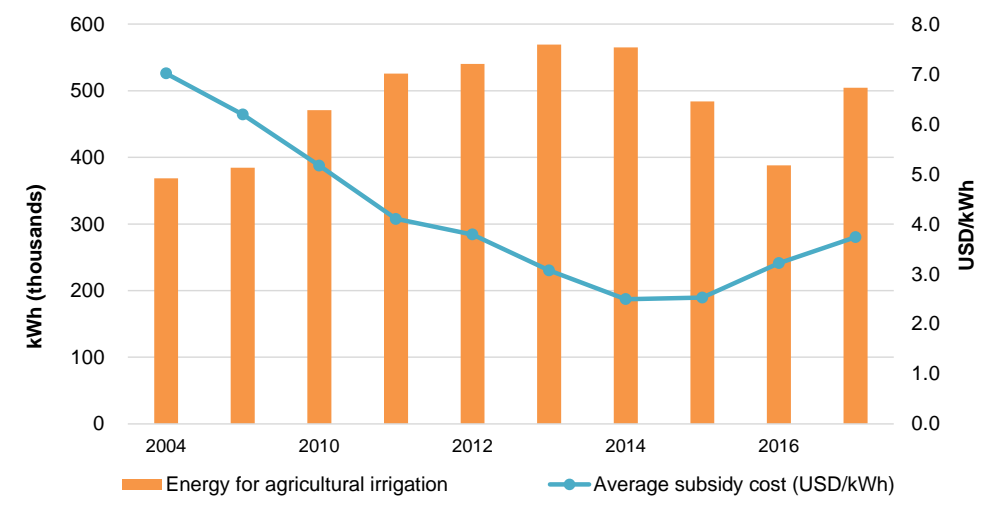

Figure 2.4: Energy consumed for agricultural irrigation (Mendoza)

The graph above shows an increasing demand for subsidized energy from the year 2009 until 2014, which grew 53\% in a decade. Since 2015, the adjustment of macroeconomic variables and reorientation of expenditure led to a formal devaluation of national currency and lower subsidy share in energy prices (DEIE 2014; EPRE 2018). Despite the national trend of diminishing energy subsidies, agricultural producers still benefit the most from the provincial subsidy scheme that continued support for small and medium farmers. The provincial budget grew in real terms from USD 1.22 in 2015 to USD 3.6 million in 2018. The average cost per subsidized kWh grew USD 2.5 in 2015 to USD 3.74 in 2018.

\subsubsection{Composition of energy prices}

Promoting agriculture irrigation by subsidizing energy prices is a policy tool that seeks to leverage small agriculture producers who are non-capable of improving their production efficiency due to their scale or previous year of economic losses. The subsidy is available upon request by farmers, but not available for consumers. Only those properties smaller than 50 ha can avoid a tariff increase from the year 2008. In addition, farmers that do not receive surface water may qualify as well. Since the subsidy is attached to a property (agricultural parcel) and not to a specific person, strategic behavior by stakeholders could lower the efficiency of the energy policy.

Regulated by the law 6,498, the irrigation tariff establishes compensation from the provincial state to the energy distributors. Moreover, the law determines tariff segments according to the time slot that energy is consumed (EPRE 2018). The time slot for high-demand has changed continuously, establishing one or two time-slots of higher pricing during the day. In fact, these changes seek to segment the demand for targeted pricing. However, as pointed out by Severino (2005), these time slots do not correspond with the national energy market that provides local distributors. 
Table 2.3: Subsidy scheme including fix costs of energy provision (2012)

\begin{tabular}{cccccc}
\hline Equipment power & & \multicolumn{2}{c}{ Low voltage } & & \multicolumn{2}{c}{ Medium voltage } \\
\cline { 3 - 4 } \cline { 5 - 6 } & High-demand & Low-demand & & High-demand & Low-demand \\
\hline $10 \mathrm{Kw}$ & $57.4 \%$ & $79.0 \%$ & & $63.2 \%$ & $79.0 \%$ \\
$10<\mathrm{Kw}<300$ & $57.3 \%$ & $79.0 \%$ & & $63.1 \%$ & $79.0 \%$ \\
$>300 \mathrm{Kw}$ & $50.5 \%$ & $69.6 \%$ & & $55.6 \%$ & $69.6 \%$ \\
\hline
\end{tabular}

Source: Own based on EPRE (2017).

On a yearly basis, the provincial energy regulator (EPRE) seeks to improve policy targeting by visiting beneficiaries randomly and checking their subsidy qualification. This action has contributed to improving the policy targeting by decreasing the list of beneficiaries by $10 \%$. Normally, the subsidized power for agriculture irrigation is near 4 megawatt hour (MWh) per year, from which $20 \%$ is estimated as inefficiency loss due to improper pumping equipment (Severino 2016).
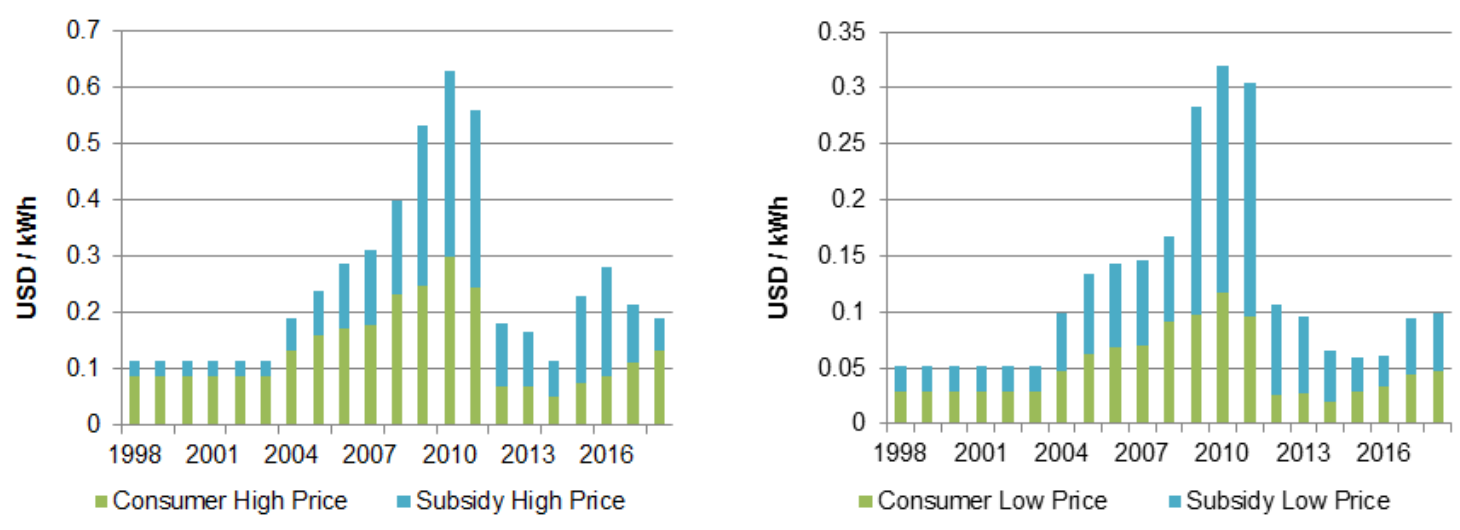

Figure 2.5: Trimestral energy tariffs for irrigation. Low and high demand prices

Source: Own based on DEIE (2014) and EPRE (2018).

In 2015, the new national administration announced lowering the subsidy share of energy tariffs. Nevertheless, agricultural beneficiaries continued to receive the subsidy provided by the province, where the total amount of subsidy budget increased to USD 1.89 million, representing a $55 \%$ increase. Attempts to withdraw the energy subsidies for agricultural irrigation have not been successful in the past.

\subsubsection{Agricultural and economic tools}

Although the agricultural contribution to the GDP of Mendoza remains below $10 \%$, the sector becomes economically relevant when the multiplicative effects are considered. Since our focus is on the grapevine production, we review the fiscal policies and economic tools employed in different sectors to improve the economic performance of vineyards over the last 25 years.

Prior to the economic crisis of 2001, wine-related associations and institutions had drafted a restructuring plan to improve the strategic opportunities of the industry. This plan included technology adoption, variety improvement and development of new markets (COVIAR/OVA 2018; 
Azpiazu and Basualdo 2001). Foreign direct investment assisted in this process since vineyards and wineries had not fully utilized present infrastructure and institutions but were prepared in terms of quality analysis frameworks and procedures. The new focus on targeted markets struggled to effectively increase the market share. Argentinean wine is welcomed in countries with highpurchasing power, but it is relatively more expensive than the competition. In particular, due to higher production costs, lack of proper infrastructure that increases the cost of logistics and relatively higher importation levies. Trade logistics represents $17 \%$ of the production and commercialization costs (COVIAR/OVA 2018).

Regarding the price paid to producers, small and medium vineyards have historically faced an uneven situation for bargaining power. Moreover, the increase in export-oriented wineries led to higher mistrust in the free-market so small and medium producers organized themselves into collectives to increase their bargaining power through the shield of cooperatives. Later, contract agreements, for partial or total production, improved the relationship between grapevine producers and wine makers. Jointly, key institutions and provincial governments agreed on the share that wine will be transformed into must to regulate the wine supply and further maintain prices. More recently, the abundance of base wine in stock and good harvest years led to lower market prices of grapevines; situation that had to be solved with government intervention. In 2016, national government spent USD 11.2 million to improve the market price through reductions in wine stock. Considering external factors in grapevine production, institutions have deployed programs for assessing potential climate risks and minimizing effects of contingencies: for example, through programs like hail storm protection and rural insurance (Gibbons et al. 2016). Institutions seek to help farmers to improve their agronomic management and practices through smarter use of agrochemicals. Uncertainty in the local currency jeopardized the competitive gains of micro-devaluations since input providers adjusted faster to real values in US dollars.

When it comes to production factors, grapevine production in Mendoza remains a labor intensive crop with a variable share of intermediate inputs according to location, grape quality and conduction system. On average, the total production cost is USD 3,824 per hectare, composed of labor (72.1\%), machinery (11.4\%), agrochemicals (9\%) and physical inputs (7.4\%) (COVIAR/OVA 2018). Regarding labor policies, institutions lagged behind in terms of formality and flexibility of the labor force. In addition to the higher employment costs for firms and small vineyards, the deployment of alternative labor standards for seasonal and permanent workers did not affect the level of employment in the sector. On the contrary, these measures led to a lower share of permanent labor with higher benefits. Seasonal workers can count on regulated salary that is constantly updated by institutions. These measures improve resource allocation and flexibility but also incentivize farm workers to seek short-term employment (Van den Bosch 2008).

Altogether, the review of the agricultural policies shows an active public sector in the regulation of all production factors. However, in the framework of political economy; we will further discuss the general environment of these regulations along with the effectiveness and suitability of the economic measures. 


\subsubsection{Framework}

For those farmers that have a well, groundwater becomes a common-pool resource with lowexcludability for pumping it (OECD 2015). The sole existence of underground resources raises concerns about their characteristics: boundaries of the reserve, the hydrogeological uncertainties, irreversibility of mismanagement, and information asymmetries (Booker et al. 2012; NRC 1997; Theesfeld 2010).

The institutional tripod framework is used. This methodology assess the tripartite institutional performance by decoupling the roles of organizations and stakeholders at different levels. It helps to understand the underlining power structures, decision making stages, and incentives of participants in the political process.

Meinzen-Dick (2007) introduced the framework acknowledging that there is no single solution for all water problems in policy analysis. An objective manner of analysis is to decompose the policy instruments into regulatory, economic, and voluntary. The regulatory instruments frame the command and control of water policies. That is the ownership of rights, standards for pollution and abstraction among others. In most of the cases, water rights are attached to agricultural land and are non-tradable.

OECD (2015) and Theesfeld (2010) agree on the importance of analyzing institutions involved, power structures, and independence of decision makers to comprehend the political process of water policy. Regarding the economic instruments, they reflect the financial incentives that may drive the decision of the stakeholders; this could be directly influenced by groundwater fees related to infrastructure, location, and services (Zilberman et al. 2008).

Furthermore, the joint analysis of physical conditions and institutional settings that consider asymmetric information are critical factors for design and implementation of policies (Dinar 2000). To achieve a comprehensive governance structure on public institutions, a systematic review of planning and policy instruments is essential (Theesfeld et al. 2010).

Energy policies that subsidize groundwater withdrawals are commonly referred as ill-conceived policies (Bailis 2011). Since the marginal cost of acquiring water for irrigation decreases, it is possible that economic agents continue or start employing water inefficiently.

As expected, diminishing subsidies translate into higher tariff for producers, who initially constrained their energy consumption for agricultural irrigation. Later, the prevailing scenario of water scarcity and the recovery of grapevine prices led to a subsequent increase in groundwater use. What is still unknown is a good estimate of the demand function of groundwater for agriculture in the area of study. Regarding other areas in the northern basin in Mendoza, the price elasticity is -0.57 for producers that only use groundwater and -1.28 for users with access to both types of irrigation systems (Barbazza 2005). This means that a $1 \%$ increase in groundwater price will diminish consumption by $0.57 \%$ for farmers that rely completely on groundwater; whilst $1 \%$ increase in water abstraction will diminish consumption by $1.28 \%$ for conjoint users.

Other studies in India analyzed the effect of a $10 \%$ reduction in energy subsidies and found a 
reduction of the pumped water between 4.4 and 6.7\% (Badiani and Jessoe 2011; OECD 2015; Shah et al. 2012). While in case of Mexico, Sun et al. (2016) consider that doubling the cost of pumping would only reduce demand by $6 \%$. However, the total withdraw of the energy subsidy would decrease pumping by $15 \%$ in the short run and settle in $19 \%$ on the long term (OECD 2015). Often, energy subsidies for irrigation efficiency are interpreted as a double-edged sword in groundwater management (OECD 2015). Acquiring higher efficiency standards on irrigation is more beneficial for farmers but could deteriorate soil quality or aquifer recharge. Some additional measures should foster cultivation of less water demanding crops to avoid negative effects of the measure.

Coady et al. (2015) propose that efficient pricing from energy producers to suppliers should equal the cost of production. Additionally, pigouvian taxation is a tool to correct externalities that are not covered by other political measures. Moreover, Sun et al. (2016) have shown that effectiveness of electricity price-based policies is certainly a reason to consider this instrument for groundwater as a common pool resource.

\subsection{Results and discussion}

The review of economic tools and policies utilized in the agricultural sector depicts an active participation of the state. One perspective could call this state-dependence the result of the institutions and organizations that have not done enough to ensure the independence of the farming sector as well as not putting in place a self-regulatory processes for the water institutions. Another view can ensure that proper regulation has been developed but implementation is failing due to weak monitoring.

The Carrizal aquifer provides irrigation to a prestigious wine region and has been the subject of numerous political and environmental conflicts with respect to water management, resource pollution and groundwater exploitation. Initially, the zoning restriction aimed to control the water quality and monitor the oil pollution in the aquifer. However, the judicial trials against the oil refinery with the involvement of DGI have delayed the abolishment of these restrictions. Assisted by the National Institute of Water (INA), the DGI seeks to improve the understanding of the aquifer characteristics promoting research with pumping trials, water table monitoring and pollution control. The budget for these expenses is now obtained from groundwater users through the annual fee, that has increased considerably.

Soon after the zoning restriction, the judicial sector supported farmers against Fiscal Oilfields (YPF, according to the Spanish name), enforcing a review of the water quality in surrounding areas. The INA performed water quality analysis in the aquifer confirming the alarming quality decrement of irrigation water, also perceived by high salinity levels.

In response to political pressure and considering the economic weight of oil refinement for the provincial GDP, the provincial government called for new water quality analysis and determined the validity of YPF exploitations. At the same time, YPF faced political and institutional consequence and had to reimburse the damage to most affected farmers. Since 2004, DGI and YPF work 
collaboratively on pollution monitoring and the collaboration with INA has decreased to almost nothing.

Simultaneously, attempts to review for adjustments with regard to energy tariffs for agricultural irrigation in the province were neutralized by local legislators. Supported by the private sector, their argument focused on the difficult scenario for farmers, in particular for those solely dependent on groundwater irrigation. Nothing was mentioned about responsible exploitation or sustainable use of the resource.

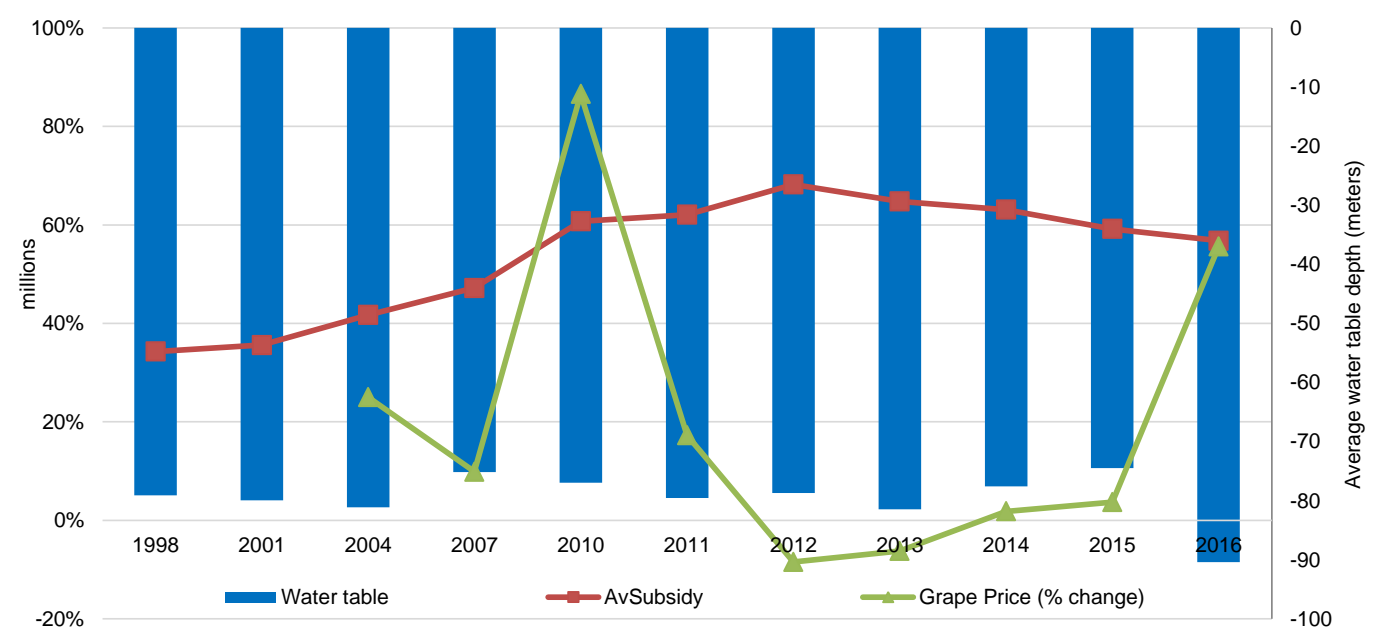

Figure 2.6: Grapevine prices, energy subsidy and groundwater table

Source: Own based on collected data: COVIAR/OVA (2018), Hernández et al. (2012), OEI/DGI (2006).

On average, the energy subsidy for irrigation increased over $20 \%$ in the last 20 years reaching $55.6 \%$ in 2016. As subsidized energy became the normal scenario farmers began to make their decisions based on other variables with no considerations of the potential diffuse pollution effects of the groundwater overdraft. In 2016, the recomposed grapevine price seemed to have an effect on pumped groundwater, when the water table reached the lowest in two decades even though the government had adjusted the energy tariffs significantly.

Although there is an agreement on quality monitoring across water institutions, levels of salinization and resource depletion have increased over time in the aquifer (Conte 2014; Foster et al. 2005; OEI/DGI 2006; Reta 2005). Water quality is affected by industrial activity and agriculture practices, in particular with regards to cadmium (Morábito 2005) and phosphorus levels (Lavie et al. 2010).

Currently, the annual consumption of subsidized energy for agricultural irrigation is $53 \%$, higher than last decade by $9.5 \%$ in the total energy demanded. In the past, the water authorities have created conditions for improving resource management in order to diminish pollution in a long term perspective (Jofré et al. 2012). However, in order to achieve earlier results, stakeholders need to be stimulated to act collectively in resource exploitation through economic tools that internalize trade-off decisions between productivity and environmental effects (Ostrom 1990; Ostrom 2014).

Participation and disputes related to water-energy policies have had a rich history over the last 15 
years (Appendix). Several external effects drive the excessive pumping of groundwater, the water scarcity period since 2009 implied lower volume of surface water to deal with higher temperatures and uncertain rainfall. Regarding the economic sphere, low profitability thwarted the incentives for improving irrigation efficiency at the parcel level.

In other words, the reform arena was not suitable for the relaxation of the subsidy scheme. This situations has led to the diminishing water-table levels in the aquifer and increments in the depth of water extracted (Álvarez et al. 2011; Álvarez et al. 2011; Foster et al. 2005; Puebla et al. 2005).

During 2017, the agricultural sector utilized 505,000 kWh for irrigation purposes. Historically, the energy utilized for agricultural irrigation has been between 8 and $10 \%$ of the total provincial consumption, with the exception of 2016 when the joint effect of subsidy cut-backs and currency devaluation constrained the demand to $390,000 \mathrm{kWh}$. From the $300 \mathrm{MW}$ of installed energy capacity for agricultural irrigation, the Ministry of Energy estimates that $15 \%$ are inefficiently used. This represents USD 6 million of government expenditure (EPRE 2018).

\begin{tabular}{|c|c|c|c|c|}
\hline \multicolumn{2}{|c|}{ Orientation } & Regulatory approaches & Economic instruments & $\begin{array}{c}\text { Collective management } \\
\text { approaches }\end{array}$ \\
\hline \multirow{3}{*}{ 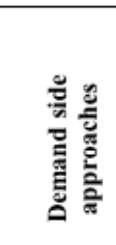 } & $\begin{array}{c}\text { Extensive margin } \\
\text { (wells) }\end{array}$ & Permit requirement & & $\begin{array}{l}\text { Association of groundwater } \\
\text { users }\end{array}$ \\
\hline & \multirow[b]{2}{*}{$\begin{array}{c}\text { Intensive margin } \\
\text { (use) }\end{array}$} & Direct: Flowmeter & $\begin{array}{l}\text { Direct: Higher annual fee } \\
\text { Energy subsidies }\end{array}$ & \\
\hline & & $\begin{array}{l}\text { Indirect: empowerment of } \\
\text { water institutions }\end{array}$ & $\begin{array}{l}\text { Indirect: assistance to } \\
\text { improve infrastructure }\end{array}$ & $\begin{array}{c}\text { Indirect: determination of turn } \\
\text { scheme }\end{array}$ \\
\hline \multirow{2}{*}{ 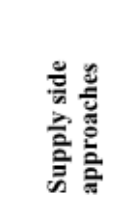 } & $\begin{array}{l}\text { Additional supply } \\
\text { for storing }\end{array}$ & & & Construction of reservoirs \\
\hline & $\begin{array}{l}\text { Additional supply } \\
\text { for use }\end{array}$ & $\begin{array}{l}\text { Surface water supply: } \\
\text { Turn scheme }\end{array}$ & Financing infrastructure & Collective management plans \\
\hline
\end{tabular}

Table 2.4: Current policy tools on water management

Source: Own based on DGI (2018), Erice (2013), OECD (2015) and Theesfeld et al. (2010).

State subsidies for energy irrigation are assigned to a Compensation Fund that ameliorates the bi-monthly costs during periods of high demand. This financial aid compensates for fixed costs of infrastructure and lowers the tariff prices for high and low demand period. Considering the state budget and the energy provided, the average cost of the subsidized energy is USD 3.74 per $\mathrm{kWh}$, the highest in the last five years.

Undoubtedly, the policy planning has been undermined by several economic and environmental facts during the last 15 years. The review of the political treatment of pollution accusations and the attempts to modify the agricultural irrigation subsidies have revealed the weaknesses of decision makers. At the first sign of modifying the status quo of acquired subsidies for water abstraction lobbyists and watershed inspectors are quick to respond in order to protect their interests.

However, the awareness of water availability and quality problems by specific institutions (DGI, INA) shows some indication of willingness to improve management and quality. Moreover, if policy 
tools continue to stimulate technology adoption and government mantains this orientation, water-use efficiency will increase in the agricultural sector contributing to the achievement of specific targets of the Sustainable Development Goals (SDGs). In particular, with respect to the change in water-use efficiency, improvement of energy efficiency and protection of water-related ecosystems.

\subsection{Conclusions}

Jointly, the review of the institutional settings and the political disputes about water resource quality and management reveal the public sensitivity towads pollution in common pool resource, like the Carrizal aquifer. In particular, when quality degradation is not diffuse but local and the guilty can be pointed out. In order to gain political credibility, public institutions need to show the risks, benefits and expose responsibility to deal with groundwater issues (Foster et al. 2012). A credible threat of losing water rights could create enough incentives to improve groundwater management (Livingston and Garrido 2004). In this analysis the beneficiaries of the irrigation policies are the agricultural producers. Findings indicate joint implications of water, agricultural and energy policies for groundwater availability. The DGI remains as the highest authority in irrigation water management in the province.

The tripod analysis reveals an unbalanced set of policy tools. There are more policy measures oriented to the demand side and relevant participation of collective action involvement in the management within the framework of 2.4. More policies on the supply side could be more difficult and possibly expensive to design but they would have a bigger effect on the water management system. Some suggestions on the supply side include fostering wastewater use, solar pumping systems and better storage facilities. As stated by Abler and Shortle (1991), these political changes will be viable if they positively effect the institutions' budget, gain confidence from large stakeholders in the political sphere, and optimize the administrative and enforcement costs. This calls for avoiding policy objectives that could backfire in the wrong direction. Although, it is expected that lowering energy subsidies for agricultural irrigation will correct the economic incentives to diminish groundwater use, in the past, no clear and consistent policies were made to improve the targeting of beneficiaries towards full-pricing of energy tariffs.

Under these conditions, the stakeholders may perceive that there are no changes in policies and incentives to continue their business as usual. If the recent modification of electricity tariffs imposed by the national government comes along with better targeting of subsidy beneficiaries, the marginal cost of water abstraction would increase which may improve irrigation practices and diminish the overexploitation of the aquifer. Conceiving a subsidy to extract water may improve the living standard of less profitable farmers but is not the right approach to improve their livelihood. On the contrary, when policies are not complemented with instructive and participatory approaches that improve water management, farmers will continue to rely on their traditional irrigation practices with marginal productivity of water constant and similar cost of production. 


\subsection{Appendix}


Table 2.5: Record of political disputes in the last 20 years

\begin{tabular}{|c|c|c|}
\hline Year & Detail & Source \\
\hline 1998 & Zoning restriction by DGI for new groundwater wells at the Carrizal aquifer. & $\begin{array}{l}\text { (Erice 2013; S. } \\
\text { Foster and } \\
\text { Garduño 2006) }\end{array}$ \\
\hline 2002 & EPRE requires more detail on energy bills & $\begin{array}{l}\text { (DGI 2016) DGI } \\
\text { (Res. 437/02) }\end{array}$ \\
\hline \multirow{2}{*}{2003} & $\begin{array}{l}\text { Public dispute about salinization pollution in the Carrizal aquifer. The privatized oil } \\
\text { refinery is accused by the stakeholders to contaminate the underground resource }\end{array}$ & \multirow{2}{*}{$\begin{array}{l}\text { (Reta 2005; } \\
\text { Oikos 2004) }\end{array}$} \\
\hline & $\begin{array}{l}\text { Judge suspends YPF to use groundwater well until environmental conditions are } \\
\text { reviewed }\end{array}$ & \\
\hline \multirow{8}{*}{2004} & $\begin{array}{l}\text { Luján de Cuyo municipality request YPF to avoid the use of groundwater as blowdown } \\
\text { water in oil production }\end{array}$ & \multirow{8}{*}{$\begin{array}{l}\text { (Conte 2014; } \\
\text { Erice 2013; } \\
\text { Garduño and } \\
\text { Foster 2010; } \\
\text { Lohn, } \\
\text { Guimaraes, and } \\
\text { Bucich 2000; } \\
\text { Oikos 2004; } \\
\text { Severino 2005) }\end{array}$} \\
\hline & $\begin{array}{l}\text { Pollution by salinization is detected at the Carrizal aquifer by the National Institute of } \\
\text { Water (INA). }\end{array}$ & \\
\hline & $\begin{array}{l}\text { Conflict between agriculture producers and YPF is mediated by the government that } \\
\text { confirms no polluting activities by YPF. }\end{array}$ & \\
\hline & $\begin{array}{l}\text { Ministry of Environment and Public Works (MAyOP) issues a decree to review the } \\
\text { voltage supply capacity and adopt new segmentation criteria based on user's pumping } \\
\text { equipment voltage. }\end{array}$ & \\
\hline & $\begin{array}{l}\text { Government estimates saving for } 2.4 \% \text { of energy for agriculture irrigation from high } \\
\text { tension users. Express their interest to resign for subsidy in } 2005 \text { onwards. }\end{array}$ & \\
\hline & $\begin{array}{l}\text { Agricultural lobbyist from central valley stops a new attempt to increase agricultural } \\
\text { irrigation energy tariffs. They requested to remain the energy subsidy for irrigation and } \\
\text { abolish the temporal sessions of water rights }\end{array}$ & \\
\hline & $\begin{array}{l}\text { Province executive sanctions decree to increase electricity tariffs by at least } 25 \% \text {. } \\
\text { Decree }(1456 / 04)\end{array}$ & \\
\hline & Strong public opposition against potential tariffs increase & \\
\hline \multirow[t]{2}{*}{2007} & $\begin{array}{l}\text { Provincial government creates a Council to review the environmental conditions of } \\
\text { Carrizal aquifer in the districts of Ugarteche and El Carrizal. }\end{array}$ & $\begin{array}{l}\text { (DGI 2016; Erice } \\
\text { 2013) } \\
\text { Decree } \\
(1684 / 07)\end{array}$ \\
\hline & $\begin{array}{l}\text { Provincial law } 7,722 \text { limits the chemical components as cyanide, mercury and sulphuric } \\
\text { acid in the exploitation of natural resources. Therefore, the use of water is protected } \\
\text { towards mining activities. }\end{array}$ & (Soria 2015) \\
\hline 2009 & $\begin{array}{l}\text { YPF lose a judicial dispute for groundwater pollution and must reimburse an individual } \\
\text { family for \$ARS } 675,000\end{array}$ & $\begin{array}{l}\text { (Fernández } \\
\text { Rojas 2012) }\end{array}$ \\
\hline 2010 & $\begin{array}{l}\text { According to INA, the water table levels of the Carrizal aquifer show signs of recovery } \\
\text { and it could resist up to } 5 \% \text { per year increase in water pumping. The DGI withdraws the } \\
\text { zoning restriction for new wells and accepts } 22 \text { requests without following proper steps. } \\
\text { DGI superintendent is criticized and resigns avoiding impeachment in } 2013 \text {. }\end{array}$ & $\begin{array}{l}\text { (Erice 2013) DGI } \\
\quad(2008)\end{array}$ \\
\hline 2011 & EPRE modifies the tariffs' segmentation scheme to lower the voltage demand peaks & $\begin{array}{c}\text { Decree } \\
(208 / 2011)\end{array}$ \\
\hline 2014 & $\begin{array}{l}\text { DGI allows YPF to perform oil exploration in new groundwater well in a conflict area for } \\
\text { pollution without confirming reception of the impact evaluation declaration }\end{array}$ & $\begin{array}{l}\text { Montacuto, } \\
\quad(2014)\end{array}$ \\
\hline 2015 & The Court of Supreme Justice ratifies the constitutionality of the law 7,722 & Soria (2015) \\
\hline 2016 & YPF announces three new wells for oil exploitation in the province & $\begin{array}{l}\text { Flores Isuani, } \\
\qquad(2016)\end{array}$ \\
\hline
\end{tabular}




\section{Chapter 3}

\section{Determinants of technical efficiency}

\subsection{Introduction}

In Argentina, over the last two decades, agriculture has become a key and growing contributor to export earnings and wine has played a relevant and rising role in sustaining regional economies. Argentina is the $7^{\text {th }}$ largest wine producer worldwide, the industry gained experience after two decades of vine quality innovations, environmental threats, and economic constraints (SSPE 2016). The growing reputation of Argentinean wines has led to the settlement of international firms in the country, which also contributed to the industry in terms of technology adoption and market orientation. With over 240,000 hectares, the province of Mendoza concentrates 70 per cent of the grape production and 65 per cent of the Argentinean wine making (INV 2017).

Despite the robust production and exports from Mendoza, the grapevine sector is facing significant challenges arising from low prices paid to producers, agronomic risks, and climate contingencies. Small and medium producers face an uncertain business environment with fixed production costs and shrinking access to natural resources. Their economic performance is sensitive to changes in regional markets and macroeconomic policies. In the current setting, this group of producers could be trapped in a declining spiral of water scarcity, declining production quality and profitability. Enologic potential and agronomic suitability have made this region an attractive recipient of foreign direct investments after the economic crisis of 2001. New market alternatives and export orientation has driven technology adoption and agronomic management strategies to focus on producing quality grapes adapted to water stress management. In the past, groundwater resource have been affected by local and diffuse pollution that led to a restriction on the construction of new wells (Reta 2005; Foster et al. 2005). Together, the surfacewater scarcity threatening Mendoza since 2009 and the zoning restriction imposed by DGI in 1998 has created a fixation of productive land that is, simultaneously, well ranked for quality grape production (Diaz Araujo et al. 2004, p.75).

Frontier function methodologies represent a captivating methodology to assess productivity and efficiency. These methods determine a benchmark frontier and provide a measure of efficiency in terms of input reduction or potential output expansion with respect to the frontier. This model was 
first applied by Farrell (1957), who decomposed economic efficiency into technical efficiency (TE) and allocative efficiency (AE). The former measures the firm ability to maximize the output given the input set, while the latter measures the capability of the firm to relocate inputs according to their prices.

Surprinsingly, the literature applying this methods to grapevine production is scarce. In general, the available literature has addressed the overall agroclimatic conditions of vineyards and employed the analysis at the farm level (Piesse et al. 2018; Latruffe et al. 2016 ; Latruffe and Nauges 2014; Conradie et al. 2006; Townsend et al. 1998). More in detail, the work of Moreira et al. (2011) decoupled the performance of vineyards at the plot level but did not include the water used as a productive input. Whilst, Coelli et al. (2012) and Andrieu et al. (2014) considered water at the vineyard level in the functional form at the Murray-Darlin Basin (Australia) and San Juan (Argentina) respectively. In general, literature has not addressed the water use for grapevine production at the plot level and there are no precedents for this type of study in Argentina.

This paper analyzes the economic performance of grapevine producers in Lujan de Cuyo, a promising but complex area for wine production due to existing conflicts over water management, pollution threats and dependence on policy tools. Moreover, it seeks to capture the unobserved heterogeneity of managerial decisions at the plot level accounting for the irrigation practices for two subgroups of farmers. To the authors' knowledge this work is unprecedented for grapevine production in the context of water scarcity in semi-arid areas.

Furthermore, this paper focuses on two issues: $(i)$ the analysis of the determinants of technical efficiency of grapevine producers and $(i i)$ the role of water management practices in improving farm productivity. In order to disentangle the implications of efficiency determinants, the Stochastic Frontier Analysis (SFA) is utilized on a primary data set from the Carrizal basin of Mendoza, Argentina. Where functional forms are tested considering the market orientation of farmers, extension services, use of policy tools and irrigation practices.

The comprehensive analysis of efficiency determinants will contribute to understanding the performance of vineyards with respect to their productive potential and deriving recomendations for the design of policy tools. The following section reviews the existing literature of TE in grapevine production. Later, the theoretical framework is explained followed by the description of the employed data in the analysis. Then, the results are presented and discussed to derive in the section of conclusions and recommendations.

\subsection{Background literature}

The literature on TE analysis is divided into two approaches: non-parametric and parametric. Widely known as Data Envelopment Analysis (DEA), the non-parametric framework allows for the analysis without specifications of the functional form. But the drawback is that it is impossible to isolate the inefficiency effects from the random noise. On the other hand, the parametric or 
deterministic frontier analysis allows for the decomposition of the statistical noise into, random noise and inefficiency (Aigner et al. 1977; Meeusen et al. 1977).

Although, the Stochastic Frontier Analysis (SFA) is very popular in the field of agricultural economics (Battese 1992), there is scarce literature on the application of this methodology to grapevine production. In particular, considering the regional effects of potential spill over of grapevine production (Van den Bosch 2008; SSPE 2016; COVIAR/OVA 2018). Townsend et al. (1998) analyzed the relationship between farm size, productivity and returns to scale for wine grape producers located in four regions of South Africa for the years 1992 to 1995. de Sousa Henriques et al. (2009) analyzed the TE from panel data of 22 vineyards in the Portuguese Alentejo region. They found increasing return to scale and a mean efficiency of 60.7 per cent for a sample of predominantly family farms.

Conradie et al. (2006) analyzed the performance of vineyards from two regions in the Western Cape, South Africa. They modeled a Cobb-Douglas production function with modest returns to scale. The variables of labor quality, age and education of the farmer, location and energy expenditures for irrigation were selected to model inefficiency. Ma et al. (2012) use 1020 farm level observations collected across 24 grape producing provinces in China to estimate a Cobb-Douglas SPF model. Manevska-Tasevska (2012) uses a panel data set for grape producers from Macedonia along with a Cobb-Douglas SPF model and a second stage regression to obtain an average TE score of 0.80, they also measured allocative efficiency (0.79) and economic efficiency (0.56).

Guesmi et al. (2012) compare the performance of traditional and organic grapevine producers in Catalonia following the translog specification. In this study, the average TE score of organic vineyards was 0.80 and 0.64 for farms that followed conventional practices. Latruffe et al. (2014) analyzed the performance of French grapevine farmers and their possibility to convert to organic farming with parametric and non-parametric techniques. The TE scores varied between 0.33 and 0.35 using DEA and 0.69 and 0.72 employing stochastic frontier.

In an effort to improve the understanding of the underlying heterogeneity in vineyard performance, Moreira et al. (2011) examined the TE of wine grape production at the plot level. They used a cross-sectional sample for Chilean farms in 2006 and found an average TE of 77.2 per cent at the farm level, with plot efficiency scores that varied between 23.4 and 95.0 per cent.

The water consumption and irrigation infrastructure represents a challenge to the analysis of grapevine production, due to measurement difficulties. Coelli et al. (2013) and Andrieu et al. (2014) documented the only work that explicitly includes water as a production input. The former used a panel data set for 135 farmers in the Murray-Darlin basin (Australia) and measured a mean TE of 79 per cent and a mean shadow price ratio of 1.07 for water. The latter a cross-sectional of 700 farms in a district of San Juan (Argentina) and estimated an average TE score of 0.41. Both studies lack specific agroclimatic conditions and detailed information on irrigation systems.

Given the limitations of water measurement and location specificity of grape production, there are few studies that include information of agroclimatic conditions or irrigation systems in an attempt 
to better understand the vineyard performance (de Sousa Henriques et al. 2009; Moreira et al. 2011; Christ et al. 2013). Energy consumption has been utilized as a proxy for groundwater irrigation (Conradie et al. 2006; Foster et al. 2005). Guesmi et al. (2012) found that vineyards located in less favorable areas have a relatively better performance.

In general, grapevine production systems are the recipients of governmental assistance through specific policy tools. The perception that small producers are missing out on technology and quality improvements is an intense discussion. Gibbons et al. (2016) and Maffioli et al. (2011) analyzed the effect of public policies on the adoption of technologies and agricultural extension services in Western Argentina. The effect of subsidies on productivity continues to divide researchers in literature (Foster et al. 2005; Hartt Kentnor 2012; Gibbons et al. 2016; Badiani et al. 2011; OECD 2003; Pfeiffer and Lin 2014; Guesmi et al. 2012).

\subsection{Methodology}

This section describes the framework employed for the analysis and the selected approach to assess the economic value of infrastructure accounting for the the quasi-fixation of irrigated land.

\subsubsection{Valuation of capital services}

This study recognizes the importance of measuring the contribution of capital endowment to the production function. Therefore, the perpetual inventory method was considered to assess the real economic value of farm endowments; this is a common practice in agricultural economics (Coelli et al. 2005; Ball et al. 2002; Ball et al. 2004; Coelli et al. 2013).

As market prices do not always reflect the economic value of capital employed on the farm, this methodology assesses the annual services provided by the stock which is priced according to their own characteristics. Taking into account the capital stock at the end of each period, $K_{t}$, as the sum of all previous investments weighted by the relative efficiency that decreases over time given by the hyperbolic function of $d_{\tau}$ :

$$
\begin{gathered}
K_{t}=\sum_{\tau=0}^{\infty} d_{\tau} I_{t-\tau} \\
d_{\tau}=\frac{L-\tau}{L-\beta_{\tau}}
\end{gathered}
$$

where $L$ is the life expectancy of the capital good, $\beta$ represents the curvature of the decay parameter, and $d_{\tau}$ is the decay in efficiency at the age $\tau$. Capital stock is composed of machinery, infrastructure and land connected to grapevine production. The value of the stocks was formed considering the capital endowment at the time of the survey, accounting for market prices and their respective age. More detail on the capital stock valuation in the sample can be found in the next section. 


\subsubsection{Model specification}

Production function models were designed under the assumption that each plot receives different treatment according to agronomic characteristics and market orientation. The likelihood-ratio test confirmed that the efficiency estimates based on the translog stochastic production frontier are preferable with respect to other functional forms. The Cobb-Douglas functional form assumes equal production elasticities, as well as scale elasticities and unitary elasticities of substitution for firms. Despite the interpretation convenience and estimation offered by the Cobb-Douglas, the translog is slightly more complex for estimation but it does not impose the restrictions mentioned above (Coelli et al. 2013; Greene 2008).

$$
\begin{aligned}
\text { Grapevine }_{i}=Y_{i}= & f\left(X_{1}, X_{2}, \ldots, X_{n}\right) \\
& f\left(K_{i}, L a b_{i}, I_{i}, W_{i}\right)
\end{aligned}
$$

The output variable is (Grapevine) represents production in tons per plot, this information was reported by farmers and the values were certified with experts and secondary data. The specification continues with the value of capital stock, explained by services received by the vineyard including the size of the farm, labor as total labor hours per year, monetary expenses in agrochemical inputs, and water as cubic meters used by the producer at each level of analysis. The estimation included shifter variables as age of the vine (vineage) and dummy variables for training system (pergola.dummy), variety color (white.variety), the total vineyard size and the categorical classification of soil (soil).

$$
\begin{aligned}
\ln (\text { Grapevine })_{i}= & \alpha_{i}+\sum_{i=1}^{647} \beta_{i} \ln X_{i}+0.5 \sum_{i=1}^{647} \beta_{i i} \ln X_{i}^{2}+ \\
& \sum_{i}^{n} \beta_{i j} \ln X_{i} * \ln X_{j}+\nu_{i}-\mu_{i}
\end{aligned}
$$

Intuitively the stochastic frontier appraised the production capacity of the inputs against the output produced by each farmer. Deviations from the output capacity can be explained by decomposing the error term $\epsilon_{i}$ into $\nu_{i}-\mu_{i}$, where $\nu_{i}$ represents statistical noise and $\mu_{i}$ represents technical inefficiency. Where the random noise could be measurement errors or uncontrollable hazzards for the farmer, whilst the inefficiency term represents the imperfect product adjustments for a given technology and reflects the managerial decisions in the production unit. Considering that we account for information from one period in time, some farms could be optimizing the use of their resources while others are limited in their allocation of resources in the short-run.

The exogenous variable $\left(Z_{j}\right)$ is represents effectivenes of the irrigation system and accordingly assigns a value from 0 to 1 to the irrigation system used at the plot level. Flooding irrigation systems receive the lowest value (0.3), furrow irrigation is distribution through small chanels within the plot (0.5), and the highest score is for drip irrigation system (0.9) considered the most effective (Hernández et al. 2012).

Also the use of technical advice provided by agricultural extensionist and plot density, measured 
as the number of vines inside the plot, are considered as exogenous variables. The analysis considers if the producer is a recipient of the energy subsidy to extract groundwater for irrigation. A dummy variable that acknowledges technology adoption in management practices like prunning and harvesting (machine technology). Associativity is a dummy variable that acknowledges the participation of the producer in any farmer association. Lastly, depth of the aquifer is the distance in meters to the underground source used for irrigation and leaf removal is the dummy variable that acknowledges the hand-performed craft of ensuring light exposure of grapevine bundles.

This paper employs the Battese (1992) estimator for the calculation of technical efficiency $\left(T E_{i}\right)$.

$$
T E_{i}=E\left[\exp -\left(\mu_{i} \mid \epsilon_{i}\right)\right]=\left[\frac{1-\Phi\left(\sigma_{*}-\mu_{* i} / \sigma_{i}\right.}{1-\Phi\left(-\mu_{* i} / \sigma_{*}\right)}\right] \times \exp \left(-\mu_{* i}+\frac{1}{2} \sigma_{*}^{2}\right)
$$

Acknowledging heteroskedasticity in the $\sigma_{\nu}^{2}$ and $\sigma_{\mu}^{2}$ we allow the external variables $\left(Z_{j}\right)$ to affect both the technical inefficiency of firms and the statistical noise. Simultaneously, we improve the estimation of the parameters avoiding the downward bias on the intercept $\left(\beta_{0}\right)$ and the remaining coefficient estimates of the production function $\left(\beta_{k}\right)$ and the coefficients of the exogeneous variables $\left(Z_{j}\right)$ (Wang and Schmidt 2002; Kumbhakar and Knox Lovell 2003; Parmeter 2014).

$$
\begin{aligned}
\mu_{i} & \sim \mathcal{N}^{+}\left(0, \rho_{j} Z_{j}\right) \quad ; \quad \sigma_{u, i}^{2}(z, \delta)=\sigma \times \exp \left(z_{i}^{\prime} \delta\right) \\
\nu_{i} & \sim \mathcal{N}\left(0, \delta_{j} Z_{j}\right) \quad ; \quad \sigma_{\nu, i}^{2}(z, \rho)=\sigma \times \exp \left(z_{i}^{\prime} \rho\right)
\end{aligned}
$$

The selected parametrization captures the idea of similar shape across all firms in the distribution of inefficiency since the scaling function stretches or shrinks the horizontal axis but holds the underlying shape of the inefficiency untouched. Considering the context of the research project in terms of quasi-fixed inputs, relatively intensive production systems, and data availability, the distribution of $\mu_{i}$ is preferred in this context (Parmeter 2014; Kumbhakar and Wang 2015). Additionally, parametrization of $\mu_{i}$ and $\sigma^{2} \mu$ by the same $Z_{i}$ could accomodate the non-monotonic relationship between firm level inefficiency and its determinants (Parmeter 2014).

\subsubsection{Marginal and partial effects of the average}

In stochastic frontier analysis it is possible to analyze the performance of firms but also the determinants of inefficiency. The inefficiency explanatory variables were introduced by Reifschneider and Stevenson (1991), who allowed the variance of the inefficiency term to be a function of the exogenous variables.

The derivation of the marginal effects (ME) allows for the estimation the magnitude of the $k$ th variable on the inefficiency. Acknowledging the non-linear relationship between $E(\mu)$ and $Z i$, we realize that the slope coefficient of $\delta_{u}$ does not represent the marginal effects of $Z_{i}$ but only the direction of the effect. 
If the inefficiency term $\mu_{i}$ follows a half-normal distribution, then its variance $\sigma_{\mu}^{2}$ is the only parameter that could still be parameterized by the $Z_{i}$ vector. There are no a priori reasons for choosing one distributional form over the other, and all have advantages and disadvantages (Coelli et al. 2005).

For example, the half-normal distributions have a mode at zero, implying that a high proportion of the firms being examined are perfectly efficient. At the same time, the truncated normal distributions allow for a wider range of distributional shapes, including non-zero modes. The distribution proposed by Aigner et al. (1977) could be interpreted as a model that posses the scaling property introduced by Wang et al. (2002), since it includes the assumption of the inefficiency term with a half-normal distribution automatically involving a single parameter family (Kumbhakar, H.-J. Wang, et al. 2015).

Following Kumbhakar and H.-J. Wang (2015), it is possible to derive the marginal effects of the external variables $\left(Z_{i}\right)$ and the marginal effect of the $k$ th exogenous variable on the expected value of inefficiency, which is:

$$
\frac{\partial E\left(\mu_{i}\right)}{\partial z_{u}[k]}=\delta_{k}^{\mu} \frac{\sigma_{\mu, i}}{\sqrt{2 / \pi}}
$$

where the $\delta k$ is the estimated coefficient of the external variable. Note that the sign of the coefficient already indicates the direction of the effect. Considering that the estimations will provide $n$ marginal effects for each exogenous variable considered in the model, the simple average of this effect would not express the magnitude of the effect. Accounting for these issues, the estimations of the Partial Effect of the Average (PEA) of the exogenous variable will provide a clear magnitude of the $Z_{i}$ in the farm performance.

$$
\operatorname{PEA}\left(z_{u}[k]\right)=\frac{\delta_{k}^{\mu}}{\sqrt{2 / \pi}} \times e^{\bar{z}_{\mu} \delta^{\mu}}
$$

These measures are able to provide an overall sense of the effect of a determined exogenous variable on the level of inefficiency (Parmeter 2014). The calculation of the ME and the APE can be found in the results.

\subsection{Data}

These effects have led to a greater intensification of agricultural management and viticultural practices in the research area, where farmers seek to maximize the production potential of quality vines and optimize the use of natural resources and intermediate inputs. Therefore, it is relevant to analyze the production efficiency to estimate general scores controlling for location, water quality and technology adoption among others.

Here we analyze the economic performance of small and medium grapevine producers in the area Lujan de Cuyo; a promising area for high-quality grape production and environmentally challenging 
due to existing conflicts over pollution potential that affect water quality. This area is located next to the Andes mountain range and has high heterogeneity in natural characteristics and primary access to pure surfacewater from the mountains.

The information used for the analysis was collected through applied surveys to grapevine producers for wine production in 5 districts from November 2016 until January 2017. The sample is composed by 177 randomly selected farmers, who were questioned on the production process, commercialization and water resource management practices.

The organization of the collected data followed a hierarchical logic. Starting at the farm-level, where general endowments were considered in order to later disaggregate production decisions down to the plot level. It is common practice that farmers have standing contracts for specific plots with several wineries depending on the output characteristics or market demand. This implies potential differences in agricultural management of plots within the vineyard.

Water availability depends on the location within the research area and water infrastructure. Water resources for irrigation are granted through water rights that are entitled to the

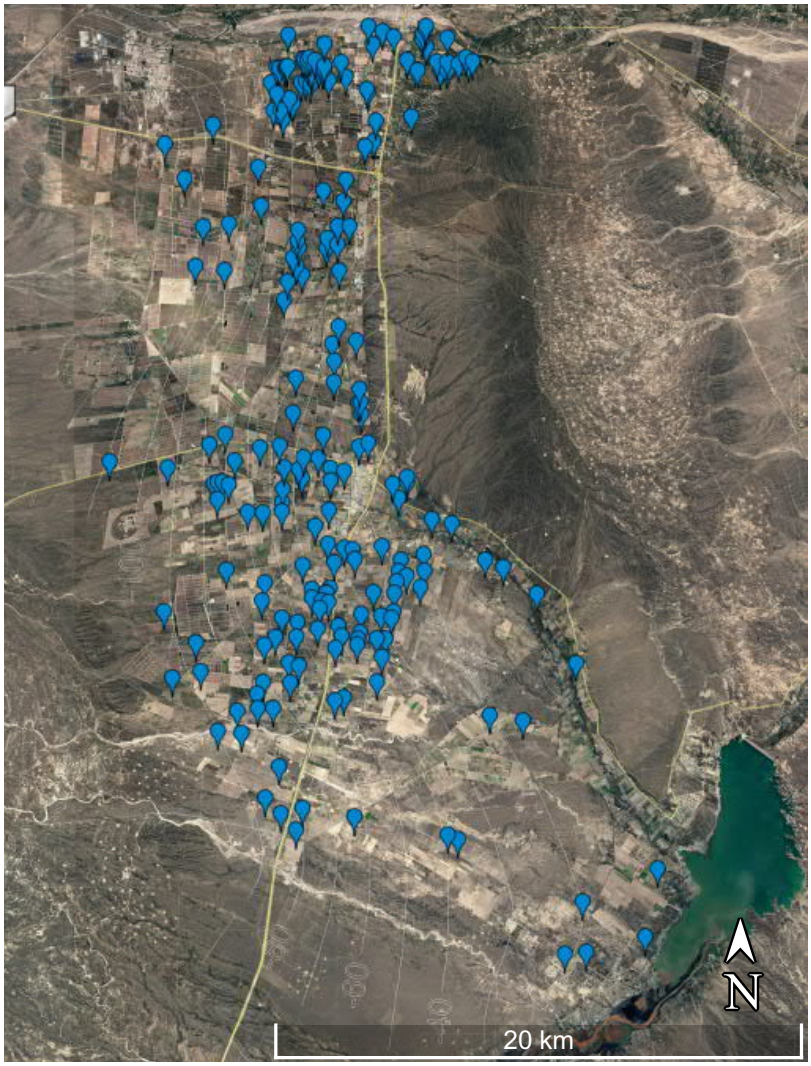

Figure 3.1: Research area producer and attached to the land, which means that they are not tradable and can only be transferred with the land property. In the districts of Agrelo and Perdriel surface water is delivered based on a turn scheme designed by the water authorities based on the climate estimates and infrastructure conditions. Whereas, in the districts of Ugarteche, Anchoris, and El Carrizal, groundwater remains the sole resource alternative for irrigation.

The collected data seeks to capture the unobserved heterogeneity in production functions for grapevine producers addressing the different management practices with respect to their quality or enological potential. Therefore, the reported information was validated through literature review, expert consultation, and institutional databases. 


\subsubsection{Sample data and variable selection}

The total area of the research project has $600 \mathrm{sq} . \mathrm{km}$. and covers nearly 15,000 ha of grapevine area, farmed by 510 producers. Bulk production is estimated at 11,000 tons from approximately 2,500 plots. As the area is situated along the Andes mountain range, the terrain and water resources vary substantially within this area. From northwest to southeast, elevation decreases from 980 to 770 meters above sea level and the depth of groundwater raises from -120 to -20 meters below the surface (Foster et al. 2006; Hernández et al. 2012). Considering the heterogeneity of the region, the sampling procedure required careful stratification and randomization in order to ensure representativeness of the sample. On average, grapevine producers have at least 2.3 plots and the plot size is 4.22 hectares. Nearly 30 per cent have 15 plots per farm.

In order to improve the analysis, information on energy consumption for pumping water, market orientation, and soil composition were considered. The use of energy data at the farm level is relevant mainly because it allowes for the estimation of pumped groundwater but also acknowledges the contradictory effects of such policies that subsidize water pumping practices without considering the effectiveness of the irrigation systems. In terms of water policies, the number of wells has been fixed for over a decade with the objectives of ensuring the Carrizal aquifer's sustainability and improving of water quality ${ }^{1}$. Considering the inheritance principle from the water rights legislation, that ensures the permanent bond between land and the water right, the zoning restriction is interpreted as a quasi-fixation of irrigated land. At the same time, many producers manage more than one vineyard and may share movable capital between them, which could imply lower management costs. The output weighted efficiency could provide some insights in line with this. There is considerable heterogeneity in terms of grape type (red or white), quality (premium or varietal), and irrigation practices. Nearly half of the sample uses drip irrigation and the rest have irrigation by gravity; however, alternative mechanisms and scheduling strategies are observed for both systems that can drive water efficiency practices.

\subsubsection{Data validation and interpretation}

At the plot level, productive information was collected using a detailed framework to assess the use of agrochemicals, water, labor, and the quality of the product. In this region is common practice to report expenses on a per hectare basis, which conditioned the structure of the survey and reporting options. In the general case, the collected information was available in monetary terms but not always declared in units terms of the input. Accounting for the fact that grapevine producers are price takers in this region, some tailored solutions were designed for each input classification. For instance, farm labor wages (permanent or seasonal) are regulated by labor syndicates and publicly announced. Regarding the use of agrochemicals, the management classification type practice was always indicated by producers and the average input price per type of agrochemical input was always accounted for.

\footnotetext{
${ }^{1}$ This policy was a concequence of the diffuse polution motivated by the excess overdraft of groundwater by farmers that damaged the sustainability of the Carrizal aquifer (Foster et al. 2005; Diaz Araujo et al. 2004). Simultaneously, the Province of Mendoza is facing a water scarcity status since 2009 (Duek and Comellas 2015).
} 


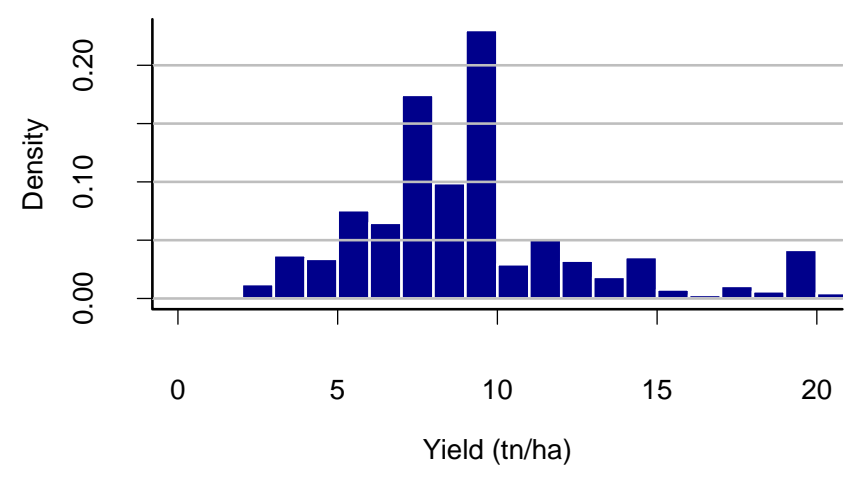

Figure 3.2: Grapevine yield per hectare

The figure 3.2 represents the yield per grapevine plot and their frequency in the sample. It is possible to recognize a bimodal distribution which indicates that some producers aim at higher yields while others may prefer more quality vines maintaining the yields at a lower stable rate. To further analyze this issue, the sample was divided according to the market orientation of the producers. Essentially, those that produce grapes only for selling to other wineries (viticulturists) and farmers that produce their own wine (winegrowers) are reflected in this distribution.

Lastly, the delivered surface water was certainly measured by the regional water management authority that annually sets the water volume per hectare for an even service delivery. From August 2016 until March 2017, this volume was 10.426 cubic meters per ha, slightly higher for the previous year. Groundwater estimations were done accounting for the characteristics of the pumping equipment, consumed energy for pumping water and depth of groundwater table.

\subsubsection{Analysis and imputation techniques}

Each vineyard plot is considered as a production unit that has access to different services in terms of capital, intermediate inputs, and human resources at the management level. For capital variable: the plot size in hectares, the use of tractors, storage facilities, water reservoirs, groundwater wells, irrigation systems, and hail protection were considered.

Assessing the capital endowment for agricultural producers in developing countries can be a real hassle. The real economic value of the endowments can differ substantially from the market value and historical information on investments is very scarce. e.g., the tractor produced in the 1940s has null market value but if a farmer still uses it, certainly is still worth something to him. On average, the annual value of the capital stock is 29,792 US dollars. However, for those farmers that do not use drip irrigation as much as the previous group, the mean value of capital is 28,697 US dollars. At the farm level, the use of agrochemicals is a common practice in grapevine production. More in detail, the mean values of table 4.1 state that 430 US dollars are spent annually on agrochemicals. The application of herbicides and fertilizers is strongly linked with the technological level of the farmer and seems to be correlated with the water source, irrigation system, and management system of the grapevine crop. 
Table 3.1: Descriptive values per hectare

\begin{tabular}{lcrr}
\hline Component & Unit & Mean & Sdt.Dev. \\
\hline Production & tons & 10.2 & 4.7 \\
Capital services & USD & 29128.8 & 13259.6 \\
Labor & days & 92.4 & 146.2 \\
- Permanent & days & 80.2 & 147.8 \\
- Temporary & days & 12.9 & 12.3 \\
Agrochemicals & USD & 429.8 & 268.8 \\
- Fertilizer & USD & 13.8 & 8.8 \\
- Pesticides & USD & 27.7 & 17.5 \\
Water & $m^{3}$ & 9339.9 & 4905.8 \\
Average plot size & ha & 4.2 & 4.1 \\
Producer Age & years & 53.1 & 11.8 \\
Agricultural income dependence & $\%$ total & 73.3 & 35.0 \\
Vine density & Plants/ha & 4370.1 & 2254.2 \\
Average planted year & year & 1990.0 & 25.3 \\
\hline
\end{tabular}

Source: Own calculation.

As a significant expenditure, energy consumption is relevant for those farmers that rely on groundwater for irrigation. On average, a farm consumes 21,608 $\mathrm{kWh}$ annually, this item is of particular interest since the energy tariff remains subsidized and the effect of this policy tool on the vineyard performance is analyzed below. Grapevine production is a labor intensive crop due to the special maintenance tasks that are mainly executed by persons. Required management practices, irrigation techniques, and a diversity of tasks are performed every year on the crop. According to the information on table 4.1, each farm demands 80.2 labor days of permanent staff and 12.9 labor days of seasonal staff on average; that focuses in crafts as harvesting, pruning and leaf removal. Although, there is a high variability among farms, the mechanical harvesting expenditure is on average 4,684 US dollar per farm representing a growing trend of vineyards adapting to replace outsourced labor. The dummy variable machine technology was created to capture the effects of such practices.

To further understand the efficiency determinants and disentangle the effect of exogenous variables in agricultural performance, the analysis was carried out acknowledging the market orientation of the farmers. In other words, the sample was split into two groups: on one hand producers that produce their own wine (winegrowers or vintners) and farmers that sell grapevine production in the market (vitciculturists). They represent a share of 24 and 76 per cent of the sample respectively.

\subsection{Results and discussion}

In this section the Maximum Likelihood (ML) estimates of the production frontier are presented and discussed. The main production factors are considered as well as vine and agroclimatic characteristics for a general perspective. The results are presented for the complete sample accompanied by the two subgroups, where the analysis is focused. The level variables are training system, grape color 
variety, age of the vines, total vineyard size and soil characteristics.

To improve the analysis, the sample was divided in two groups with respect to the output destination. Grapevine producers that sell their output to wine makers were grouped into the Viticulturists subsample (444 plots). This subgroup represents the biggest share in the sample. Whilst, those farmers that not only cultivate grape but also produce wine are clustered in the group named Winegrowers (203 plots). The sample division allows for a better focus on economic and managerial performance and, simultaneously, improves the interpretation of the efficiency determinants. A likelihood-ratio test validated the explanatory power of these subgroups.

\subsubsection{Functional form and efficiency determinants}

In this region, the production of grapevine is better explained econometrically with a translog functional form: where capital, labor, agrochemical expenses, and water used are the main inputs. The first order coefficients of the production function are all significant and positive with the exception of labor in the subgroup of winegrowers. At the sample mean, the contribution of production factors is similar between the complete sample and the farmers subgroups; while it is relatively different among these clusters. In principle, this can be explained by the smaller share of vintners in the sample and quality preferences of these winegrowers.

The average TE score is 0.829 for viticulturists and 0.819 for winegrowers. The histograms of the efficiency scores in 3.3 deploy the frequency for each subgroup. Moreover, the mean yield for viticulturists (10.6 tons) is significatly higher than that reported by winegrowers (9.19 tons), as confirmed by the t-test ( $\mathrm{p}$-value $=0.0001)$. 
Table 3.2: Estimation coefficients of production function

\begin{tabular}{|c|c|c|c|c|c|c|}
\hline & \multicolumn{2}{|c|}{ Complete sample } & \multicolumn{2}{|c|}{ Viticulturists } & \multicolumn{2}{|c|}{ Winegrowers } \\
\hline & $\beta_{\text {sample }}$ & $S E_{\text {sample }}$ & $\beta_{V i t}$ & $S E_{V i t}$ & $\beta_{W i n e}$ & $S E_{W i n e}$ \\
\hline intercept & $5.653^{*}$ & $(1.343)$ & $6.196^{* * *}$ & $(1.808)$ & $8.463^{* * *}$ & $(2.442)$ \\
\hline capital & $287^{*}$ & $(0.047)$ & $0.217^{* * *}$ & $(0.058)$ & $0.719^{* * *}$ & $(0.095)$ \\
\hline labor & $120^{* * *}$ & $(0.030)$ & $0.215^{* * *}$ & $(0.040)$ & $-0.211^{* * *}$ & $(0.070)$ \\
\hline agrochemicals & $142^{* * *}$ & $(0.032)$ & $0.144^{* * *}$ & $(0.041)$ & $0.247 * * *$ & $(0.066)$ \\
\hline water & $382^{* * *}$ & $(0.036)$ & $0.376^{* * *}$ & $(0.052)$ & $0.157^{* *}$ & $(0.074)$ \\
\hline capital $^{2}$ & $428^{* * *}$ & $(0.105)$ & $0.528^{* * *}$ & $(0.129)$ & 0.209 & $(0.162)$ \\
\hline labor ${ }^{2}$ & $-0.106^{* *}$ & $(0.044)$ & $-0.107^{* *}$ & $(0.050)$ & 0.180 & $(0.176)$ \\
\hline agrochemicals $^{2}$ & -0.045 & $(0.061)$ & 0.073 & $(0.085)$ & 0.030 & $(0.098)$ \\
\hline water $^{2}$ & 0 & $(0.0$ & 0.055 & $(0.094)$ & -0.005 & $(0.105)$ \\
\hline capital $\times$ labor & .004 & $(0.054)$ & 0.082 & $(0.060)$ & -0.120 & $(0.153)$ \\
\hline capital $\times$ & $-0.143^{* *}$ & $(0.057)$ & $-0.238^{* * *}$ & $(0.074)$ & 0.006 & $(0.101)$ \\
\hline capital $\times$ & -0.092 & $(0$. & $-0.190 *$ & $(0.100)$ & -0.042 & $(0.143)$ \\
\hline labor $\times$ agroch & 0.063 & $(0$. & 0.065 & $(0.1$ & -0.112 & $(0.096)$ \\
\hline labor $\times$ water & .028 & $(0$. & -0.058 & $(0.057)$ & -0.081 & $(0.130)$ \\
\hline agroch $\times$ water & 0.08 & $(0.0$ & 0.083 & $(0.078)$ & 0.119 & $(0.094)$ \\
\hline pergola training syst. & $0.161^{* * *}$ & $(0.042)$ & $0.228^{* * *}$ & $(0.054)$ & $0.212^{* * *}$ & $(0.081)$ \\
\hline white variety & $0.112^{*}$ & $(0.059)$ & 0.098 & $(0.064)$ & 0.152 & $(0.164)$ \\
\hline vine age & $-0.003^{* * *}$ & $(0.001)$ & $-0.003^{* * *}$ & $(0.001)$ & $-0.004^{* * *}$ & $(0.001)$ \\
\hline vineyard siz & $0.001^{* *}$ & $(0.001)$ & $0.003^{* *}$ & $(0.001)$ & $0.003^{* * *}$ & $(0.001)$ \\
\hline well drained s & $0.225^{* *}$ & $(0.094)$ & $0.261^{* * *}$ & $(0.101)$ & 0.013 & $(0.392)$ \\
\hline excessively drained soil & -0.057 & $(0.038)$ & -0.015 & $(0.052)$ & 0.113 & $(0.079)$ \\
\hline
\end{tabular}

Source: Own estimation.

Significance level: $\quad 10 \%\left({ }^{*}\right) ; 5 \%\left({ }^{* *}\right) ; 1 \%\left({ }^{* * *}\right)$.

The contribution of capital is relatively higher for winegrowers (0.72) than for viticulturists (0.22). Accounting for the composition of the capital variable and considering that wineries focus on output quality, the vineyard location is relevant for the economic services of land as well as their machinery and infrastructure to perform special managerial practices. Due to the input quasi-fixation, it is possible that viticulturists are unable to invest in irrigated land and increase their capital services with other assets, which may contribute to production but the variable may be beyond their optimum $\left(\right.$ capital $^{2}=0.53$ ). Similarly, the use of agrochemicals is relatively more important for winegrowers (0.25) than viticulturists (0.14) that would rely on professional advice and finance tools to comply with crop agrochemical requirements and a pest management plan.

The coefficients of labor hours at the plot level have different values for the different groups. This is not surprising considering that grapevine production is the main input for a high-value product such as wine, whose quality is also subject to labor quality crafts and management practices. The labor coefficient is almost as important as capital for viticulturists (0.21). However, it is also relevant for winegrowers, in practice, since their quality focus is implemented through manual tasks on the vineyard.

Regarding the water input, the coefficient is the greatest among the other production factors for the viticulturists subgroup (0.38). In the case of the winegrowers, the coefficient is significant and represents the third greatest value among the production factors (0.16). Both subgroups seem to 
employ the resource near the optimum ${ }^{2}$.

The selected level variables also have the expected sign. Pergola is the roof-topped training system for vineyards that is expected to be more productive: for viticulturists (0.23) and winegrowers (0.21) the variable has significant values. Also the variety color dummy variable, where the estimation confirms that white varieties are more productive than red grapevines (0.1 and 0.15). In both subsamples, the effect of total vineyard area is positive but could be outweighted by the age of the vines effect.

The latter confirms the market orientation of vineyards and their focus on intensive management and quality oriented output (Cerdán-Infantes 2008). Although, old vineyards are less likely to adapt to newer enological practices, as they had been planted before the Productive Reconversion Plan was carried out by national authorities (Van den Bosch 2008; Maffioli et al. 2011). The mean plantation year of grapevines is 1990. Accounting for the soil characteristics, those plots with relatively higher stony content become more effective for grape production but this is only significant for viticulturists $(0.26)$

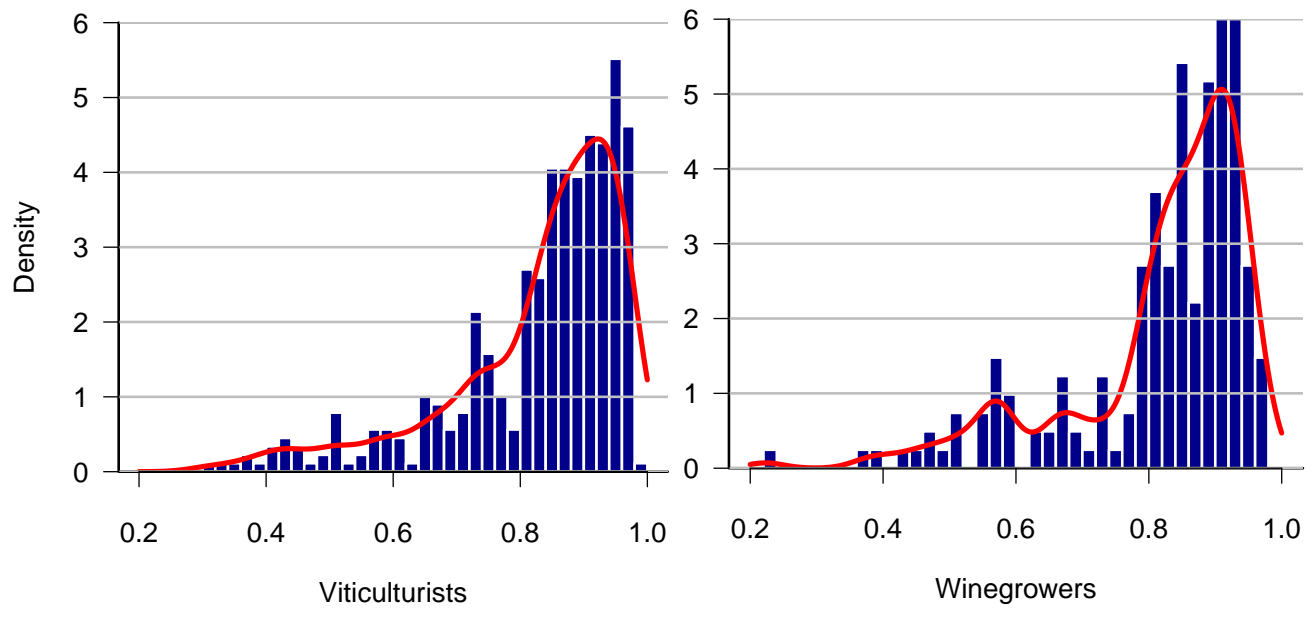

Figure 3.3: Histograms of TE scores

In the context of competitive markets there is a higher probability for farmers to remain efficient. In accordance with this, firms are expected to show less variability in their economic performance since non-competitive farmers will be forced out of the market in the long-run (Kumbhakar, H.-J. Wang, et al. 2015). Higher values of the variance parameter are interpreted as more diverse performance of wineries within the region. For the inefficiency models a half-normal distribution was selected, which alings with the descriptive context of a competitive market for grapevine production in Mendoza.

Regarding the exogenous variables, the resulting coefficients for the inefficiency variance $\left(\sigma_{\mu}^{2}\right)$ are generally similar but with notable exceptions between the subgroups. More effective irrigation systems have the effect of decreasing inefficiency for both clusters but this is only significant for the viticulturists $(-9.11)$. This could be interpreted as efficiency gains from improvements in the irrigation systems.

\footnotetext{
${ }^{2}$ The second order coefficient for water is almost zero in both subgroups.
} 
Furthermore, the technical assistance given by extensionists increases efficiency significantly for viticulturists (-0.73) and the effect intensifies for winegrowers (-2.03). Also, vine density increases efficiency for both subsamples but is only significant for viticulturists (-0.48).

Table 3.3: Estimation coefficients for external variables

\begin{tabular}{|c|c|c|c|c|c|c|}
\hline & \multicolumn{2}{|c|}{ Complete sample } & \multicolumn{2}{|c|}{ Viticulturists } & \multicolumn{2}{|c|}{ Winegrowers } \\
\hline & Estimate & Std. Dev. & Estimate & Std. Dev. & Estimate & Std. Dev. \\
\hline \multicolumn{7}{|l|}{ Technical inefficiency } \\
\hline$\rho$ intercept & $4.301^{* *}$ & $(1.886)$ & 3.827 . & $(2.331)$ & 3.850 & $(3.321)$ \\
\hline$\rho$ irrigation syst. & $-9.554^{* * *}$ & $(2.937)$ & $-9.111^{* *}$ & $(3.638)$ & -5.830 & $(5.404)$ \\
\hline$\rho$ extensionist & $-1.419^{* * *}$ & $(0.387)$ & $-0.732^{* *}$ & $(0.365)$ & $-2.028^{* * *}$ & $(0.731)$ \\
\hline$\rho$ vine density & -0.300 & $(0.221)$ & $-0.483^{* *}$ & $(0.241)$ & -0.546 & $(0.447)$ \\
\hline$\rho$ energy subsidy & $-1.386^{* *}$ & $(0.625)$ & $-0.791 *$ & $(0.448)$ & 0.656 & $(0.655)$ \\
\hline$\rho$ machine technology & -0.649 & $(0.766)$ & $-1.609^{* *}$ & $(0.819)$ & $1.738^{*}$ & $(1.006)$ \\
\hline$\rho$ associativity & -0.746 & $(0.557)$ & -0.584 & $(0.555)$ & $-2.295^{* *}$ & $(1.121)$ \\
\hline$\rho$ depth aquifer & 0.007 & $(0.005)$ & 0.006 & $(0.007)$ & $-0.036^{* * *}$ & $(0.011)$ \\
\hline$\rho$ leaf removal & $0.980^{* * *}$ & $(0.312)$ & $1.104^{* * *}$ & $(0.394)$ & 0.849 & $(0.627)$ \\
\hline \multicolumn{7}{|l|}{ Statistical noise } \\
\hline$\delta$ intercept & $-2.680 * * *$ & $(0.606)$ & $-3.104^{* * *}$ & $(0.749)$ & $-2.465^{* * *}$ & $(0.178)$ \\
\hline$\delta$ irrigation syst. & 0.791 & $(0.765)$ & 1.228 & $(0.982)$ & - & - \\
\hline$\delta$ extensionist & $-0.547 * * *$ & $(0.180)$ & 0.050 & $(0.309)$ & - & - \\
\hline$\delta$ vine density & $-0.598^{* * *}$ & $(0.106)$ & $-0.571^{* * *}$ & $(0.129)$ & - & - \\
\hline$\delta$ energy subsidy & 0.259 & $(0.184)$ & 0.144 & $(0.256)$ & - & - \\
\hline$\delta$ machine technology & 0.277 & $(0.187)$ & -0.194 & $(0.228)$ & - & - \\
\hline$\delta$ associativity & -0.419 & $(0.277)$ & -0.449 & $(0.458)$ & - & - \\
\hline$\delta$ depth aquifer & $-0.008 * * *$ & $(0.003)$ & $-0.009 * *$ & $(0.004)$ & - & - \\
\hline$\delta$ leaf removal & $0.556^{* * *}$ & $(0.179)$ & 0.293 & $(0.254)$ & - & - \\
\hline$\sigma_{u}$ & - & - & - & - & $0.292^{* * *}$ & $(0.026)$ \\
\hline
\end{tabular}

Source: Own estimation.

Significance level: $\quad 10 \%\left({ }^{*}\right) ; 5 \%\left({ }^{* *}\right) ; 1 \%\left({ }^{* *}\right)$.

Some external variables have dispair effects between the subgroups. In the case of machine technology for viticulturists (-1.61) and winegrowers (1.74), which seeks to capture the use of machinery that could supplement labor in vineyard tasks. While some winegrowers could seek to minimize labor costs through adopting these technologies, they could also apply machinery for regular management and have specialized labor to focus on quality optimization crafts.

The effect of energy subsidies on the variance of TE is also different between the subgroups but is only significant for the viticulturists. The benefit of this policy tool translates into efficiency gains only to grapevine producers that sell their output to third parties for wine production $(-0.79)$. The depth of the aquifer decreases inefficiency for winegrowers (-0.04), which is explained by the fact that better water quality for irrigation is found deeper in the second confined aquifer. Additionally, many winegrowes are able to irrigate vines with surface and groundwater.

Lastly, vine density increases efficiency for both subsamples but is only significant for viticulturists $(-0.483)$. This is also the case for the effect and significance of the specialized task of leaf removal (1.104). This specialized task is recommendable from wineries to perform as a quality management practice, however it is relatively labor-intensive and therefore may have inefficiency implications for 
viticulturists.

Regarding the statistical noise estimation $\left(\sigma_{\nu}^{2}\right)$, wine growers displayed a homoskedastic variance for the noise of external variables. In the case of viticulturists, the regression included the same exogenous variables and distributional assumptions as the inefficiency model. The results pointed only to the intercept, vine density and depth of the aquifer as significant variables. This means that the greater the vine density of the plot $(-0.57)$ and the greater the distance of the aquifer $(-0.009)$, the lower the statistical variability of the output for viticulturists will be.

Estimations of the mean TE scores were performed at the district level and are displayed in table 3.4. The performance of winegrowers is relatively better than viticulturists in every district with the exception of El Carrizal. Within the viticulturists subsample, better performances were estimated in the districts of Agrelo and El Carrizal, while the plots in Anchoris and Agrelo have relatively better efficiency performance for winegrowers. Interpretation would not be complete without acknowledging that the analysis is output-oriented and some plots may seek lower yield per ha to concentrate the tanins and sugar content per grape bundle.

Table 3.4: Mean efficiency scores per district

\begin{tabular}{lrr}
\hline District & $\overline{T E}_{\text {Vit }}$ & \multicolumn{1}{c}{$\overline{T E}_{\text {Wine }}$} \\
\hline Agrelo & 0.868 & 0.848 \\
Anchoris & 0.600 & 0.849 \\
El Carrizal & 0.868 & 0.799 \\
Perdriel & 0.742 & 0.777 \\
Ugarteche & 0.793 & 0.830 \\
\hline Source: Own estimation.
\end{tabular}

These results contradict initial expectations that grapevine plots located in the southern area of the research (districts of Ugarteche, El Carrizal and Anchoris) would score lower TE estimates, considering the higher production costs derived from pumping water. Instead, the results show that vineyards located in these districts are cautious about the employment of inputs. In the case of winegrowers of these districts, they seem to manage their resources more wisely as oposed to the farmers in Perdriel, where surface water is guaranteed since the location is ideal in the distributional scheme.

\subsubsection{Marginal and average partial effects}

To further acknowledge the effects of the exogenous variables in the variance of inefficieny, the marginal effects $(M E)$ and partial effect of the average $(P E A)$ were calculated. Results are in table 3.5 and imply that the monotonicity condition holds for all the selected variables. Irrigation system seems to be the variable with higher marginal partial effect for both subgroups, while vine density and depth of the aquifer (in meters) express lower effects. 
Table 3.5: Marginal and average partial effects of external variables

\begin{tabular}{lrrrr}
\hline Variable $(Z)$ & $M E_{\text {Vit }}$ & $A P E_{\text {Vit }}$ & $M E_{\text {Wine }}$ & APE $E_{\text {Wine }}$ \\
\hline Irrigation syst. & -1.0101 & -3.5864 & -0.6599 & -17.356 \\
Extensionist & -0.0811 & -0.2881 & -0.2295 & -6.0366 \\
Vine density & -0.0535 & -0.19 & -0.0618 & -1.6247 \\
Energy subsidy & -0.0877 & -0.3115 & 0.0743 & 1.9532 \\
Machine technology & -0.1784 & -0.6332 & 0.1968 & 5.1756 \\
Associativity & -0.0648 & -0.23 & -0.2598 & -6.8326 \\
Depth aquifer & 0.0006 & 0.0021 & -0.004 & -0.1061 \\
Leaf removal & 0.1224 & 0.4346 & 0.0961 & 2.5268 \\
\hline
\end{tabular}

Source: Own estimation.

In general, the PEA of the exogenous variables is greater than the marginal effect. This concise statistic weights the estimated coefficient with the variance of the inefficiency calculated at the sample mean; that is, when the external variables take the sample mean value. Therefore, in this case, the effects are intensified but there are no changes in the direction of the effects.

\subsection{Conclusions}

Western Argentina is characterized by intensive agricultural systems due to climate disparities, uneven access to irrigation water and heterogeneous terrain. In the pursuit of a profitable business, farmers focus on high-value crops such as grapevine production for wine production in Mendoza. The project area is on the right-margin of the Mendoza River in Lujan de Cuyo with an extension of 600 sq. km. covered with grapevines of high enological quality (INV 2017).

The economic and enological potential of this region is threatened by water management and pollution issues. Inherent business uncertainties, climate contingencies and fixed costs in real terms may jeopardize the sustainability of this economic activity. Competition for land and water has called into question the farmers' efficiency and may trigger changes in distribution of resources. Historically, sector specific policies aimed to solve seasonal difficulties but did not focus specifically on potential solutions to diminish production inefficiency. Inaccurate policy tools have undermined macroeconomic cyclical opportunities.

This paper estimates the TE of grapevine producers and explains the determinants of inefficiency for local grapevine producers. The analysis assessed the economic performance of vineyards with respect to their use of inputs, agroclimatic conditions and managerial decisions in two subgroups according their output destination. On average, the performance of viticulturists (0.8292) is slightly better as compared to the winegrowers (0.8191) but performance also varies across districts. In general the output weighted is slightly higher for viticulturists than for vintners, 0.872 and 0.864 respectively, which sustains the capital exploitation within the vineyard. These results provide unprecedent analysis for this arid region in Argentina. 
Grape production is strongly focused on quality, that will ease the job of professionals in the wine elaboration process. It is expected that vineyards that produce their own wine will allocate more resources into quality optimization. This is visible in the results of the analysis where more capital and agrochemical weight in the overall production process. While the viticulturists cluster is significant in the overall sample, the heterogeneous treatment of certain plots is explained by their optimization process of resource allocation that could, indeed, follow contract agreements with wineries, technical advice and market orientation advice.

This study found that areas that solely rely on groundwater for irrigation have relatively good performance with respect to counterparts that irrigate with surface water. Across the subsamples, higher efficiency scores are explained by higher share of precision systems for irrigation, agronomic extension services, associativity and vine density. Some efficiency determinants have uneven effects for each of the subgroups. In particular, the employment of machinery technology and the benefit of energy subsidy for pumping water improves the TE for viticulturists but increases the distance to the frontier for winegrowers. Other variables like the depth of the aquifer decreases inefficiency for winegrowers.

The marginal and partial effects of the average for the inefficiency determinants improve the understanding of the direction of the effects at the sample mean. Results point towards effective irrigation systems, associativity, technical advice and vine density as factors that improve vineyard performance. We conclude that the industry shows positive signs of economic performance but is still sensitive to goverment assistance. The economic performance of farmers is good with respect to the regional documented literature but still needs improvement to face changes in the tax scheme and climate contingencies in the near future.

Policy interventions that take account of these results could contribute to improving the performance of small and medium producers. Further studies can improve the spatial effects between producers and explore the suitability of redirecting the budget of energy subsidies into better irrigation systems for vineyards. 


\section{Chapter 4}

\section{Environmental efficiency of grapevine production}

\subsection{Introduction}

Irrespective of the intention, any production process will have an effect on the environment. In the agricultural sector this bond is more clear due to the direct interaction with natural resources, where the agroecosystem suffers the collateral effects of agricultural activities.

The region on the right bank of the Mendoza river is a prestigious region for wine production, where vineyards have uneven access to water depending on their location and infrastructure. The quality of surface and groundwater sources is influenced by the stakeholders and their exploitation practices. Increased pumping of groundwater is expected during periods of scarcity, which may lead to diffuse pollution caused by the overdraft pressure on the Carrizal aquifer. In the past, serious pollution threats unfolded from local and diffuse sources that significantly affected agricultural activity (Lohn et al. 2000; Foster et al. 2005). When it comes to groundwater, both pollution sources are considered common-pool resources due to their low excludability and high rivalry (Ostrom 2012; OECD 2015). As an additional limitation, the pollution effects are visible in the medium-term and the measurement of resource availability is not completely clear (Theesfeld 2010).

Under the current water scarcity conditions, the demand for groundwater is likely to increase. Ceteris paribus, confined aquifers experience significant pumping pressures that could affect their hidrogeological characteristics and the quality of irrigation water through salinization (Álvarez and Fasciolo 2011). In the research area, soils are relatively more saline, which would require additional water to induse salt percolation and subsequently increase saline content of soil and the aquifer. Similar experiences have been documented in semi-arid areas (FAO/IWMI 2018). The Departamento General de Irrigacion (DGI) has been aware of the pollution and the scarcity scenario and therefore imposed the zoning restriction that is still active (Diaz Araujo et al. 2004; Álvarez et al. 2009). While the environmental threats have stimulated the focus on natural resources, competition for water continues to grow fiercely across economic sectors (Rodriguez et al. 2013; WEF 2011a; WEF 
2011b). Until now parametric techniques have not been sufficiently used to investigate this situation and shed light on these critical issues (Azad et al. 2015; Bravo-Ureta et al. 2015).

This paper analyzes the environmental efficiency of grapevine producers in Mendoza accounting for the grapevine production and the salinity hazard of irrigation water. The use of the directional distance functions (DDF) in an efficiency model has the advantage of allowing for efficiency estimation that accounts for desirable and undesirable outputs given a production technology of each producer (Ancev, M A Samad Azad, et al. 2017; Azad and Ancev 2014). The selected framework is a suitable approach to evaluate the detrimentral effects of diffuse pollution while improving the production performance under water scarcity given the quasi-fixed access to land and water. This joint-approach of expanding the desired output and, simultaneously, contracting the undesired output is embedded within the directional output distance function (DODF) methodology.

This chapter shows the results of modeling the joint production of grapevines for wine production (desired output) and the saline content of irrigation water (undesired output). In particular, the research questions to be addressed are: $(i)$ What is the performance of vineyards in the underlying trade-off function between grapevine production and saline content of irrigation water? $(i i)$ What is the estimation of the shadow price for undesirable output?

The content of the paper continues in the next section with the description of the theoretical model, empirical specification, and description of data. Followed by the analysis and the discussion of the research findings, and finally this paper concludes with the environmental analysis and recommendations for grapevine producers in this region of Mendoza.

\subsection{Methods and materials}

\subsubsection{Theoretical model}

The literature on efficiency and environmental adjustment is one of the promising lines of research in productivity analysis. Currently, modeling technology and the measurement of inefficiency in the presence of undesired outputs is not a trivial issue and the joint analysis of the relationship between economic and environmental performance has grew substantially since 1990s (Ancev, M A Samad Azad, et al. 2017; Parmeter 2014).

Several approaches have been developed with the objective of measuring environmentally adjusted productivity and efficiency, where, suitability and techniques are relevant in the integration of technical efficiency and environmental performance measures. Suitability can be focused on the analysis of deterministic or stochastic processes. The former can be estimated using parametric and non-parametric techniques, while the latter employs exclusively parametric estimation. The evidence shows a greater share of applications of the non-parametric techniques such as Data Envelopment Analysis (DEA) rather than Stochastic Frontier Analysis (SFA) (Ancev, M. S. Azad, et al. 2017). Initial efforts to model good output and bad output were carried out by using inputs, good and 
bad outputs as arguments in a by-production function while imposing regularity conditions. This approach embedded the bad output as an input in the production function and imposed the regularity conditions to separate the good from the bad (Reinhard et al. 1999; Hailu et al. 2001). Since inputs are freely disposable, the model indirectly assumes output disposability, which led to the main criticism of this methodology. Färe et al. (2005) acknowledge the implied strong disposability of the undesired output and assumed the null-jointness to treat both outputs as by-products.

Continuing on parametric approaches, Cuesta and Zofío (2005) introduced the parametric hyperbolic distance function specification to estimate technical efficiency and later included the undesired outputs in this approach (Cuesta et al. 2009). Murty et al. (2012) argued in favor of the suitability of these approaches.

As Kumbhakar and H.-J. Wang (2015) state: while assuming that the bad output represents an unintended output, modeling production processes using standard tools may not be appropriate. The measurement of inefficiency envisages two modeling issues: How to model technical and environmental efficiency and whether they can be separated. Later, the literature found two different paths to model the undesirable output. On one hand, the by-production model considers different technologies for the two outputs, acknowledging the bad output as a production process itself (Fernández et al. 2002). Along these lines, the estimation of technical and environmental efficiency is carried out under the separability assumptions, which implies two different technologies.

Färe et al. (2007) acknowledge the shortcomings of the environmental production function, for example, that it does not directly credit the reduction of bads. The environmental production function credits a producer solely for expanding good output production, while the directional environmental distance function credits a producer for simultaneously increasing production of the good output and reducing production of bad outputs. The specification of the directional distance function (DDF) was introduced by Chung et al. (1997) and Färe et al. (2005) as a variation of the Luenberger shortage function. The DDF overcame the limitation of the SFA to study multi-output technologies (Bogetoft and Otto 2011). However, employing this methodology may create problems regarding the choice of the direction, appropiate variable scaling, and the presence of non-unitary Jacobian transformation (Parmeter 2014).

Empirical applications in the agricultural sector following input and output distance functions and DDF have increased over time (Njuki and Bravo-Ureta 2015; Huang et al. 2016; Tamini et al. 2012; Njuki et al. 2016). While environmental threats have stimulated the focus on natural resources and competition for water growth continuously across economic sectors (Rodriguez et al. 2013; WEF 2011a; WEF 2011b), parametric techniques have not been abundantly applied providing little attention to these critical issues (Azad et al. 2015; Bravo-Ureta et al. 2015). There is little evidence on the employment of non-parametric techniques that account for the dependent but fragile bond between agricultural activity and water resource preservation (Azad et al. 2014; Azad and Ancev 2016).

The theoretical properties can be accomodated in a quadratic DDF. To acknowledge the representation of DDF, assume a sample of $K$ production units that employ a vector of inputs 
$x=\left(x_{1}, x_{2}, \ldots, x_{N}\right) \in \Re_{N}^{+}$to produce a desirable output $y=\left(y_{1}, y_{2}, \ldots, y_{N}\right)$ with the drawback of also producing an undesitable output $b=\left(b_{1}, b_{2}, \ldots, b_{N}\right)$. The representation of this technology is feasible with the DODF:

$$
\overrightarrow{D_{0}}\left(x, y, b, g_{y},-g_{b}\right)=\max \left\{\beta\left(y+\beta g_{y}, b-\beta g_{b}\right) \epsilon P(x)\right\}
$$

In this specification, $\beta$ is the maximum feasible expansion of good outputs along the $g_{y}$ vector and contraction of bad outputs along the $g_{b}$ vector. When the expansion and contraction are identical quantities for a given vector of inputs, $\beta$ is maximized under the condition that the vector $\left(y+g_{y}, b-g_{b}\right)$ is feasible in the production set $P(x)=\{(y, b), x(y, b)\} \times \epsilon \Re_{N}^{+}$.

$$
-\theta=\overrightarrow{D_{0}}\left(x, y+\theta g_{y}, b-\theta, g_{b}, g_{y},-g_{b}\right)-\mu_{i}+\nu_{i}
$$

Given the production technology and input endowment, if a firm is environmentally efficient, potential reductions of bad outputs are only feasible when the good output is reduced. The application of distance functions requires the fulfillment of different properties (Färe et al. 2005; Färe et al. 2007):

i. $\overrightarrow{D_{0}}\left(x, y, b ; g_{y},-g_{b}\right) \geq 0$ if only if $(y, b)$ is an element of $P(x)$.

ii. $\overrightarrow{D_{0}}\left(x, y^{\prime}, b ; g_{y},-g_{b}\right) \geq \overrightarrow{D_{0}}\left(x, y, b ; g_{y},-g_{b}\right)$ for $\left(y^{\prime}, b\right) \leq(y, b) \in P(x)$.

iii. $\overrightarrow{D_{0}}\left(x, y, b^{\prime} ; g_{y},-g_{b}\right) \geq \overrightarrow{D_{0}}\left(x, y, b ; g_{y},-g_{b}\right)$ for $\left(y, b^{\prime}\right) \geq(y, b) \in P(x)$.

iv. $\overrightarrow{D_{0}}\left(x, \theta y, \theta b ; g_{y},-g_{b}\right) \geq 0$ for $(y, b) \in P(x)$ and $0 \leq \theta \leq 1$.

v. $\overrightarrow{D_{0}}\left(x, \theta y, \theta b ; g_{y},-g_{b}\right)$ is concave in $(y, b) \in P(x)$.

The first property, also known as representation property, states that DDF will be non-negative for output vectors that are feasible with the technology set $P(x)$. An observation will be technically efficient if $\overrightarrow{D_{0}}\left(x, y, b ; g_{y}, g_{b}\right)$ is equal to zero. Points $(i i)$ and $(i i i)$ acknowledge the monotonicity property and strong disposability of desirable and undesirable outputs. It states that the $\overrightarrow{D_{0}}\left(x, y, b ; g_{y},-g_{b}\right)$ is decreasing in $y$ and increasing in $b$. For property $(i i)$, if a firm employs equal amounts of inputs but produces more of the desired output, and the same amount of undesired output, inefficiency will not increase (or decrease).

The concept of weak disposability was introduced by Shephard (1972) and also applies to this framework by acknowledging the foregone benefits of reducing one of the outputs.

Weak disposability of desirable and undesirable outputs are attained in property $(i v)$. Then, the concavity property $(v)$ will assist in the determination of the output elasticity of substitution.

Additionally the directional distance function also satisfies the translation property, similar to the homogeneity property in the output distance function by Shephard (1972), which states that with the addition of a non-negative $\theta$ to the directional vector, the desired output will expand by $\theta g_{y}$ and the undesired output will contract by $\theta g_{b}$. 


$$
\overrightarrow{D_{0}}\left(x, y+\theta g_{y}, b-\theta g_{b}, g_{y},-g_{b}\right)=\overrightarrow{D_{0}}\left(x, y, b, g_{y},-g_{b}\right)-\theta
$$

Intuitively, this means that if the directional vector is doubled in size, ceteris paribus, the resulting value of the distance function will be halved. Accounting for the translation property, Feng et al. (2014) suggested the normalization setting $(\theta=-y)$ that will satisty the property by construction.

The estimation of shadow price is key to expose the existing link between standard productivity of the distance-function framework (Färe et al. 2008). As the directional distance functions are differentiable, it is possible to estimate the shadow price for the bad-output, a desired calculation to value outputs where market prices are non-existant. Traditional productivity models can employ quantity and price information for the estimation, whereas direction-function based models only require quantity information. For correct economic interpretation, the shadow price of the badoutput is calculated at the frontier, which means that the value of the distance function with respect to the good-output equals to zero (Fare et al. 1993). Therefore, in this context, the estimation is:

$$
P_{b}=-\bar{P}_{y} \times \frac{\frac{\partial \overrightarrow{D_{0}}\left(x, y, b, g_{y},-g_{b}\right)}{\partial b}}{\frac{\partial \overrightarrow{D_{0}}\left(x, y, b, g_{y},-g_{b}\right)}{\partial y}}
$$

At least one output price must be known and equal to its shadow price. The shadow price describes the good-output production that must be foregone in order to reduce the bad-output by one unit for all the production units along the efficiency frontier (Färe et al. 2005). In line with this, production units that comply with the monotonicity conditions should be avoided including some observations that might be on the negative slope of the production possibility set $P(x)$.

\subsubsection{Empirical specification}

Calculation and decomposition of TE is based on an output distance function. The preference for this framework relies on the multiple-output nature of grapevine production and the influence of inputs' quasi-fixation due to the current legal restrictions. The share of viticulturists in the region and the favorable context for pumping water in a pollution-sensitive area motivated the selection of the DODF approach. The Stochastic Frontier Analysis (SFA) is a methodology that involves an arbitrary function to approximate to the real production frontier. One advantage is that this methods separates errors of approximation and statistical noise, but at the cost of greater sensitivity of results to different functional forms and small sample sizes (O'Donnell 2014; Murillo-Zamorano 2004).

The Shepard output distance function, $D_{o}(x, y)$ measures the distance to the best practice or benchmark. Therefore, for fully efficient farmers, the function returns a value of zero since they are already at the frontier. Other producers may achieve feasible output sets within their possibilities but employing their resources inefficiently. Moreover, the specified technology assumes free disposability of good outputs and weak disposability for good and bad outputs. The employed quadratic 
specification accounts for fewer restrictions for substitution possibilities between inputs. The selected directional vector is $g=(1,-1)$, which has the advantage of allowing parameterization of the quadratic functional form according to the translation property and reflects the desired contraction of the bad output with a feasible expansion of the good output.

The econometric specification of the DODF seeks to fulfill the required properties for a valid analysis. Although, the choice of $\theta$ is arbitrary, selecting $\theta=-y$ would achieve the translation property and ease the estimation (Feng et al. 2018; Holtkamp 2017). The parametrization includes one desirable output $(M=1)$ and one undesirable output $(\mathrm{L}=1)$; as such the DODF can be specified as follows:

$$
\begin{array}{r}
\overrightarrow{D_{0}}\left(x,(y+\theta),(b+\theta), g_{y},-g_{b}\right)=\overrightarrow{D_{0}}\left(x_{i}, y_{i}, b_{i}, g_{y},-g_{b}\right)-\theta \\
=\alpha_{0}+\sum_{k=1}^{K} \alpha_{k} x_{i, k}+\sum_{m=1}^{M} \beta_{m}\left(q_{i, m}+\theta_{i}\right)+\sum_{l=1}^{L} \gamma_{l}\left(b_{i, l}+\theta_{i}\right) \\
+\frac{1}{2} \sum_{i=1}^{K} \sum_{k=1}^{K} \alpha_{k k^{\prime}} x_{i, k} x_{i, k^{\prime}}+\frac{1}{2} \sum_{m=1}^{M} \sum_{m^{\prime}=1}^{M} \beta_{m m^{\prime}}\left(q_{i, m}+\theta_{i}\right)\left(q_{m, m^{\prime}}+\theta_{i}\right) \\
+\frac{1}{2} \sum_{l=1}^{L} \sum_{l^{\prime}=1}^{L} \gamma_{l l^{\prime}}\left(b_{i, l}+\theta_{i}\right)+\sum_{k=1}^{K} \sum_{m^{\prime}=1}^{M} \psi_{k m} x_{i, k}\left(q_{i, m}+\theta_{i}\right) \\
+\sum_{k=1}^{K} \sum_{l=1}^{L} \omega_{k l} x_{i, k}\left(b_{i, m}+\theta_{i}\right)+\sum_{k=1}^{K} \sum_{l=1}^{L}\left(q_{i, m}+\theta_{i}\right)\left(b_{i, l}+\theta_{i}\right)
\end{array}
$$

The selected specification allows for heterogeneity in the variance of the inefficiency term $\left(\mu_{i}\right)$, as well as the stochastical noise $\left(\nu_{i}\right)$. As the variance of the inefficiency and stochastic noise depend on the exogenous variables $\left(Z_{i}\right)$, the dependence of the variance parameter on the vineyard's characteristics is allowed.

$$
\begin{aligned}
\mu_{i} & \sim \mathcal{N}^{+}\left(0, \rho_{j} Z_{j}\right) \quad \text { where } \quad \sigma_{u, i}^{2}(z, \delta)=\sigma \times \exp \left(z_{i}^{\prime} \delta\right) \\
\nu_{i} & \sim \mathcal{N}\left(0, \delta_{j} Z_{j}\right) \quad \text { where } \quad \sigma_{\nu, i}^{2}(z, \rho)=\sigma \times \exp \left(z_{i}^{\prime} \rho\right)
\end{aligned}
$$

In this framework, all the parameters are estimated in a single step. The employment of the exponential function seeks to ensure a positive estimate of the variance parameter for all $Z_{i}^{\prime}$ and $\delta_{\mu_{i}}$ (Parmeter 2014). The selected parametrization captures the idea of similar shape across all firms in the distribution of inefficiency since the scaling function stretches or shrinks the horizontal axis but holds the underlying shape of the inefficiency untouched (Alvarez et al. 2006; Wang et al. 2002). The point estimates for TE follow the specification from Kumbhakar et al. (2003).

$$
T E_{i}=E\left[\exp -\left(\mu_{i} \mid \epsilon_{i}\right)\right]=\left[\frac{1-\Phi\left(\sigma_{*}-\mu_{* i} / \sigma_{i}\right.}{1-\Phi\left(-\mu_{* i} / \sigma_{*}\right)}\right] \times \exp \left(-\mu_{* i}+\frac{1}{2} \sigma_{*}^{2}\right)
$$

Since the effects of the exogenous variables on the efficiency estimates are non-linear and can vary among observations, the estimation of the marginal effect of firms' characteristics on the efficiency can shed some light on the interpretation. 


$$
\frac{\partial E\left(\mu_{i}\right)}{\partial z_{u}[k]}=\delta_{k}^{\mu}(\sqrt{2 / \pi}) \sigma_{\mu, i} \approx 0.8 \times \delta_{k}^{\mu} \sigma_{\mu, i}
$$

Noting that the maximum likelihood estimators of $\delta_{\mu}$ may not be very informative about the magnitude of the external variables $z_{\mu, i}[k]$ on $E(\mu)$, the calculation of the marginal effects may facilitate the interpretation of the coefficient estimates. The sign of the marginal effect will reveal the direction and the magnitude of the effect of the $Z$ (Parmeter 2014).

\subsubsection{Data}

This research employed a primary data set collected between November 2016 and February 2017 in five districts of Lujan de Cuyo, Mendoza. Data were collected through a structured questionaire that addressed quantitative information on grapevine production systems, water management practices, market orientation, and technology assessment. A total of 420 wine grape plots were randomly selected.

Water application at the plot level was estimated following reported values of irrigation. The watershed inspection provided the delivered volumes of surfacewater at the farm level. While, the groundwater volume was estimated from the energy used for water pumping; this estimation considered the characteristics of the pumping equipment and distance to the water table. The local energy authority (EPRE) provided monthly records of energy consumption for groundwater irrigation. Regarding water quality, farmers voluntarily provided a sample of irrigation water for the analysis ${ }^{1}$.

Besides the economic budget, there are several reasons for heterogeneous crop management inside the vineyard: agronomic characteristics, market requirements and water sources are the most common driving forces. First, terrain conditions and enological potential determine the planted variety, training system and pest management practices (Jackson 2008; Morábito et al. 2007). Also, vineyard treatment could vary following market preferences, e.g., viticulturists can establish contract agreements for certain plots under a strict crop management schedule (Van den Bosch 2008; COVIAR/OVA 2018). Furthermore, the water source determines to a great extent the management practices and adoption of irrigation systems (MAGyP 2010; FAO/PROSAP 2015).

\footnotetext{
${ }^{1}$ A sensor HI98129 was employed to obtain temperature adjusted values of electro-conductivity (EC), total dissolved solids (TDS), and acidic levels $(\mathrm{pH})$.
} 


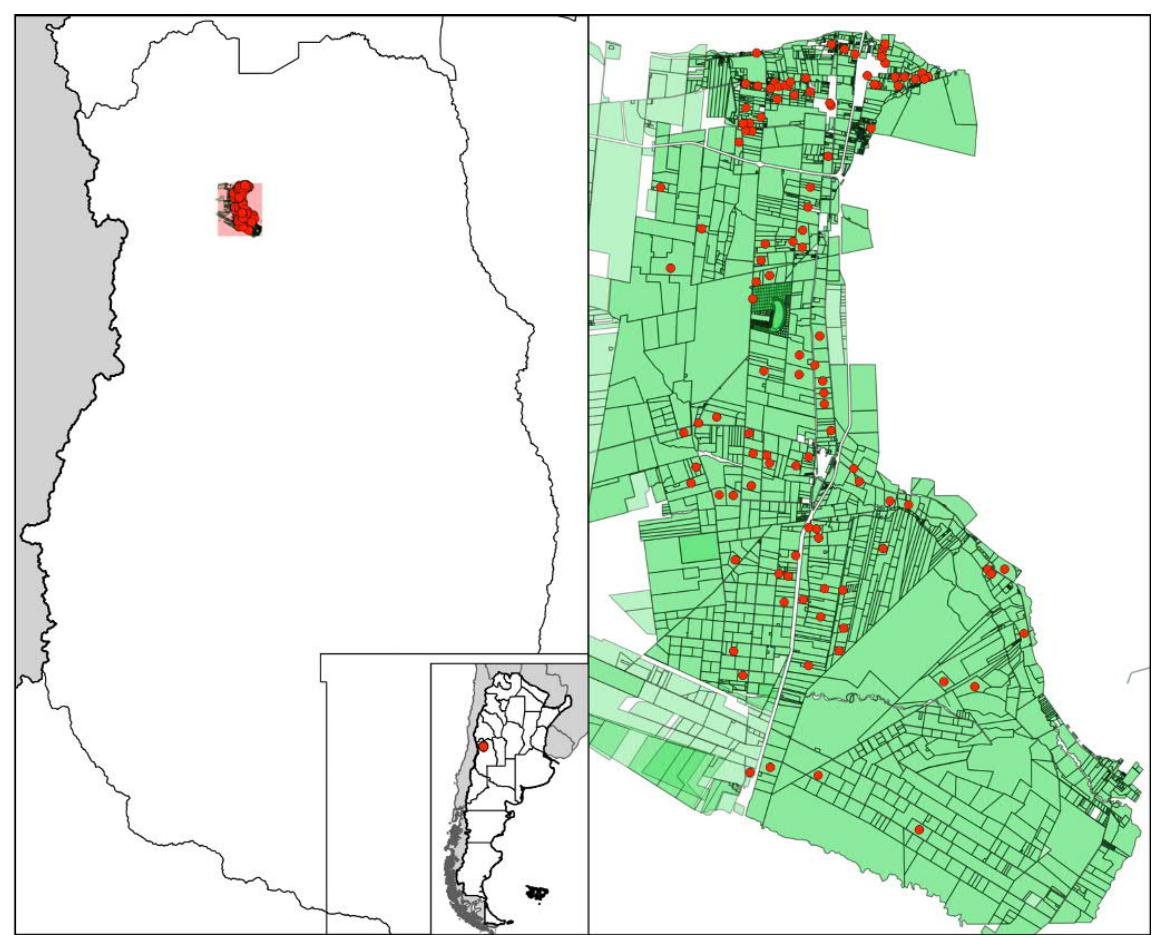

Figure 4.1: Geographical location of the research area and water sample points

Table 4.1: Descriptive values per hectare

\begin{tabular}{lcrr}
\hline Component & Unit & Mean & Sdt.Dev. \\
\hline Production & tons & 10.2 & 4.7 \\
Capital services & USD & 29128.8 & 13259.6 \\
Labor & days & 92.4 & 146.2 \\
- Permanent & days & 80.2 & 147.8 \\
- Temporary & days & 12.9 & 12.3 \\
Agrochemicals & USD & 429.8 & 268.8 \\
- Fertilizer & USD & 13.8 & 8.8 \\
- Pesticides & USD & 27.7 & 17.5 \\
Water & $m^{3}$ & 9339.9 & 4905.8 \\
Average plot size & ha & 4.2 & 4.1 \\
Producer Age & years & 53.1 & 11.8 \\
Agricultural income dependence & $\%$ total & 73.3 & 35.0 \\
Plots per vineyard & & 7.7 & 7.9 \\
Vine density & Plants/ha & 4370.1 & 2254.2 \\
Average planted year & year & 1983.0 & 31.5 \\
EC 2017 & $\mu S /$ cm & 967.7 & 524.5 \\
Salinity hazard & $\mathrm{kg} / \mathrm{ha}$ & 6.7 & 4.8 \\
\hline Source: Own & & &
\end{tabular}

Source: Own estimation.

On average, each vineyard has 7.7 plots and produces 10.2 tons of grapes per hectare employing 92.4 labor hours and USD 429.8 of agrochemicals. Regarding water consumption, the average consumption is 9339.9 cubic meters per hectare. Most of the surveyed plots irrigate with a duel source of water $(68 \%)$, while a considerable share rely solely on groundwater $(30 \%)$ and only a small proportion irrigate with surface water $(2 \%)$. As for irrigation systems at the plot level, furrow is the 
largest in the region (68\%), followed by drip irrigation (28\%) and flooding (4\%).

In light of the recent pollution threats, water quality for irrigation is certainly important for this area. The mean acidity values in the sample were $6.9 \mathrm{pH}$ which is in line with the literature (Van den Bosch 2008; Drovandi et al. 2005) and within the acceptable range for wine grape production (Jackson 2008). On average, the EC values were moderately acceptable according to international standards and reference values for the region (FAO/IWMI 2018; Girman et al. 2006). The term of salinity hazard is commonly employed in viticulture to acknowledge the grapevine yield sensibility threshold with respect to kilograms of saline content in the applied water for irrigation. This variable is explained in more detail below.

\subsubsection{Variables selection}

In this section the input variables for the estimation of the functional form are discussed. The capital variable represents the annual economic value of services provided by infrastructure involved in the production process including land. Since water rights are not tradable and they are inherent to the piece of land, on account of the still active zoning restriction for new wells, a quasi-fixation of the land and water inputs is assumed. As a result, capital mobility became less dynamic as prices for land are highly associated with water rights (Álvarez et al. 2009; Van den Bosch 2008). This motivated the estimation of the capital variable following the valuation methodology for agricultural productivity by Ball et al. (2004).

Regarding the other input variables, the total amount of working hours was considered for labor and total expenses in agrochemicals at the plot level. Some surveyed farmers provided total expenses in inputs and details on management practices performed. This information was decomposed into labor hours and agrochemical expenses with no limitations; due to the fact that vineyards are price-takers with respect to their inputs and labor wages are regulated. All variables were normalized by their means. Concerning the level variables, white varieties and pergola trained grapevines are production alternatives that aim for relatively higher yields than red varieties or spalier training system, respectively. The depth of the water table measured in meters was also selected as production shifter, acknowledging the difficulties to pump water with reliable quality for irrigation (Van den Bosch 2008; Foster et al. 2006). A categorical variable of soil characteristics was introduced in the production function. This variable is a satellite classification of the National Institute of Agricultural Technology (INTA) that accounts for the most representative soil content in the first meter layer. In the research area, the soil variable has three categories based on their main component, superficial texture and drainage.

Within the sample, drainage is the only characteristic in which soils differ substantially, the categorization is based on this trait, but also includes other aspects of the soil components. For example, well and moderately drained soils have a predominantly loamy surface texture, while excessively drained soils have a predominantly sandy composition. The secondary surface layer for excessively and well drained soils is often a stony layer, whereas moderately drained soils suffer salinity issues in this layer (SAGyP - INTA 2007). Lastly, the level variable of electro-conductivity 
(EC) was included in the analysis, which represents the measured value in micro-Siemens per centimeter $(\mu S / \mathrm{cm})$ reported from the water quality analysis.

\subsubsection{Undesirable output}

As mentioned, irrigation water contains inorganic salts, minerals, metals, and cations or anions dissolved in the resource. Salinity effects diminish the osmotic potential of soil and excessive concentrations could cause salt accumulation in the wooden tissue and leaves of vines (Jackson 2008; Morábito et al. 2007; De Lorenzi et al. 2009). These conditions are tolerated by the crop up to certain values that also depend on the surrounding ecosystem. FAO/IWMI (2018) states that salts in soil or water can reduce water availability to the crop to such an extent that yield is significantly affected. In other words, the yield and quality of wine grapes are sensitive to the saline content of irrigation water (Morábito 2005; Zhang et al. 2002). Their sensitivity depends on the grape variety, soil characteristics and irrigation practices. Excess irrigation could stimulate the rise of freatic levels and further increase soil salinity provoking radicular suffocation that could affect vine development and yields substantially (Global Water Partnership 2012; Lavie et al. 2010).

The Carrizal aquifer has been subject to salinity threats for the past two decades (Foster et al. 2005; Diaz Araujo et al. 2004), which led farmers to pump water from deeper sources that could further damage the aquifer by saline intrusion or increasing the level of water tables. Considering previous experiences, the quality control check of saline content of the soil and irrigation water constitutes a periodic practice by stakeholders. The Salinity Hazard (SH) was estimated according to the standard calculation of salt concentrations in irrigation water and adapted according to the grapevine sensitivity in the research area (Miyamoto et al. 2010).

$$
S H_{(k g / p l o t)}=640 \times \psi \times E C_{i}^{b} \times \text { water }_{\left(m^{3} / p l o t\right)}
$$

Where $\psi$ is a scale volume conversion from micro-Siemens per centimeter to kilograms per cubic meter $\left(10^{-6}\right)$ and the standard conversion value is 640 for the calculation. The value of $b$ varies in accordance with crop resistance to salinity. Evidence has shown that the relationship between grapevine yields and salinity content is not linear and can be adjusted to the salt concentration levels by varying the values of $b$ according to certain thresholds that acknowledge the crop sensitivity to increments of EC values (Romero et al. 2016; Ayers and Westcot 1994; Zhang et al. 2002; Maas 1990; Jackson 2008).

In this region, the threshold for EC values for grapevines is 1 desiSiemens per miligram of water $(d S / m g)$, which is equal to 1.000 micro-Siemens per centimeter $(\mu S / \mathrm{cm})$. The relationship between grapevine yields and salinity hazard in the sample is shown in figure 4.2. Within the sample, the mean values and variance of grapevine yields decreases as the salinity hazard increases: this bivariate relationship could also be driven by several factors. It is possible to observe existing differences among the districts. Details of the calculation can be found in the appendix. 


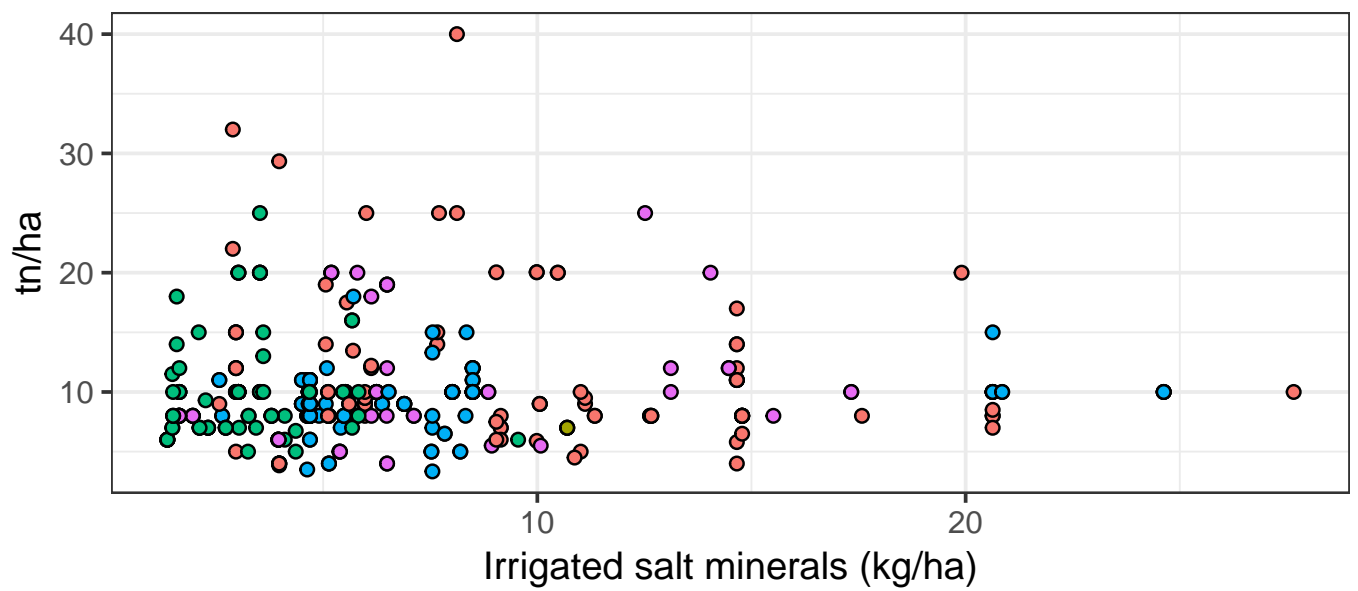

district $\circ$ Agrelo $\bigcirc$ Anchoris $\bigcirc$ El Carrizal $\odot$ Perdriel $\circ$ Ugarteche

Figure 4.2: Salinity hazard and yield relation

\subsubsection{Noise and inefficiency determinants}

The variables for the environmental efficiency model were selected according to their relevance in interpreting the behavior and production decisions of grape growers at the plot level. Technical assistance received through extension programs or paid consultants is captured by the extensionist dummy. Vine density is the number of plants existing in the plot and energy subsidy is a dummy variable that acknowledges that the producer pays a lower rate for pumping water. On account of technological improvements and facing the difficulty to employ qualified labor in the area (Van den Bosch 2008), some vineyards are adopting technology to substitute labor for some tasks, e.g., mechanical harvesting and vine prunning.

The water balance variable is the difference between the supplied water by the farmer and the demanded resource by the vine in cubic meters. For the water supply, the volume estimations considered the reported irrigation practices by the farmer adapted to their irrigation system, water source and pumping equipment.

$$
\begin{aligned}
\text { WaterBalance }_{i} & =\text { WaterSupply }_{i}-\text { WaterDemand }_{i} \\
& =\left(\text { irrigation }+A W_{i}+\text { rain }\right)-\left(\text { dep }_{i}-E T_{0} \times K_{c} \times \text { days } \times \text { hail }\right)
\end{aligned}
$$

Calculations were made for every month from August until March and included adjustments for rainfall and available water in the soil $\left(A W_{i}\right)^{2}$. The estimation of water demanded by the

\footnotetext{
${ }^{2}$ The formula for available water is

$$
A W_{i}=C R_{i} \times H_{i} \times I T_{i} \times C A_{i} \times S S_{i}
$$
}

The variables and their values in the Carrizal ecosystem are: $C R_{i}$ represents the soil retention capacity $(0.12-0.17 \mathrm{~mm})$; $H_{i}$ the depth of explorable soil by the vine roots $(530-780 \mathrm{~mm}) ; I T_{i}$ is the irrigation threshold and represents the drainage capacity values $(0.5-0.8) ; C A_{i}$ is the percentage of covered area by irrigation $(30-100 \%) ; S S_{i}$ represents the stone share in the soil (50-100\%) (Crescimanno and Marcum 2013; Hernández et al. 2012; Maffei and Nijensohn 2003; Maas 1990). 
vines considered density, training system, evapotranspiration $\left(E T_{0}\right)$, plant transpiration $\left(K_{c}\right)$, soil percolation requirements, and hail protection of the grapevine (Maas 1990; De Lorenzi et al. 2009; Crescimanno et al. 2013). The variable calculation is the best approximation of the water usage and consumption relationship based on the available information. The components are detailed in the appendix.

\subsection{Results and discussion}

This section provides the discussion of results focusing on the environmental performance of grapevine plots. Starting with the parameter estimates for the directional function that are presented in table 4.2 and followed by the determinants of technical efficiency shown in table 4.4. As noted, the DODF framework focuses on the distance with respect to the best performances accounting the output vector $g(1,-1)$, that gauges the vineyard performance in the direction of augmenting the good output and reducing the undesired output (Färe et al. 2005). Therefore, the distance to the frontier is expected to be shorter towards the good output with respect to the use of production inputs. In other words, a negative sign of the input coefficient implies that as the input-usage increases the farmer would move closer to the frontier.

\subsubsection{Estimates of the DODF}

All the estimated coefficients have the expected sign with the exception of labor. The second order coefficients of productive inputs are negative with the exception of water. In the case of water, this result can be interpreted as its application going beyond the optimum and therefore further increments of irrigation would not necessarily improve the productivity. Accounting for the sensitivity of the aquifer and previous documentation of difuse pollution, excessive water pumping may trigger salinity content of the resource decreasing its quality for irrigation.

For the undesirable output bStar $=\left(\right.$ Sal.Haz. $\left.-\theta_{i} g_{b}\right)$ both coefficients were significant. The coefficient of the $b \operatorname{Star}^{2}(-0.06)$ confirms a concave function that allows for the trade-off interpretation with respect to the desirable output due to the translation property. That is, the acknowledgement that saline hazard is inherent to grapevine production in this context.

Accounting for the labor coefficients, the first order coefficient has a positive sign (0.03), which affirms that increasing the labor hours at the plot level will decrease production. Although, the value of the second order estimate for labor is insignificant $(-0.01)$ which the interpretation that adding more hours of labor at the plot level would improve the productivity. As mentioned earlier, this interpretation is feasible considering the quality focus in wine grape production in the region but also incomplete without considering the estimation of the elasticities. Only two level variables were statistically significant, the well-drained soil implies greater distance to the frontier. Whereas, the electro-conductivity $(E C)$ estimator indicates lower distances to the frontier upon increments 
Table 4.2: Estimation coefficients of environmental efficiency

\begin{tabular}{llllll}
\hline & $\beta_{i}$ & $\sigma_{i}$ & & $\beta_{i}$ & $\sigma_{i}$ \\
\hline intercept & $0.448^{* * *}$ & $(0.033)$ & bStar & $-0.064^{* *}$ & $(0.025)$ \\
capital & -0.028 & $(0.042)$ & bStar & $1.128^{* * *}$ & $(0.034)$ \\
labor & 0.028 & $(0.028)$ & bStar $\times$ capital & 0.032 & $(0.032)$ \\
agrochemicals & $-0.196^{* * *}$ & $(0.036)$ & bStar $\times$ labor & $-0.082^{* * *}$ & $(0.016)$ \\
water $_{\text {capital }^{2}}$ & $-0.786^{* * *}$ & $(0.090)$ & bStar $\times$ agroch & $0.081^{* * *}$ & $(0.015)$ \\
labor $^{2}$ & $-0.097^{*}$ & $(0.053)$ & bStar $\times$ water & $-0.148^{* * *}$ & $(0.043)$ \\
agrochemicals $^{2}$ & -0.010 & $(0.009)$ & pergola training syst. & -0.007 & $(0.015)$ \\
water $^{2}$ & -0.007 & $(0.028)$ & white variety & $0.040^{*}$ & $(0.024)$ \\
capital $\times$ labor $^{*}$ & $0.519^{* * *}$ & $(0.116)$ & water depth & -0.010 & $(0.014)$ \\
capital $\times$ agroch & 0.011 & $(0.040)$ & well drained soil & $0.212^{* * *}$ & $(0.059)$ \\
capital $\times$ water $^{* *}$ & -0.098. & $(0.034)$ & excessively drained soil & $0.035^{*}$ & $(0.021)$ \\
labor $\times$ agroch & -0.018 & $(0.024)$ & & $-0.460^{* * *}$ & $(0.027)$ \\
labor $\times$ water & $0.076^{* *}$ & $(0.033)$ & & & \\
agroch $\times$ water & 0.059 & $(0.040)$ & & & \\
\hline Signi. & & & \\
\hline
\end{tabular}

Signif. level: $10 \%\left({ }^{*}\right) ; 5 \%\left({ }^{* *}\right) ; 1 \%\left(^{* * *}\right)$.

Source: Own estimation.

in the saline content of water. Although surprising, this result is still interpretable, because the quality indicator is the value considered for the saline hazard estimation.

For a better understanding of the effects of productive inputs with respect to the output in the DODF framework, the elasticities were calculated. The interpretation is as follows: increments of inputs with negative signs shorten the distance to the frontier improving the vineyard performance. Conversely, those inputs with positive signs would expand the distance to the frontier upon increasing their usage. Listed in table 4.3 are the estimations that were done considering the performance of vineyards at the frontier, which assumes that $D_{o}(x, y)=1$. With the exception of labor, all inputs provided the expected elasticity sign at the frontier. The greatest effect is attributed to the water input representing a $-0.379 \%$ decrease in the distance towards the frontier for a $1 \%$ increase in applied water. Capital services and agrochemicals also have the expected signs; the case of the former, a $1 \%$ increase in their usage at the plot level would reduce the distance to the frontier by $-0.115 \%$. Furthermore, a small value was reported for the elasticity of agrochemicals, the sign is negative and close to zero which implies that farmers may be close to the optimum usage of agrochemicals. The interpretation of these value should be considered with caution since several pest threats and climate contingencies have affected the vineyard performance in the last decade (González 2011). In particular, bortytis cinerea, grapevine moth, and oidium (Van den Bosch 2012; Becerra et al. 2015; Grainger 2009).

The labor factor is relevant for grapevine management since many management practices are labor intensive and crucial for quality development (Jackson 2008). Given the scarcity of qualified labor in the region (Van den Bosch 2008) some vineyards are exploring mechanization of certain tasks to substitute labor, while other farmers may be over employing people to carry out management activities by hand with their focus on quality. Therefore, the relationship of labor and output 
Table 4.3: Summary elasticities

\begin{tabular}{lrrrr}
\hline Variable & Median & Std.Dev. & $25 \%$ & $75 \%$ \\
\hline $\boldsymbol{\xi}_{\text {Capital }}$ & -0.035 & 0.248 & -0.109 & -0.016 \\
$\boldsymbol{\xi}_{\text {Labor }}$ & 0.003 & 0.143 & -0.023 & 0.031 \\
$\boldsymbol{\xi}_{\text {Agroch }}$ & -0.005 & 0.428 & -0.033 & 0.085 \\
$\boldsymbol{\xi}_{\text {Water }}$ & -0.399 & 0.478 & -0.507 & -0.290 \\
$\boldsymbol{\xi}_{\text {RTS }}$ & 0.449 & 0.582 & 0.281 & 0.561 \\
$\boldsymbol{\xi}_{\text {bStar }}$ & 0.656 & 0.493 & 0.443 & 0.938 \\
\hline \multicolumn{2}{r}{ Source } \\
Own estimation
\end{tabular}

Source: Own estimation.

belongs to the second stage of production where marginal returns start to decrease.

The results show that grapevine production has a decreasing returns to scale in this area at the sample mean. The calculations estimated $0.391 \%$ increase in output when all the inputs increase simultaneously by $1 \%$. A positive sign of the output distance function elasticity of the bStar $(0.774 \%)$ means that increments in the undesired output will expand the distance to the frontier and vineyards will be less productive.

\subsubsection{Efficiency determinants}

In addition to the efficiency measure, the DODF gives the maximum unit expansion of the desiredoutput and the unit contraction of the undesired-output (Färe et al. 2005). Vineyard-specific technical efficiency scores are reported in the direction of the output vector $g(1,-1)$, which implies that the measure of efficiency reflects the vineyards' capacity to improve grapevine production while reducing the salinity hazard.

Given the normalization and directional vector, results report a mean estimate technical efficiency of 0.869 , corresponding to a mean inefficiency of 0.131 . The interpretation is that production per hectare could potentially increase by 1.33 tons $(10.2 \times 0.133)$, considering the average market price of USD 588.24 per ton in 2017 (INV 2018c; BCM 2018; OVA 2018), potential gains could be USD 780.15 per hectare. At the same time, there is potential to reduce their saline hazard by 0.876 kilograms $(6.7 \times 0.133)$ at the sample mean.

Most of the exogenous variables are significant in both models with the exception of energy subsidy in the inefficiency model and extensionists in the stochastical noise model. The economic connotation of the coefficients is initially determined by the direction of the effect; e.g., negative (positive) signs decrease (increase) inefficiency. The interpretation will begin with managerial variables that model the irrigation at the plot level and will continue with decisions' focus on crop management. 
Table 4.4: Estimated coefficients and marginal effects of external variables

\begin{tabular}{|c|c|c|c|c|c|c|c|c|}
\hline & \multicolumn{2}{|c|}{ Technical inefficiency } & \multicolumn{2}{|c|}{ Statistical noise } & \multicolumn{4}{|c|}{ Marginal Effects } \\
\hline & $\delta_{Z}$ & $\sigma_{\delta_{Z}}$ & $\rho_{Z}$ & $\sigma_{\rho_{Z}}$ & Mean & Std.De & $25 \%$ & $75 \%$ \\
\hline Water balance & $1.839^{* * *}$ & $(0.175)$ & $-0.961^{* * *}$ & $(0.284)$ & 0.239 & 0.842 & 0.048 & 0.146 \\
\hline Energy subsidy & -0.434 & $(0.296)$ & $-1.083^{* * *}$ & $(0.263)$ & -0.056 & 0.199 & -0.035 & -0.011 \\
\hline Extensionist & $-0.482^{*}$ & $(0.268)$ & $-0.602^{* *}$ & $(0.255)$ & -0.063 & 0.221 & -0.038 & -0.013 \\
\hline Vine density & $-1.467^{* * *}$ & $(0.292)$ & $0.505^{* * *}$ & $(0.121)$ & -0.191 & 0.672 & -0.117 & -0.039 \\
\hline Machine technology & $0.973^{* *}$ & $(0.419)$ & $-1.138^{* * *}$ & $(0.309)$ & 0.127 & 0.446 & 0.026 & 0.077 \\
\hline Intercept & $-4.259 * * *$ & $(0.382)$ & $-3.764^{* * *}$ & $(0.341)$ & - & - & - & - \\
\hline
\end{tabular}

Significance level: $\quad 10 \%\left({ }^{*}\right) ; 5 \%\left({ }^{* *}\right) ; 1 \%\left({ }^{* * *}\right)$.

Similar effects are shown by the created variable of water balance, the inefficiency coefficient indicates that oversupplying vines with water could be translated into forgone efficiency (1.84) for less uncertainty (-0.96). The marginal effect of further increasing irrigation when the crop water demand has already been fulfilled by $1 \%$ would increase inefficiency by $0.24 \%$. The economic tool energy subsidy decreased inefficiency and statistical noise but only the latter effect was significant $(-1.08)$.

At this point, acknowledging that farmers may be applying far more water than the the optimal value, $\left(\right.$ water $\left.^{2}=0.52\right)$ and recalling that irrigation system is a function based on the technology for irrigation, moving towards a more effective irrigation system would not improve efficiency if the producer focus is on increasing output. However, if the interest is in higher quality, which implies greater sugar content and tannins per berry, then moving towards more effective irrigation systems would go along with their production objectives. In any case, oversupplying the vine with water if the crop demand is already satisfied would not improve efficiency but dimish stochastical noise. Recalling that the energy subsidy is voluntary and, originally, designed for farms with less than 50 ha cropland winegrowers that account with this economic incentive will not significantly improve efficiency in production but only decrease uncertainty.

Focusing on the crop management aspects, the technical advice of extensionists can improve efficiency significantly, the marginal effect of increments in technical assistance would contribute to a better performance $(-0.06 \%)$. While vine density can contribute to efficiency gains $(-1.47)$, performance variability will also increase (0.51). On average, the marginal effect of increasing vine density by $1 \%$ would improve efficiency by $-0.19 \%$.

Furthermore, table 4.5 summarizes some underlying performance factors that may drive vineyard's efficiency through market orientation of grapevine plots and water source for irrigation. Starting with market orientation, the grapevine producers plot sample was separated into viticulturists $(\mathrm{n}=308)$ and wine growers $(\mathrm{n}=95)$. The former produces exclusively for selling to wineries under contract agreements or traditional market operations, their mean environmental efficiency score is (0.868). The latter produces their own wine with the plot production, which could translate into greater care with the quality standards.

The significant difference between these subgroups can be observed by their performance within their 


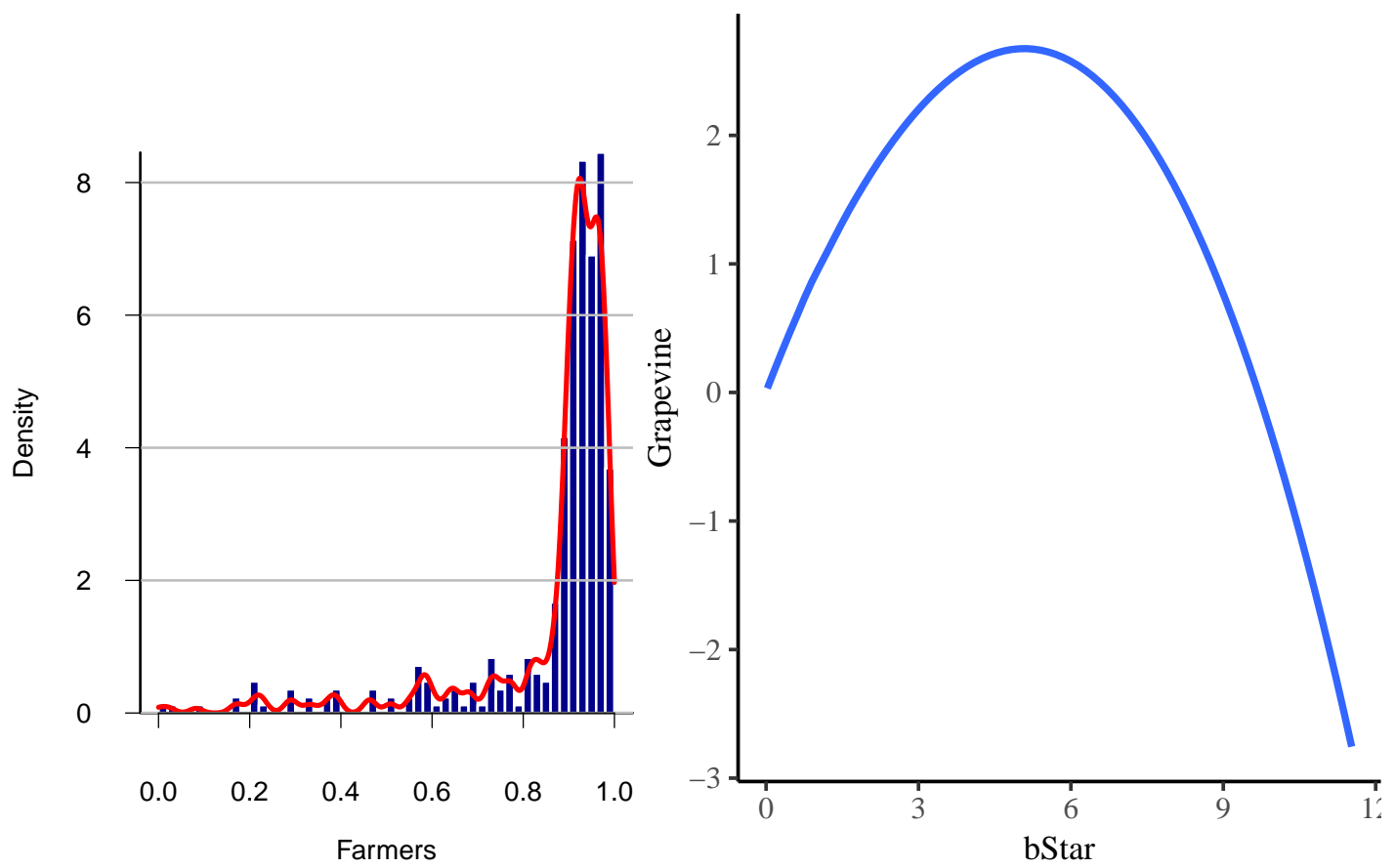

Figure 4.3: Histograms of EE scores and trade-off visualization

production possibilities and location with respect to the frontier. Regarding the undesired output elasticity (bStar), the two subgroups alternatives confirmed significant differences for their mean values, market orientation $(\mathrm{p}$-value $=0.05)$ and water source $(\mathrm{p}$-value $=0.014)$. Wine growers and users of both water sources are among the most sensitive to saline threat in each alternative subgroup respectively. Since their mean scale elasticities are only statistically different for the water source subgroup ( $\mathrm{p}$-value $=0.01$ ) and the grapevine yield is relatively higher for groundwater users, lower sensitive to their distance to the frontier by increasing the production is expected. Furthermore, recipients of both water sources are less sensitive to the saline hazard than the groundwater group. Thus a $1 \%$ increase of salinity content in irrigation water would increase their distance to the frontier by $0.355 \%$ while groundwater irrigators would be pushed $0.489 \%$ farther from the frontier.

Table 4.5: Mean differences in alternative subgroups

\begin{tabular}{ccccccccc}
\hline & \multicolumn{3}{c}{ Market orientation } & & \multicolumn{3}{c}{ Water source } \\
\cline { 2 - 3 } & Viticulturists & Wine growers & p-value & & Conjoint & Groundwater & p-value \\
\hline Mean efficiency & 0.868 & 0.824 & 0.115 & & 0.820 & 0.962 & 0.000 \\
Yield (tons/ha) & 10.800 & 9.100 & 0.000 & & 10.500 & 10.100 & 0.500 \\
$\xi_{\text {bStar }}$ & 0.745 & 0.893 & 0.050 & & 0.816 & 0.677 & 0.014 \\
$\xi_{\text {RTS }}$ & 0.399 & 0.361 & 0.564 & & 0.355 & 0.489 & 0.010 \\
\hline
\end{tabular}

Source: Welch two sample t-test, own estimation.

From the water source perspective, it is possible to cluster the sample into dual irrigation practices and those farmers that solely rely on groundwater. Dual users are located in the northern part of the research area $(n=279)$ and mainly differ from the groundwater users $(n=124)$ with respect to their location inside the irrigation network and the fact that may rely on wells as an additional 
water source. These subgroups have statistically different means on envrironmental efficiency scores and elasticity with respect to the undesired output. While conjoint water users have relatively lower mean efficiency and higher elasticity of the undesired output, groundwater users perform better environmentally and are less sensitive to salinity hazard. Altogether, groundwater dependent producers perform better than their counterparts maybe due to their optimization practices adapted to the already constrained access to water resources.

\subsubsection{Shadow price of saline hazard}

Since the DODF is a differentiable function that allows estimations of technical efficiency for multiple products, it is possible to estimate the shadow price for products that do not have a market. In this case the by-production of grapevine for wine production and salinity hazard. Assuming that the market price for grapevine $P_{\text {grape }}$ equals its shadow price, the equation for the shadow price estimation is:

$$
P_{S H_{2017}}=-\bar{P}_{\text {grape }} \times \frac{\frac{\partial \overrightarrow{D_{0}}\left(x, y, b, g_{y},-g_{b}\right)}{\partial b}}{\frac{\partial \overrightarrow{D_{0}}\left(x, y, b, g_{y},-g_{b}\right)}{\partial g r a p e}}
$$

The shadow price describes the production output that must be foregone in order to reduce the saline hazard by one unit, until all the inefficiency has been eliminated and wine grape is produced at the frontier of the production possibilities. In line with this, only observations that do not violate the monotonicity conditions are considered $(\mathrm{n}=325)$. The median price for $1 \mathrm{~kg}$ of saline content in water is USD 3.09. Although not statistically significant, the median shadow price for plots dependant on groundwater is slightly higher than those plots that have coinjoint irrigation sources, USD 3.85 and USD 2.53 per kilogram of saline content respectively.

Table 4.6: Mean efficiency and shadow price per district

\begin{tabular}{lcccc}
\hline & Efficiency $_{i}$ & Median & Std.Dev. & Observations \\
\hline Perdriel & 0.87 & 3.46 & 15.41 & 127 \\
Agrelo & 0.76 & 1.68 & 8.32 & 81 \\
Ugarteche & 0.91 & 3.39 & 7.58 & 53 \\
El Carrizal & 0.96 & 5.30 & 8.51 & 44 \\
Anchoris & 0.70 & 2.57 & 0.54 & 4 \\
\hline
\end{tabular}

Source: Own estimation.

If the combination of inputs and management variables $(\mathrm{x}, \mathrm{z})$ of a grapevine plot is located at the frontier of their production possibilities of the output set $P(x, z)$, it is possible to affirm that this plot has fully improved its environmental technical efficiency (Njuki et al. 2016). Therefore, the price ratio $\left(P_{u} / P_{d}\right)$ could be interpreted as the slope of the trade-off relationship estimated curve and reveals their approximate location in the production set and the relative cost of reducing the undesired output. Furthermore, comparing the median shadow prices among the districts could reveal additional insights about the shadow prices and potential abatement cost. The table 4.6 
shows the calculations for the median value at the district level for those plots that accomplish the properties mentioned above. For those districts with a considerable number of observations, it is possible to formulate some statements.

The district of Agrelo has the lowest shadow price, which may imply that vine plots functioning in this area could be farther along the frontier than the rest of the plots. Although, grapevine plots located in El Carrizal perform relatively better in terms of efficiency, it would be relatively expensive to reduce their salinity hazard in irrigation water. The estimated value is a proxy for the environmental benefit of removing salinity hazard at the plot level (Hernández-Sancho and Bellver-Domingo 2017), or in other words as the avoidance of the potential environmental damage that could be caused by inefficient producers (Hernández-Sancho et al. 2017). Moreover, the estimation allows environmental externalities to be internalized within the decision making process or the design of sector specific policies.

\subsection{Conclusions}

This paper estimates the environmental efficiency of grapevine production in Mendoza and elaborates on the effects of current policies that influence the decision making process of wine growers. The application of the directional output distance function (DODF) approach improves the comprehension and critical analysis of environmental efficiency and provides guidance towards a more efficieny system. That is, to improve grapevine production while reducing the salinity hazard for stakeholders. The data collection was concluded in January 2017 and consisted of 420 grapevine plot surveys and water quality samples.

Results confirm a trade-off relationship between grapevine production and salinity hazard, that can be desired and undesired output represented by a concave curve. Without minizing the diffuse pollution threat, vineyards scored a tolerable environmental efficiency mean value of 0.869 . At the sample mean and per hectare of production, this implies that vineyards are facing potential economic losses for USD 780.15 and suffering from saline hazard by 0.876 kilograms. The framework properties enable the estimation of the shadow price for the undesired output; the resulting economic value is USD 3.09 for the reduction of one kilogram of saline content in irrigation water.

The functional form and location specific characteristics are decisive in the determinats of environmental performance and therefore relevant policy implications for this region can be derived. First, economic tools contribute to reducing the variability of production but do not lead farmers to significantly improve efficiency. Second, redirecting efforts towards technology adoption supported by professional technical advice would ultimately have greater effects in reducing output variability, while simultaneously optimizing irrigation practices and introducing mechanization. While the hypothesis of greater vine quality at the expense of foregone output is valid, these technical advice would ultimately have greater effect in diminishing uncertainty but improving output quality. Third, groundwater dependent producers perform better than their counterparts maybe due to their optimization practices adapted to the already constrained resource. Similarly, farmers that sell their 
output to wineries have better output performance than vineyards that produce their own wine. Both subclassifications have higher elasticity to scale and lower sensitivity to salinity hazard. Upon changes in the zoning restrictions, these subgroups should be promoted.

Results show that economic tools that aim to support farmers do not significantly improve productivity but reduce uncertainty. In a water scarcity context, farmers are prone to irrigate whenever it is possible ignoring vine water threshold. This represents an intervention point that an agricultural extensionist could address and where, their input translates into efficiency significantly. Exact reasons for the above-mentioned behavior towards irrigation may be beyond this research but it is possible to point to some potential scenarios. In a extreme case, for example, higher vine density under ineffective irrigation systems would imply compensation of effects since wasted water could be watering the roots of neighboring vines.

Overall, efficiency improvement can be a major motivation for establishing environmental practices in this sector and this research shows that low efficiency scores can be possitively influenced. There is evidence that vineyard associations and viticulturist cooperatives have increasing interest in the environmental performance of farmers. Targeted programs on technology adoption for agricultural irrigation through extensionists would improve the overall understanding of the causes and effects of diffuse pollution and could steer farmers away from overexploitation of natural resources in the direction of more sustainable practices. 


\section{Chapter 5}

\section{General conlusions}

\subsection{Main findings}

Mendoza has suffered from water scarcity since 2009 and access to water is limited in the area under analysis. Water rights are non-tradable and they are attached to land property. Due to the scarcity context and legal restrictions, water supply for irrigation is constrained, which allows for the treatment of land and water as quasi-fixed production inputs. Under the water scarcity scenario, groundwater plays an important role as a reserve input, complementary for some vineyards with surface water rights and main source for certain districts.

The first paper in the dissertation analyzes the political and economic factors that shape the relationship among institutions and different water users. A review of the political, environmental, and economic disputes improved the understanding of the political and economic forces at work in the study area. At the same time, policy instruments were categorized according to their approach as regulatory, economic or collective action, and the corresponding area of influence in water management i.e. demand or supply side. Relatively more instruments are designed for the demand side but it is possible to envisage a great potential for management improvements on the water supply, mainly from areas where collective action and legislation can influence water consumption. While incentives remain distorted and the pressure on water resources increases overtime, the paper describes the relation between the subsidized energy prices, market price for grapevine, and levels of water table in the aquifer. The combination of higher grapevine prices and subsidized energy rates seem to have negative effects on the groundwater levels in the aquifer. As long as the energy tariff remains subsidized and the irrigation technology deficient, aquifer sustainability could be jeopardized. At some point, the DGI became aware of the environmental threat and imposed a zoning restriction in the research area, translating into land and water quasi-fixation for agricultural exploitation. The environmental pollution threat in the Carrizal aquifer raises questions and accusations among stakeholders. While accusations are mostly linked with local pollution from the petrochemical complex of YPF, general discussions do not address the diffuse pollution caused by groundwater overdraft. This point is vaguely acknowledged by institutions that seem unresponsive and indifferent to the broad assessment of energy subsidies for agricultural irrigation. Furthermore, new queries 
have emerged on the production potential and managerial skills at a smaller scale that would provide further information on the appropriate design of sector specific policies in this context.

In line with this, the second paper estimated the technical efficiency at the plot level in the Carrizal aquifer. This study estimated a stochastic frontier for grapevine producers on the right bank of Mendoza river and the efficiency determinants that improve the understanding of economic performance with respect to their potential. The sample was split according to the destination of their production output into viticulturists $(\mathrm{n}=444)$, if their output is sold to wineries, and winegrowers $(n=203)$, if they produce their own wine. Where the former performs relatively better in output yield (10.6 tn/ha), and the latter aims at higher quality production (9.19 tn/ha). Functional forms acknowledged the quasi-fixation of inputs and showed that water and capital are relevant in the production function for viticulturists and winegrowers. In light of the limitation to acquire more irrigated land, viticulturists may invest in other forms of capital that improve the farm endowment and performance but may go beyond their optimum. Overall, production inputs contribute positively to the production with the exception of labor for winegrowers. This result is somehow surprising considering the relevance of labor in the pursuit of enological quality, which relies on specific tasks carried out by hand. However, if winegrowers prefer quality over quantity, and farm mechanization continues to increase, then the effect of labor hours could be brought in line with production objectives at the frontier.

The results of the stochastic frontier analysis provided several clues to disentangle the effects of managerial decisions and economic policies in the performance of grapevine plots. Mean technical efficiency is similar between viticulturists (0.83) and winegrowers (0.82), which implies that viticulturists produce 1.81 fewer tons less per hectare $(10.6 \times 0.83)$ and winegrowers forgo 1.66 tons due to systematic pitfalls. Partial effects of the average (PEA) are used to report the general outcome of determined variables on inefficiency. The effectiveness of the irrigation systems generates the highest efficiency gain, followed by associativity and technical guidance received through extensionists. In other words, this implies that technology adoption in irrigation practices fostered through farmers association and supported by professionals can increase efficiency in grapevine production at the plot level. More in detail, with respect to crop management, higher vine density improves efficiency while the practice of leaf removal decreases the performance. Some external variables have uneven effects on the subgroups. While machine technology and energy subsidies improve efficiency for viticulturists, they have the opposite effect in winegrowers. This is possible accounting for the increasing use of mechanization at the vineyard level and considering that a greater share of winegrowers are located within the surface irrigation system $(78 \%)$, which tends to mask the use of groundwater as complimentary water source. Heterogeneity in economic performance is noticeable within the research area and between the subgroups. For those districts that rely on groundwater for irrigation, winegrowers have relatively better performance than viticulturists. Viticulturists perform relatively better in the districts of Agrelo and El Carrizal, while winegrowers performance is higher in Agrelo and Anchoris. The estimation of technical efficiency provided a clear assessment of the farmers' performance with respect to the best practices but also generated further research questions to consider the environmental effects of current practices. 
The fourth chapter accounts for this research gap and contributes to the estimation of the environmental efficiency of grapevine production in Mendoza. It considers the effects of current policies that influence the decision making process of winegrowers. Here, the saline hazard is identified as the undesired output, which refers to the kilograms of saline content in irrigation water, which it is detrimental for grapevine output yield and enological characteristics (Jackson 2008; Morábito et al. 2007). The application of the directional output distance function (DODF) approach improves the comprehension and critical analysis gauging the efficiency estimation towards a feasible direction. In this manner, it provides joint efficiency estimates; technical efficiency for the grapevine expansion and environmental efficiency for the saline hazard reduction.

Results confirm the trade-off relationship between saline hazard and grapevine production with a concave function. Vineyards scored on average a tolerable joint efficiency mean value (0.869), which implies a potential economic output losses of USD 780.15 at the sample mean and per hectare of production. Moreover, the potential increase in grapevine production yield is 1.4 tons for viticulturists and 1.19 tons for winegrowers, both producing at decreasing returns to scale and whose elasticity seems to acknowledge the inputs quasi-fixation. The weights of water and capital elasticity are relatively higher in the scale elasticity estimation, -0.379 and -0.115 respectively. In general, viticulturists and groundwater users are less sensitive to increases in water salinity in comparison to their counterparts, in part because they have optimized their management practices accordingly. Embracing environmental efficiency would translate into diminishing 0.88 kilograms of saline hazard per hectare. The estimated shadow price for the reduction of one kilogram of saline content in irrigation water is USD 3.09. Within the sample, the average salinity hazard is 6.71 kilograms per hectare and therefore the value of halving salinity hazard is USD 148,460 in the research area. ${ }^{1}$

Further interpretation of the determinants of vineyards joint performance can be explained by water and crop management decisions. Overall, water management practices have significant effects on reducing variability in the noise but expanding the distance to the frontier. While a considerable share of plots faces water stress (28\%), the remaining share seems to overuse water beyond the crop needs, which does not necessarily improve performance. Soils with greater saline content may require additional water to leach the salinity underground, but this effect was captured by including percolation requirements in the water balance equation. Adoption of irrigation systems supported by professional extensionists contributed to reducing the distance from the frontier, while small vineyards receiving energy subsidies had a reduced variability. With respect to agricultural management, the vine density and the assistance by extensionists could improve joint efficiency at the plot level. The mechanization of some management practices would reduce productive and environmental pitfalls but at a certain efficiency cost, with the additional benefit of substituting scarce labor in the region.

\footnotetext{
${ }^{1}$ Total planted area with grapevines in the selected districts of Lujan de Cuyo is 14,314 ha (INV 2018a).
} 


\section{$5.2 \quad$ Policy implications}

Local governments should seek the best possible economic and environmental outcome in the exploitation of natural resources following a sustainable path. In order to attain to these objectives, certain ambitious regulations are needed in the interconnected areas of agriculture, energy, and water use. In the past, large development programs aimed to foster agricultural development and grapevine production through technology adoption and extension services. Despite the effort of emerging institutions, some impact assessments of these policy programs have not been of sufficient quality due to improper baseline and further policy design (World Bank 2017; Cerdán-Infantes 2008). This dissertation aims to jointly fill the evidence gap that will effectively contribute to sector-specific tailored policies with a sustainable perspective.

In this context, some aspects of current policies are reviewed and various viewpoints are discussed. In addition, individual policies are less likely to provide desired outcomes as often times policy options complement each other. Therefore, the magnitude of the problems requires scalable scientific evidence to achieve a broader and representative perspective of the underlying mechanism for solutions (Grafton et al. 2018; Pulido-Velázquez et al. 2006). With the support of DGI, local water inspections do their water management planning in their area of influence, however, more interactions at the regional scale is needed. Moreover, additional strategies to address water accounting and optimal control are needed in order to set guidelines for sustainable production practices that contribute to the efficient management of environmental resources (Scott et al. 2014; Pulido-Velázquez et al. 2013). Water and energy policies should consider the effects on the basin scale to avoid the Jevons paradox or the rebound effect of improving irrigation efficiency but increasing water consumption (Berbel et al. 2014; Qureshi et al. 2010).

To be sure, the perspective on political and economic support of agricultural development through taxation policies needs to be revisited. The second chapter of the dissertation addressed the complex interactions between stakeholders in the Carrizal sub-basin and the conflicts which have arisen from the environmental threats of local and diffuse pollution. Transparent political, economic and environmental guidelines could promote greater and more active participation from stakeholders: in particular water inspections, farmers associations, energy regulators, and the provincial government. Political involvement of the society is fundamental to overcome lobbyists and make politicians accountable for their decisions. Moreover, the water inspections are organizations where decisions are made following a bottom-up approach. If the solutions for environmental threats are addressed collectively, major improvements could be achieved in reworking the existing groundwater legislation. The taxation scheme needs to be reworked into a more disciplinary framework that provides improvement opportunities, while acknowledging investments in technology adoption or shifts to renewable energy. The energy subsidy for irrigation should be temporal and under strict requirements, that could be reviewed by existing technology or fiscalization bodies, that may share information with energy institutions to establish automated controls. After an energy consumption and agricultural assessment, water and energy accounting can provide indexes to evaluate water intensiveness and propose adjustments according to deviations. Effectiveness in the employment 
of water should be rewarded. Institutions overlook the environmental harm of energy subsidies by showing their weakness to seasonally fulfill economic performance based on incorrect incentives. Ambitious regulations rely on political strength to make decisions with economic support, that would improve water and electricity management at the farm through technology adoption and responsible use of groundwater resources. Dual benefits are obtained by removing inefficient subsidies, policy orientation towards environmental responsibility and the reduction of tax budget (OECD 2018).

The existing water right quota limits the potential of grapevine producers to some extent, who had to invest in other capital services as a result of the prohibition of new groundwater wells. Under certain circumstances, the withdraw of restrictions could facilitate capital mobility and diminish the dependence of land prices on water rights. Programs that promote scaling to small vineyards through technology adoption and extension services could enhance productive and environmental gains for the region.

In parallel, economic policy incentives play an important role supporting vineyards to ensure some degree of technical adoption, protection of climate contingencies or water endowment in the short run. But a proportion of these incentives may have backfired as environmental degrading practices with respect to the aquifer sustainability. In contrast to the winegrowers, viticulturists can improve their technical efficiency through the energy subsidy but should be supported by technical assistance. Greater adoption of irrigation systems supported by technical advice from professional extensionists would significantly narrow the gap with the frontier. Targeted programs on technology adoption for agricultural irrigation through extensionists would improve the overall understanding on the causes and effects of diffuse pollution and further adjust or redirect exploitation of natural resources into more sustainable practices. Results show that economic tools aiming to support farmers are not improving productivity or efficiency but reduce uncertainty with respect to the total output. Nevertheless, smaller farmers can benefit from energy subsidies reducing variability through the energy subsidy tool. In a water scarcity context, it is understandable that farmers will irrigate whenever they have the chance to do it, even though it is pointless to continue irrigating beyond the vine demanded threshold, as it was formulated. This represents an intervention point that an extensionist would address, in particular considering that their contribution translates into efficiency gains.

The strategic viticulture plan (PEVI 2020) seeks to set a general target for quality development and promote technical innovations within the vineyard (COVIAR 2001). The implementation provided general guidelines for the industry as a whole, and there is a need for a redrafting taking account for the results and implications based on scientific evidence and interactions with other sectors of the economy. Since efficiency improvements can be a major motivation for establishing environmental practices in this sector, this research can contribute substantially to the environmental-economic performance of quality grapevine production. There is evidence that vineyard association and viticulturist cluster groups have interest in the environmental performance of farmers. Further persuasion of their members to adapt and improve their practices inline with environmental efficiency could effectively widespread to a broader spectrum (Gibbons et al. 2016; Maffioli et al. 2011). 


\subsection{Limitations and suggestions for future research}

This dissertation was developed in accordance with the formulated research questions and data availability to analyze the technical and environmental efficiency of grapevine producers. The pollution threat and judicial trials presented significant limitations to access public data on water management, water quality and sub-basin studies, which, in turn became research incentives to unfold the economic potential of grapevine producers in the region. The simulation study by Hernández et al. (2012) is the last available research at a basin scale. Although a unique dataset was collected with the complementary support of institutions and their secondary data, further potential studies could enrich greatly by adding new waves of data collection from vineyards at the plot level.

In order to effectively achieve sustainability on water issues, consumption must be assessed broadly accounting for strategic behavior of stakeholders and deviations of water consumption from expected paths after technology has been adopted (Grafton et al. 2018; Hellegers 2006). Most of the efficiency literature that includes water as a productive input is region specific and compares farms within a sector or sub-basin, but they tend to overlook the interactions among modern irrigation techniques, water flows (surface and underground) and water consumption levels. Further studies can address the farmers' behavior toward policy measures and assess whether improvements in technical and environmental efficiency have positive or negative spill-overs for farmers downstream. The ability to quantify the economic effects of a regulatory intervention is important from a policy perspective since it will allow the clear assessment of environmental regulations across affected regions.

Estimation of basin specific water demand constitutes a step further in the modeling and economic planning for semi-arid areas in Latin America. In Mendoza, the DGI acknowledged the potential of basin analysis but policy makers have not fully acknowledged the basin mechanisms and tailored economic policies accordingly. This constitutes a research opportunity, yet the difficulty of measuring water application remains one of the main barriers to push research into a broader perspective (Bravo-Ureta et al. 2015), in particular for those farms with lower technology adoption and lack of planning.

Among the New World wine countries, Argentina is the smallest in export value with almost USD 1 billion and with the potential to grow (COVIAR/OVA 2018). Several economic factors and infrastructure limitations have undermined the viticulture development, however, business potential cannot be unleashed with traditional interventions that overlook agroecological characteristics and do not value natural resources accordingly. Therefore, a meta-frontier analysis of Argentinean viticulture could address the production potential of vineyards and contribute to assessment of real limitations for development and systematic environmental disturbances in production. There is considerable scope for research on this topic, which is complex and highly site specific. Spatial stochastic frontiers supported by an effective national agricultural census of the year 2018 could contribute to the technical efficiency estimations substantially. This would indeed constitute a valuable contribution for the national strategic viticulture plan and the design of sector specific policies. 


\section{References}

Abler, D.G., and J.S. Shortle. 1991. "The political economy of water quality protection from agricultural chemicals." Northeastern Journal of Agriculture and Resource Economics:53-60.

Agosta, E., P. Canziani, and M. Cavagnaro. 2012. "Regional Climate Variability Impacts on the Annual Grape Yield in Mendoza, Argentina." Journal of Applied Meteorology and Climatology 51(6):993-1009. Available at: http://journals.ametsoc.org/doi/abs/10.1175/JAMC-D-11-0165.1.

Aigner, D., C. Lovell, and P. Schmidt. 1977. "Formulation and estimation of stochastic frontier production function models." Journal of Econometrics 6(1):21-37. Available at: http://linkinghub. elsevier.com/retrieve/pii/0304407677900525.

Allan, T., M. Keulertz, and E. Woertz. 2015. "The water-food-energy nexus: an introduction to nexus concepts and some conceptual and operational problems." International Journal of Water Resources Development 31(3):301-311. Available at: http://www.tandfonline.com/doi/full/10.1080/ 07900627.2015.1029118.

Altamirano, J.C., N.B. Lana, J.A. D'Angelo, and N. Ciocco. 2005. "Polybrominated diphenyl ethers in Mendoza river basin and el Carrizal reservoir: levels, distribution and correlation with physico-chemical variables.":1-4.

Alvarez, A., C. Amsler, L. Orea, and P. Schmidt. 2006. "Interpreting and Testing the Scaling Property in Models where Inefficiency Depends on Firm Characteristics." Journal of Productivity Analysis 25(3):201-212. Available at: http://link.springer.com/10.1007/s11123-006-7639-3.

Ancev, T., M.A.S. Azad, and F. Hernández-Sancho. 2017. New Directions in Productivity Measurement and Efficiency Analysis. Edward Elgar Publishing. Available at: https://www.elgaronline. com/view/9781786432414.xml.

Ancev, T., M.S. Azad, and M. Akter. 2017. "Environmentally adjusted productivity and efficiency: a review of concepts, methods and empirical work." In New directions in productivity measurement and efficiency analysis. Edward Elgar Publishing, pp. 9-58. Available at: https://www.elgaronline. com/view/9781786432414.00006.xml.

Andrieu, J., O. Miranda, N. Gatti, and R. Novello. 2014. "Riego y acción colectiva: impacto en la eficiencia técnica de la producción vitícola de San Juan." In Asociación argentina de economía 
agraria. pp. 1-23. Available at: https://goo.gl/A6NdDe.

Ayers, R.S., and D.W. Westcot. 1994. Water quality for agriculture 2nd ed. Rome: FAO; FAO. Available at: http://www.fao.org/docrep/003/t0234e/T0234E00.htm\{\\#\}TOC.

Azad, M.A.S., T. Ancev, and F. Hernández-Sancho. 2015. "Efficient Water Use for Sustainable Irrigation Industry." Water Resources Management 29(5):1683-1696. Available at: http://link. springer.com/10.1007/s11269-014-0904-8.

Azad, M.A.S., and T. Ancev. 2016. "Economics of Salinity Effects from Irrigated Cotton: An Efficiency Analysis." Water Economics and Policy 02(01):1650002. Available at: http://www. worldscientific.com/doi/10.1142/S2382624X16500028.

Azad, M.A.S., and T. Ancev. 2014. "Measuring environmental efficiency of agricultural water use: A Luenberger environmental indicator." Journal of Environmental Management 145:314-320. Available at: http://dx.doi.org/10.1016/j.jenvman.2014.05.037.

Azpiazu, D., and E. Basualdo. 2001. "El complejo vitivinícola argentino en los noventa: potencialidades y restricciones." CEPAL.

Azpiazu, D., N. Bonofiglio, and C. Nahón. 2014. "Agua y Energía. Mapa de situación y problemáticas regulatorias de los servicios públicos en el interior del país." No. 18, FLACSO - Fac. Latinoamericana de Ciencias Sociales. Available at: http://biblioteca.clacso.edu.ar/ar/libros/argentina/flacso/tesis/ dt18.pdf.

Álvarez, A., and G.E. Fasciolo. 2011. "Vulnerabilidad de acuíferos, una herramienta para el ordenamiento territorial." No. 1, Instituto Nacional del Agua.

Álvarez, A., A. Drovandi, J. Hernández, R. Hernández, N. Martinis, J. Maza, C. Mirábile, J.A. Morábito, S. Salatino, and A. Vargas Aranibar. 2009. "El agua en Mendoza y su problemática ambiental."

Álvarez, A., M. D’Elía, M. Paris, G.E. Fasciolo, and C. Barbazza. 2011. "Evaluación de la contaminación de acuíferos producida por actividades de saneamiento y re-uso de efluentes en el norte de la provincia de Mendoza." Revista de la Facultad de Ciencias Agrarias 43(1):19-39. Available at: http://bdigital.uncu.edu.ar/2720.

Badiani, R., and K.K. Jessoe. 2011. "The impact of electricity subsidies on groundwater extraction and agricultural production." Available at: http://are.berkeley.edu/documents/seminar/JessoeDraft. pdf.

Badiani, R., K.K. Jessoe, and S. Plant. 2012. "Development and the environment: The implications of agricultural electricity subsidies in India." The Journal of Environment $\&$ Development 21(2):244262. Available at: http://jed.sagepub.com/cgi/doi/10.1177/1070496512442507.

Bailis, R. 2011. "Energy and Poverty: The Perspective of Poor Countries." In I. Galarraga, M. González-Eguino, and A. Markandya, eds. Handbook of sustainable energy. Edward Elgar Publishing, 
pp. 505-538. Available at: http://www.elgaronline.com/view/9781849801157.00035.xml.

Ball, V.E., J.P. Butault, and C. San Juan Mesonada. 2004. "Measuring real capital input in OECD agriculture." Canadian Journal of Agricultural Economics 52(3):351-370.

Ball, V.E., R. Färe, S. Grosskopf, F. Hernandez-Sancho, and R.F. Nehring. 2002. "The Environmental Performance of the U.S. Agricultural Sector." In V. Elton Ball and G. W. Norton, eds. Agricultural productivity. Boston, MA: Springer US, pp. 257-275. Available at: http://link.springer.com/10.1007/978-1-4615-0851-9\{\_\}10.

Barbazza, C.V. 2005. "Funciones de demanda de agua subterránea para el Este mendocino." In CONAGUA. Mendoza, Argentina.

Battese, G.E. 1992. "Frontier production functions and technical efficiency: a survey of empirical application in agricutural economics." Agricultural Economics (7):185-208.

BCM. 2018. "Mercado Vitivinícola - Uvas." Available at: https://www.bolsamza.com.ar [Accessed September 23, 2018].

Becerra, V.C., M.E. Herrera, M.F. Gonzalez, G.B. Mendoza, and C.V. Dagatti. 2015. "Lobesia botrana Den et Schiff." In M. N. Rossini, J. P. Agostini, and D. M. Dummel, eds. Plagas cuarentenarias de frutales de la república argentina: Avances en los resultados. Buenos Aires: Ediciones INTA, pp. 19-29. Available at: http://hdl.handle.net/20.500.12123/828.

Berbel, J., C. Gutiérrez-Martín, J.A. Rodríguez-Díaz, E. Camacho, and P. Montesinos. 2014. "Literature Review on Rebound Effect of Water Saving Measures and Analysis of a Spanish Case Study." Water Resources Management 29(3):663-678.

Bermejo, M. 1884. "Ley de aguas." Available at: http://www.agua.gob.ar/dgi/ley-aguas.

Bertranou, A.V., A. Llop, and A.J. Vazquez. 1983. "Water Use and Reuse Management in Arid Zones-The Case of Mendoza, Argentina." Water International 8(1):2-12. Available at: http://www.tandfonline.com/doi/abs/10.1080/02508068308685991.

Bogetoft, P., and L. Otto. 2011. Benchmarking with DEA, SFA, and R F. S. Hillier, ed. New York, NY: Springer New York. Available at: http://link.springer.com/10.1007/978-1-4419-7961-2.

Booker, J.F., R.E. Howitt, A.M. Michelsen, and R.A. Young. 2012. "Economics and the modeling of water resources and policies." Natural Resource Modeling 25(1):168-218. Available at: http: //doi.wiley.com/10.1111/j.1939-7445.2011.00105.x.

Bos, M.G., and J.L. Chambouleyron eds. 1999. "Parámetros de desempeño de la agricultura de riego de Mendoza, Argentina." Available at: http://hdl.handle.net/10568/36302.

Bowmer, K.H. 2011. "Water resource protection in Australia: Links between land use and river health with a focus on stubble farming systems." Journal of Hydrology 403(1-2):176-185.

Bravo-Ureta, B.E., R. Jara-Rojas, M. Lachaud, V. Moreira, and S.M. Scheierling. 2015. "Water 
and farm Efficiency: Insights from the Frontier Literature." Working Paper.

Brozović, N., D.L. Sunding, and D. Zilberman. 2006. "Optimal management of groundwater over space and time." In R.-U. Goetz and D. Berga, eds. Frontiers in water resource economics. Natural resource management and policy. Boston: Kluwer Academic Publishers, pp. 109-136. Available at: http://link.springer.com/10.1007/0-387-30056-2.

Calcagno, A., N. Mendiburo, and M. Gaviño Novillo. 2000. "Informe sobre la gestión del agua en la República Argentina." World Water Vision.

Castex, V., E.M. Tejeda, and M. Beniston. 2015. "Water availability, use and governance in the wine producing region of Mendoza, Argentina." Environmental Science \& Policy 48:1-8. Available at: https://linkinghub.elsevier.com/retrieve/pii/S1462901114002366.

Cerdán-Infantes, P. 2008. "The impact of agricultural extension services: The case of grape production in Argentina." OVE Working Papers. Available at: http://www.iadb.org/intal/intalcdi/ PE/2009/03159.pdf.

Christ, K.L., and R.L. Burritt. 2013. "Critical environmental concerns in wine production: an integrative review." Journal of Cleaner Production 53:232-242. Available at: http://linkinghub. elsevier.com/retrieve/pii/S0959652613002084.

Chung, Y., R. Färe, and S. Grosskopf. 1997. "Productivity and Undesirable Outputs: A Directional Distance Function Approach." Journal of Environmental Management 51(3):229-240. Available at: http://linkinghub.elsevier.com/retrieve/pii/S0301479797901468.

Coady, D., I. Parry, L. Sears, and B. Shang. 2015. "How large are global energy subsidies?" Fiscal Aff:30. Available at: https://www.imf.org/external/pubs/ft/wp/2015/wp15105.pdf.

Codron, J.-M., E. Montaigne, and S. Rousset. 2013. "Quality management and contractual incompleteness: grape procurement for high-end wines in Argentina." Journal on Chain and Network Science 13(1):11-35. Available at: https://www.wageningenacademic.com/doi/10.3920/ JCNS2013.x218.

Coelli, T.J., and O. Sanders. 2013. "The Technical Efficiency of Wine Grape Growers in the Murray-Darling Basin in Australia." In Wine economics. London: Palgrave Macmillan UK, pp. 231-249. Available at: http://link.springer.com/10.1057/9781137289520\{\_\}11.

Coelli, T.J., and O. Sanders. 2012. "The technical efficiency of wine grape growers in the MurrayDarling Basin in Australia." In Enometrics xix. Coimbra \& Viseu. Available at: www.vdqs.net/ 2012Coimbra.

Coelli, T.J., D.S. Prasada Rao, C.J. O’Donnell, and G.E. Battese. 2005. An introduction to efficiency and productivity analysis 2nd ed. New York: Springer.

Conradie, B., G. Cookson, and C. Thirtle. 2006. "Efficiency and farm size in Western Cape grape 
production: Pooling small datasets." South African Journal of Economics 74(2):334-343.

Conte, S. 2014. "Agroindustrias contaminan el agua." Available at: http://losandes.com.ar/article/ agroindustrias-contaminan-el-agua-793310.

COVIAR. 2001. "Plan Estratégico Argentina Vitivinícola 2020 (PEVI 2020)." Corporación Vitivinícola Argentina (COVIAR). Available at: http://coviar.com.ar/2018/wpcontent/uploads/2018/03/Plan-Estrat $\{\backslash$ ' $\{$ e $\}$ gico-Vitivin $\{\backslash\{\{$ i $\}$ cola-PEVI.pdf.

COVIAR/OVA. 2018. "Impacto de la Vitivinicultura en la Economía Argentina." Corporación Vitivinícola Argentina; Observatorio Vitivinícola Argentino; COVIAR. Available at: https://goo.gl/ A9AUDQ.

Crescimanno, G., and K.B. Marcum. 2013. "Plant Response to Saline-Water Irrigation in a Sicilian Vineyard." In Developments in soil salinity assessment and reclamation. Dordrecht: Springer Netherlands, pp. 419-435. Available at: http://www.springerlink.com/index/10.1007/978-94-0075684-7\{\_\}29.

Cuesta, R.A., and J.L. Zofío. 2005. "Hyperbolic Efficiency and Parametric Distance Functions: With Application to Spanish Savings Banks." Journal of Productivity Analysis 24(1):31-48. Available at: http://link.springer.com/10.1007/s11123-005-3039-3.

Cuesta, R.A., C.K. Lovell, and J.L. Zofío. 2009. "Environmental efficiency measurement with translog distance functions: A parametric approach." Ecological Economics 68(8-9):2232-2242. Available at: http://linkinghub.elsevier.com/retrieve/pii/S0921800909000573.

Dagnino, M., and F.A. Ward. 2012. "Economics of agricultural water conservation: Empirical analysis and policy implications." International Journal of Water Resources Development 28(4):577600.

De Lorenzi, F., J.A. Morábito, M. Menenti, R. Dell'Aquila, and C. Elmida. 2009. "Evapotranspiración, transpiración y evaporación en un viñedo var. malbec. Mendoza, Argentina." In CONAGUA. Trelew, Chubut.

de Sousa Henriques, P.D., M.L. da Silva Carvalho, and R.M. de Sousa Fragoso. 2009. "Technical efficiency of portuguese wine farms." New Medit 8(1):4-9.

DEIE. 2014. "Anuario económico." Available at: https://goo.gl/D4yV4a [Accessed January 1, 2015].

DGI. 2015. Aqualibro 2nd ed. Mendoza: Irrigación Edita.

DGI. 2016. "Departamento General de Irrigación. Resolución 641.”:6148-6149. Available at: https://boe.mendoza.gov.ar/publico/pdf\{\_\}pedido/70.

DGI. 2018. "Servidor de mapas - IDE Irrigación." Available at: http://ide.irrigacion.gov.ar [Accessed May 14, 2018].

Diaz Araujo, E., and A. Bertranou. 2004. "Systemic Study of Water Management Regimes: 
Mendoza, Argentina.":1-102.

Dinar, A. 2018. "The Challenges of Reducing Water-related Subsidies in Agriculture." In Facilitating policy change towards sustainable water use in agriculture. Washington, D.C.: World Bank - OECD.

Dinar, A. 2000. The political economy of water pricing reforms 1st ed. A. Dinar, ed. New York: Oxford University Press. Available at: http://documents.worldbank.org/curated/en/2000/04/ 437127/political-economy-water-pricing-reforms.

Donoso, G., M.M. Aldaya, W.J. Cabral de Sousa, X. Cai, D. Chico, A. de Miguel, A. Dumont, L. Gurovich, J. Lautze, E. López-Gunn, M. Pahlow, J.C. Pascale-Palhares, and E. Zarate. 2014. "Water efficiency: Status and trends." In B. A. Willaarts, A. Garrido, and M. R. Llamas, eds. Water for food and wellbeing in latin america and the caribbean. social and environmental implications for a globalized economy. Routledge, Oxon, New York, pp. 261-283. Available at: http://new-test.fundacionbotin.org/89dguuytdfr276ed $\left\{\backslash \_\right\}$uploads/Observatorio Tendencias/PUBLICACIONES/LIBROS SEM INTERN/water for food security/capitulo10.pdf.

Drovandi, A., J. Zuluaga, M. Filippini, A. Bermejillo, P. Peralta, M. Bustamante, M. Ruiz, M. Granero, A. Morsucci, M. Velgas, A. Valdes, and N. Nacif. 2005. "Diagnóstico preliminar del estado trófico de las aguas del embalse el Carrizal, provincia de Mendoza." In XX congreso nacional del agua y iii simposia de recursos hídricos del cono sur. Mendoza, Argentina.

Duek, A.E., and E.A. Comellas. 2015. "Consumo de agua en la cadena vitivinícola de Mendoza, Argentina. Escenarios de uso sostenible." Revista Iberoamericana de Viticultura, Agroindustria y Ruralidad 6(2):110-130. Available at: https://goo.gl/dHcDJ2.

Duek, A.E., G.E. Fasciolo, M.E. Quiles, and O. Zoia. 2013. "Uso del agua en la industria alimenticia de Mendoza." In Congreso nacional del agua xxiv (conagua). San Juan, Argentina.

Elhag, M. 2017. "Efficiency concept under stochastic consideration of water value in irrigated agriculture land in Crete, Greece." Water Science and Technology: Water Supply 17(4):ws2017019. Available at: https://iwaponline.com/ws/article/17/4/1185-1192/15042.

EPRE. 2013. "Informe de la demanda Mendoza y Cuyo." Ente Provincial Regulador Eléctrico (EPRE). Available at: https://goo.gl/1Bx8gg.

EPRE. 2018. "Informe de la demanda Mendoza y Cuyo." Ente Provincial Regulador Eléctrico (EPRE). Available at: https://goo.gl/H6ZXr8.

EPRE. 2017. "Informe de la demanda Mendoza y Cuyo." Ente Provincial Regulador Eléctrico (EPRE). Available at: https://goo.gl/vxwMF2.

Erice, M.V. 2013. "Necesidad de transparencia y legalidad en la gestión y uso de las aguas subterráneas (El reciente caso de la Provincia de Mendoza)." Derecho y Ciencias Sociales Octubre(9):191202.

FAO/IWMI. 2018. More people, more food, worse worse water? A global review of water pollution from agriculture J. Mateo-Sagasta, S. Marjani Zadeh, and H. Turral, eds. Rome: FAO; IWMI. 
Available at: http://www.fao.org/documents/card/en/c/CA0146EN.

FAO/PROSAP. 2015. "Estudio del potencial de ampliación del riego en Argentina." Desarrollo institucional para la inversión Organización de las Naciones Unidas para la Agricultura y la Alimentación (FAO); Programa de Servicios Agrícolas Provinciales (PROSAP).

Fare, R., S. Grosskopf, C.A.K. Lovell, and S. Yaisawarng. 1993. "Derivation of Shadow Prices for Undesirable Outputs: A Distance Function Approach." The Review of Economics and Statistics 75(2):374. Available at: https://www.jstor.org/stable/2109448?origin=crossref.

Farinelli, F. 2007. "The awakening of the sleeping giant: export growth and technological catch-up of the Argentine wine industry." International Journal of Technology and Globalisation 3(2/3):179. Available at: http://www.inderscience.com/link.php?id=14332.

Farrell, M.J. 1957. "The measurement of productive efficiency." Journal of the Royal Statistical Society 120(3):253-290.

Färe, R., S. Grosskopf, and D. Margaritis. 2008. "Productivity and Efficiency: Malmquist and More." In H. D. Fried, C. A. Knox Lovell, and S. S. Schmidt, eds. The measurement of productive efficiency and productivity growth. Cambridge University Press, pp. 522-617.

Färe, R., S. Grosskopf, and C. Pasurkar. 2007. "Environmental production functions and environmental directional distance functions." Energy 32(7):1055-1066. Available at: http: //linkinghub.elsevier.com/retrieve/pii/S0360544206002519.

Färe, R., S. Grosskopf, D.W. Noh, and W. Weber. 2005. "Characteristics of a polluting technology: Theory and practice." Journal of Econometrics 126(2):469-492.

Feng, G., and A. Serletis. 2014. "Undesirable outputs and a primal Divisia productivity index based on the directional output distance function." Journal of Econometrics 183(1):135-146. Available at: http://linkinghub.elsevier.com/retrieve/pii/S0304407614001559.

Feng, G., C. Wang, and A. Serletis. 2018. "Shadow prices of CO2 emissions at US electric utilities: directional output distance function approach." Empirical Economics:231-258.

Fernández, C., G. Koop, and M.F. Steel. 2002. "Multiple-output production with undesirable outputs: An application to nitrogen surplus in agriculture." Journal of the American Statistical Association 97(458):432-442.

Fernández Rojas, J. 2012. "4 historias judiciales y contaminantes de la YPF privatizada." Available at: http://www.mdzol.com/nota/383062-4-historias-judiciales-y-contaminantes-de-la-ypf-privatizada/.

Ferreyra, M.A., and J.A. Vera. 2018. "Mendoza: vitivinicultura y transferencia de ingresos. Del sobrestock a la importación." Mundo Agrario 19(41):e087. Available at: https://www.mundoagrario. unlp.edu.ar/article/view/MAe087.

Fleming, E., S. Mounter, B. Grant, G. Griffith, and R. Villano. 2014. "The New World challenge: Performance trends in wine production in major wine-exporting coun- 
tries in the 2000s and their implications for the Australian wine industry." Wine Economics and Policy 3(2):115-126. Available at: http://dx.doi.org/10.1016/j.wep.2014.12.002 http://linkinghub.elsevier.com/retrieve/pii/S2212977414000295.

Foster, E.T., A. Dinar, and A. Rapoport. 2016. "Comparing Alternative Modifications of Energy Subsidies: The Case of Groundwater Extraction.":1-32.

Foster, S., and H. Garduño. 2005. "Gestión sustentable del agua subterránea. Argentina: Enfoque de gestión integrada para la conservación del agua subterránea en los acuíferos de Mendoza." World Bank. Available at: www.worldbank.org/gwmate.

Foster, S., and H. Garduño. 2012. "Groundwater-resource governance: Are governments and stakeholders responding to the challenge?" Hydrogeology Journal:317-320.

Foster, S., and H. Garduño. 2006. "Integrated approaches to groundwater resource conservation in the Mendoza aquifers of Argentina." World Bank.

Garduño, H., and S. Foster. 2010. "Sustainable groundwater irrigation: approaches to reconciling demand with resources." World Bank. Available at: www.worldbank.org/gwmate.

Gibbons, M.A., A. Maffioli, and M.A. Rossi. 2016. "Money for Wine? Complementarities in the provision of private and public goods to wine producers."

Giraud-Héraud, E., and M.-C. Pichery eds. 2013. Wine Economics. Quantitative Studies and Empirical Applications. London: Palgrave Macmillan UK. Available at: http://link.springer.com/10. $1057 / 9781137289520$.

Girman, J., J. van der Gun, N. Haie, R. Hirata, A. Lipponen, E. Lopez-Gunn, B. Neupane, T. Shah, J. Vrba, and B. Wallin. 2006. Groundwater resources sustainability indicators 14th ed. J. Vrba and A. Lipponen, eds. Available at: http://waterwiki.net/images/d/d0/ GroundwaterResourcesSustainabilityIndicator.pdf.

Global Water Partnership. 2012. "Groundwater resources and irrigated agriculture." Global Water Partnership.

González, M.F. 2011. "Estudio de la Bioecología de Lobesia Botrana Den. \& Shiff en las Condiciones Agroecológicas del Oasis Norte de Mendoza." In 1er simposio argentino de viticultura y enología. Mendoza, Argentina.

Grafton, R.Q., J. Williams, C.J. Perry, F. Molle, C. Ringler, P. Steduto, B. Udall, S.A. Wheeler, Y. Wang, D. Garrick, and R.G. Allen. 2018. "The paradox of irrigation efficiency." Science 361(6404):748-750. Available at: http://www.sciencemag.org/lookup/doi/10.1126/science.aat9314.

Grainger, K. 2009. Wine Quality: Tasting and Selection.

Greene, W.H. 2008. "The econometric approach to efficiency analysis." The Measurement of Productive Efficiency and Productivity Growth:92-250.

Gruère, G., C. Ashley, and J.-J. Cadilhon. 2018. "Reforming water policies in agriculture. Lessons 
from past reforms." Available at: http://dx.doi.org/10.1787/1826beee-en.

Guesmi, B., T. Serra, Z. Kallas, and J.M. Gil Roig. 2012. "The productive efficiency of organic farming: the case of grape sector in Catalonia." Spanish Journal of Agricultural Research 10(3):552. Available at: http://revistas.inia.es/index.php/sjar/article/view/2153.

Hailu, A., and T.S. Veeman. 2001. "Non-parametric Productivity Analysis with Undesirable Outputs: An AppHailu, A., Veeman, T.S., 2001. Non-parametric Productivity Analysis with Undesirable Outputs: An Application to the Canadian Pulp and Paper Industry. Am. J. Agric. Econ. 83, 605-616.lica." American Journal of Agricultural Economics 83(3):605-616. Available at: https://aae.wisc.edu/aae746/Ref/AJAE-2001-Hailu-605-16.pdf.

Hartt Kentnor, J. 2012. "Vintage matters: the political economy of wine cooperatives in San Rafael, Argentina.":1-145.

Hellegers, P. 2006. "The impact of recovering irrigation water losses on the choice of irrigation technology with heterogeneous land quality and different crops." In R.-U. Goetz and D. Berga, eds. Frontiers in water resource economics. Natural resource management and policy. Boston: Kluwer Academic Publishers, pp. 241-254. Available at: http://link.springer.com/10.1007/0-387-30056-2.

Hernández, J., N. Martinis, and L. Fornero. 2012. "Modelación hidrológica de la cuenca norte de Mendoza." No. 146, Instituto Nacional del Agua (INA).

Hernández-Sancho, F., and Á. Bellver-Domingo. 2017. "Environmentally adjusted efficiency of municipal water suppliers." In New directions in productivity measurement and efficiency analysis. Edward Elgar Publishing, pp. 195-216. Available at: https://www.elgaronline.com/view/ 9781786432414.xml.

Hernández-Sancho, F., B. Lamizana-Diallo, and W. Ingram. 2017. "Valuing environmental and health impacts from no action in wastewater management." In New directions in productivity measurement and efficiency analysis. Edward Elgar Publishing, pp. 217-231. Available at: https://www.elgaronline.com/view/9781786432414.00014.xml.

HLPM. 2017. "Plan Provincial de Ordenamiento Territorial." Available at: https://goo.gl/haURS4. Holtkamp, A.M. 2017. Technical and environmental efficiency of smallholder palm oil and rubber production. Doctoral thesis. Georg-August-Universität Göttingen. Available at: http://hdl.handle. net/11858/00-1735-0000-0023-3ECF-0.

Huang, W., B. Brümmer, and L. Huntsinger. 2016. "Incorporating measures of grassland productivity into efficiency estimates for livestock grazing on the Qinghai-Tibetan Plateau in China." Ecological Economics 122:1-11. Available at: http://dx.doi.org/10.1016/j.ecolecon.2015.11.025.

Hurlbert, M., and P. Mussetta. 2016. "Creating resilient water governance for irrigated producers in Mendoza, Argentina." Environmental Science \& Policy 58:83-94. Available at: https://linkinghub. elsevier.com/retrieve/pii/S1462901116300041.

Hurlbert, M.A., and E. Montana. 2015. "Dimensions of adaptive water governance and drought 
in Argentina and Canada." Journal of Sustainable Development 8(1):120-137. Available at: http: //www.ccsenet.org/journal/index.php/jsd/article/view/41413.

IDR. 2016. "Ecoatlas." Available at: http://www.ecoatlas.org.ar/index.html [Accessed January 26, 2016].

IERAL. 2011. "Una Argentina Competitiva, Productiva y Federal. La cadena vitivinícola." 4790.

INV. 2017. "Analisis de la evolucion de superficie de vid por provincias - Periodo 2000-2016." Instituto Nacional de Vitivinicultura (INV). Available at: https://goo.gl/VfYEq1.

INV. 2018a. "Anuario vitivinícola." Instituto Nacional de Vitivinicultura. Available at: https: //goo.gl/D4FBPZ.

INV. 2018b. "Mercado Externo de Productos Vitivinícolas." Instituto Nacional de Vitivinicultura. Available at: https://goo.gl/dDMDGb.

INV. 2018c. "Sistema de información de productos vitivinícolas (SIO-VINOS)." Available at: https://pinot.inv.gov.ar/web $\left\{\backslash \_\right.$\}inv/siovinos/vinos.php [Accessed September 13, 2018].

Jackson, R.S. 2008. Wine science. Principles and applications Third. London: Elsevier.

Jofré, J.L. 2010. Efectos de las innovaciones productivas en la agricultura sobre la materialidad institucional del régimen hídrico. El caso mendocino entre 1976-2010. Doctoral. Universidad Nacional de Cuyo.

Jofré, J.L., and A. Duek. 2012. "Criterios de política hídrica para el ordenamiento territorial." In I encuentro de investigadores en formación en recursos hídricos. Buenos Aires, Argentina: Instituto Nacional del Agua (INA).

Karagiannis, G., V. Tzouvelekas, and A. Xepapadeas. 2003. "Measuring Irrigation Water Efficiency with a Stochastic Production Frontier." Environmental and Resource Economics 26(1):57-72. Available at: http://link.springer.com/10.1023/A:1025625402762.

Khanna, M., and R. Farnsworth. 2006. "Economic analysis of green payments to protech water quality." In R.-U. Goetz and D. Berga, eds. Frontiers in water resource economics. Natural resource management and policy. Boston: Kluwer Academic Publishers, pp. 199-225. Available at: http://link.springer.com/10.1007/0-387-30056-2.

Kumbhakar, S.C., and C.A. Knox Lovell. 2003. Stochastic Frontier Analysis First. Cambridge: Cambridge University Press.

Kumbhakar, S.C., and K. Sun. 2013. "Derivation of marginal effects of determinants of technical inefficiency." Economics Letters 120(2):249-253.

Kumbhakar, S.C., and H.-J. Wang. 2015. "Estimation of Technical Inefficiency in Production Frontier Models Using Cross-Sectional Data." In Benchmarking for performance evaluation. New 
Delhi: Springer India, pp. 1-73. Available at: http://link.springer.com/10.1007/978-81-322-2253$8\{\backslash \ldots 1$.

Kumbhakar, S.C., H.-J. Wang, and A.P. Horncastle. 2015. A Practitioner's Guide to Stochastic Frontier Analysis Using Stata. Cambridge: Cambridge University Press. Available at: http: //ebooks.cambridge.org/ref/id/CBO9781139342070.

Kupper, E., E. Querner, J.A. Morábito, and M. Menenti. 2002. "Using the SIMGRO regional hydrological model to evaluate salinity control measures in an irrigation area." Agricultural Water Management 56(1):1-15. Available at: http://linkinghub.elsevier.com/retrieve/pii/S0378377401001950.

Lankoski, J., H. Lehtonen, M. Ollikainen, and S. Myyrä. 2018. "Modelling Policy Coherence Between Adaptation , Mitigation and Agricultural Productivity.":28. Available at: https://www.oecd-ilibrary.org/agriculture-and-food/modelling-policy-coherence-betweenadaptation-mitigation-and-agricultural-productivity $\left\{\backslash \_\right\}$ee62a5ae-en.

Latruffe, L., and C. Nauges. 2014. "Technical efficiency and conversion to organic farming: the case of France." European Review of Agricultural Economics 41(2):227-253. Available at: https://academic.oup.com/erae/article-lookup/doi/10.1093/erae/jbt024.

Latruffe, L., B.E. Bravo-Ureta, A. Carpentier, Y. Desjeux, and V.H. Moreira. 2016. "Subsidies and Technical Efficiency in Agriculture: Evidence from European Dairy Farms." American Journal of Agricultural Economics 0(Massot):aaw077. Available at: http://ajae.oxfordjournals.org/lookup/doi/ 10.1093/ajae/aaw077.

Lavie, E., J.A. Morábito, S.E. Salatino, A. Bermejillo, and M.F. Filippini. 2010. "Contaminación por fosfatos en el oasis bajo riego del río Mendoza." Revista de la Facultad de Ciencias Agrarias 42(1):169-184.

Li, M., W. Xu, and T. Zhu. 2018. "Agricultural Water Allocation under Uncertainty: Redistribution of Water Shortage Risk." American Journal of Agricultural Economics 00(0):141. Available at: http://fdslive.oup.com/www.oup.com/pdf/production $\left\{\backslash \_\right\}$in $\left\{\backslash \_\right.$\}progress.pdf https://academic.oup.com/ajae/advance-article/doi/10.1093/ajae/aay058/5077444.

Livingston, M.L., and A. Garrido. 2004. "Entering the policy debate: An economic evaluation of groundwater policy in flux." Water Resources Research 40(12). Available at: https://agupubs. onlinelibrary.wiley.com/doi/abs/10.1029/2003WR002737.

Llop, A., M. Buccheri, E. Comellas, A. Duek, C. Marziali, P. Puebla, and J. Reta. 2016. "Hacia la incorporación del agua subterránea en la gestión del recurso." In IFRH. 3er encuentro de investigadores en formación en recursos hídricos. Buenos Aires, Argentina. Available at: https://www.ina.gob.ar/ifrh-2016/trabajos/IFRH $\left\{\backslash \_\right\} 2016\left\{\backslash \_\right\}$paper $\left\{\backslash \_\right\} 92 . p d f$.

Lohn, P., R. Guimaraes, and N. Bucich. 2000. "Evaluación hidroquímica y de la contaminación químico-biológica de la cuenca el Carrizal - zona norte - provincia de Mendoza. Republica Argentina." In XI congresso brasileiro de Águas subterrâneas. Sao Paulo, Brazil, pp. 1-23. Available 
at: http://aguassubterraneas.abas.org/asubterraneas/article/view/23923/15985.

Ma, C., W. Mu, J. Feng, and W. Jiao. 2012. "Assessing the technical efficiency of grape production in open field cultivation in China." Journal of Food, Agriculture ES Environment 10(1):345-349.

Maas, E.V. 1990. "Crop salt tolerance." In K. K. Tanji, ed. Agricultural salinity assessment and management. asce manuals and reports on engineering. New York: ASCE, pp. 262-304.

Maccari, L.C. 2004. "Proyecto de fortalecimiento institucional. Provincia de Mendoza." PROSAP. Available at: https://goo.gl/QJgDwK.

Maffei, J.A., and L. Nijensohn. 2003. "Requerimiento de Lixiviación Funcional. Concepto, Método de Determinación y Validación Biológica." Revista de la Facultad de Ciencias Agrarias UNCuyo $\operatorname{XXXV(2):1-12.~Available~at:~http://bdigital.uncu.edu.ar/objetos~}\{\backslash$ \} digitales/1719/maffeiagrarias352.pdf.

Maffioli, A., D. Ubfal, G.V. Baré, and P. Cerdán-Infantes. 2011. "Extension services, product quality and yields: the case of grapes in Argentina." Agricultural Economics 42(6):727-734. Available at: http://doi.wiley.com/10.1111/j.1574-0862.2011.00560.x.

MAGyP. 2010. Hacia una estrategia para el manejo integrado del agua de riego en la Argentina 2009 1st ed. Buenos Aires: MAGyP.

Manevska-Tasevska, G. 2012. Efficiency analysis of commercial grape-producing family farms in the Republic of Macedonia. Doctoral thesis. Swedish Universit of Agricultural Sciences. Uppsala. Available at: https://core.ac.uk/download/files/385/11697915.pdf.

Margat, J., and J. van der Gun. 2013. Groundwater around the world 1st ed. Boca Raton, FL: CRC Press. Available at: http://www.crcpress.com.

Medawar, A., I. Perlbach de Maradona, E. Pasteris, M. Garcia, M.E. Carretero, and M. Calderón. 2011. "El producto geográfico bruto de la Provincia de Mendoza en los años 2010-2011." FCE, UNCuyo. DEIE.

Meeusen, W., and J. van Den Broeck. 1977. "Efficiency Estimation from Cobb-Douglas Production Functions with Composed Error." International Economic Review 18(2):435. Available at: https: //www.jstor.org/stable/2525757?origin=crossref.

Meinzen-Dick, R. 2007. "Beyond panaceas in water institutions." Proceedings of the National Academy of Sciences 104(39):15200-15205. Available at: http://www.pnas.org/content/104/39/ 15200.full.

Miyamoto, S., F. Yuan, and S. Anand. 2010. "A Simple Model for Estimating Water Balance and Salinity of Reservoirs and Outflow."

Morábito, J.A. 2005. Desempeño del riego por superficie en el área de riego del río Mendoza Eficiencia actual y potencial. Parámetros de riego y recomendaciones para un mejor aprovechamiento 
agrícola en un marco sustentable. Master Thesis. Universidad Nacional de Cuyo. Available at: http://bdigital.uncu.edu.ar/objetos $\left\{\backslash \_\right\}$digitales/4137/morabito.pdf.

Morábito, J.A., C.M. Mirábile, and S.E. Salatino. 2007. "Eficiencia de riego superficial, actual y potencial en el área de regadío del río Mendoza (Argentina)." Ingeniería del Agua 14(3):199-213.

Morábito, J.A., S.E. Salatino, and C. Schilardi. 2012. "El desempeño del uso agrícola del agua en los oasis de los ríos Mendoza y Tunuyán a través de nuevos indicadores." In VI jornadas de actualización en riego y fertirriego. prácticas para incrementar la productividad y asegurar la sostenibilidad del uso del agua y del suelo. Mendoza, Argentina.

Moreira, V.H., J.L. Troncoso, and B.E. Bravo-Ureta. 2011. "Technical efficiency for a sample of Chilean wine grape producers: A stochastic production frontier analysis." Ciencia e Investigación Agraria 38(3):321-329.

Morello, J., S.D. Matteucci, A.F. Rodríguez, M.E. Silva, and J.C. de Haro. 2012. Ecorregiones y complejos ecosistémicos argentinos 1st ed. Buenos Aires: Orientación Gráfica Editora. Available at: https://books.google.de/books?id=q-RrngEACAAJ.

Murillo-Zamorano, L.R. 2004. "Economic efficiency and frontier techniques." Journal of Economics Surveys 18:1(1):33-77.

Murty, S., R. Robert Russell, and S.B. Levkoff. 2012. "On modeling pollution-generating technologies." Journal of Environmental Economics and Management 64(1):117-135. Available at: http://linkinghub.elsevier.com/retrieve/pii/S0095069612000356.

Njuki, E., and B.E. Bravo-Ureta. 2015. "The Economic Costs of Environmental Regulation in U.S. Dairy Farming: A Directional Distance Function Approach." American Journal of Agricultural Economics 97(4):1087-1106. Available at: https://academic.oup.com/ajae/article-lookup/doi/10. 1093/ajae/aav007.

Njuki, E., B.E. Bravo-Ureta, and D. Mukherjee. 2016. "The Good and the Bad: Environmental Efficiency in Northeastern U.S. Dairy Farming." Agricultural and Resource Economics Review 45(01):22-43.

NRC. 1997. Valuing ground water. Economic concepts and approaches. Washington, D.C.: National Academy Press.

OECD. 2017. Diffuse Pollution, Degraded Waters OECD Studi. Paris: OECD Publishing. Available at: http://www.oecd-ilibrary.org/environment/diffuse-pollution-degradedwaters $\left\{\backslash \_\right.$\}9789264269064-en.

OECD. 2015. Drying Wells, Rising Stakes. Paris: OECD Publishing. Available at: http://www.oecdilibrary.org/agriculture-and-food/drying-wells-rising-stakes $\left\{\backslash \_\right.$\}9789264238701-en.

OECD. 2003. Environmentally Harmful Subsidies M. Hartmann and X. Kostrov, eds. OECD Publishing. Available at: http://www.oecd-ilibrary.org/agriculture-and-food/environmentally-harmful- 
subsidies\{\_\}9789264104495-en.

OECD. 2018. "Financing Climate Futures." No. September, OECD/UN/World Bank Group 2018. OECD. 2011. Water governance in OECD countries: A multi-level approach. OECD Publishing. Available at: http://www.oecd-ilibrary.org/agriculture-and-food/mitigating-droughts-and-floods-inagriculture $\left\{\backslash \_\right\} 9789264246744$-en.

OECD/FAO. 2012. Agricultural Outlook 2012. OECD Publishing. Available at: http://www.oecdilibrary.org/agriculture-and-food/oecd-fao-agricultural-outlook-2012\{\_\}agr $\left\{\backslash \_\right.$\}outlook-2012-en.

OECD/FAO. 2018. OECD-FAO Agricultural Outlook 2018-202\%. Paris/Rome: OECD. Available at: http://www.agri-outlook.org/Agricultural-Outlook-2018.pdf.

OEI/DGI. 2006. "Integración de información, para el diagnóstico y gestión de la calidad del recurso hídrico en cuencas de la provincia de Mendoza, Argentina." Organización de los Estados Iberoamericanos (OEI). Departamento General de Irrigación (DGI).

OIV. 2018. "State of the Vitiviniculture World Market." The International Organization of Vine; Wine. Available at: http://www.oiv.int/en/technical-standards-and-documents/statistical-analysis/ state-of-vitiviniculture.

Oster, J.D., and D. Wichelns. 2003. "Economic and agronomic strategies to achieve sustainable irrigation." Irrigation Science 22(3-4):107-120.

Ostrom, E. 1990. Governing the commons: the evolution of institutions for collective actions 1st ed. Cambridge: Cambridge University Press.

Ostrom, E. 2014. "Institutions and sustainability of ecological systems." In S. Galiani and I. Sened, eds. Institutions, property rights, and economic growth. Cambridge: Cambridge University Press, p. 339.

Ostrom, E. 2012. The Future of the Commons. London: The Institute of Economic Affairs.

OVA. 2018. "Precio promedio mensual de uva." Available at: http://observatoriova.bolsamza.com.ar [Accessed September 23, 2018].

O'Donnell, C.J. 2014. "Econometric estimation of distance functions and associated measures of productivity and efficiency change." Journal of Productivity Analysis 41(2):187-200.

Parmeter, C.F. 2014. "Efficiency analysis: a primer on recent advances." Foundations and Trends in Econometrics 7(3-4):191-385. Available at: http://www.nowpublishers.com/articles/ foundations-and-trends-in-econometrics/ECO-023.

Pfeiffer, L., and C.-Y.C. Lin. 2014. "The effects of energy prices on agricultural groundwater extraction from the high plains aquifer." American Journal of Agricultural Economics 96(5):1349-1362. Available at: http://ajae.oxfordjournals.org/cgi/doi/10.1093/ajae/aau020 
http://ajae.oxfordjournals.org/content/96/5/1349.abstract.

Piesse, J., B. Conradie, C. Thirtle, and N. Vink. 2018. "Efficiency in wine grape production: comparing long-established and newly developed regions of South Africa." Agricultural Economics 49(2):203-212. Available at: http://doi.wiley.com/10.1111/agec.12409.

Pinto, M., G.E. Rogero, and M.M. Andino. 2006. Ley de aguas de 1884. Comentada y concordada 1st ed. Mendoza, Argentina: Irrigación Edita. Available at: https://goo.gl/DR8p6s.

Puebla, P., A. Llop, A. Bertranou, O. Zoia, N. Falótico, G.E. Fasciolo, E.A. Comellas, and J. Reta. 2005. "Gestión integral de los recursos hídricos (GIRH). El caso del agua subterránea."

Pulido-Velázquez, M., E. Alvarez-Mendiola, and J. Andreu. 2013. "Design of efficient water pricing policies integrating basinwide resource opportunity costs." Journal of Water Resources Planning and Management 139(5):583-592.

Pulido-Velázquez, M., J. Andreu, and A. Sahuquillo. 2006. "Economic optimization of conjunctive use of surface water and groundwater at the basin scale." Journal of Water Resources Planning and Management 132(6):454-467.

PwC. 2009. "Efectos del cambio climático sobre la industria vitivinícola de Argentina y Chile."

Qureshi, M.E., K. Schwabe, J. Connor, and M. Kirby. 2010. "Environmental water incentive policy and return flows." Water Resources Research 46(4). Available at: http://doi.wiley.com/10.1029/ 2008WR007445.

Reifschneider, B.Y.D., and R. Stevenson. 1991. "Systematic Departures From the Frontier: A Framework For The Analysis of Firm Inefficiency." International Economic Review 32(3):715-723.

Reinhard, S., C.K. Lovell, and G. Thijssen. 1999. "Econometric Estimation of Technical and Environmental Efficiency: An Application to Dutch Dairy Farms." American Journal of Agricultural Economics 81(1):44-60. Available at: https://academic.oup.com/ajae/article-lookup/doi/10.2307/ 1244449.

Reta, J. 2005. "La contaminación de las aguas subterráneas: el caso de los acuíferos de UgartecheCarrizal." In A. Scoones and E. Sosa, eds. Conflictos socio-ambientales y políticas públicas en la provincia de mendoza. Mendoza, Argentina: OIKOS red ambiental, pp. 340-357.

Richard-Jorba, R.A. 2007. "Crisis y transformaciones recientes en la región vitivinícola argentina: Mendoza y San Juan, 1970-2005." Estudios Sociales 16(31):81-123. Available at: http://www.scielo. org.mx/pdf/estsoc/v16n31/v16n31a3.pdf.

Riera, F.S., B. Bruemmer, and A.J. Gennari. 2017. "Política Económica de los Subsidios Energéticos para Riego con Agua Subterránea en Mendoza, Argentina." In M. Pinto, J. Estrella, and A. J. Gennari, eds. Agua y sociedad. Ciudad Autónoma de Buenos Aires: Lajouane, pp. 255-290. Available 
at: http://grupomontevideo.org/sitio/wp-content/uploads/2015/11/Agua-y-Sociedad-ebook-.pdf.

Rodriguez, D.J., A. Delgado, P. DeLaquil, and A. Sohns. 2013. "Thirsty Energy.”

Romero, P., J. García García, J.I. Fernández-Fernández, R.G. Muñoz, F. del Amor Saavedra, and A. Martínez-Cutillas. 2016. "Improving berry and wine quality attributes and vineyard economic efficiency by long-term deficit irrigation practices under semiarid conditions." Scientia Horticulturae 203:69-85. Available at: https://linkinghub.elsevier.com/retrieve/pii/S0304423816301194.

Rosegrant, M.W., C. Ringler, D.C. McKinney, X. Cai, A. Keller, G. Donoso, C. Ringler, X. Cai, G. Donoso, D.C. McKinney, X. Cai, A. Keller, and G. Donoso. 2000. "Integrated economic-hydrologic water modeling at the basin scale: The Maipo river basin." Agricultural economics 24(63):33-46.

Ruiz, A.M., and J.A. Vitale. 2011. "Prospectiva y Estrategia: El Caso del Plan Estratégico Vitivinícola 2020 (PEVI).” Estudios socioeconómicos de los sistemas agroalimentarios y agroindustriales Instituto Nacional de Tecnología Agropecuaria (INTA). Available at: https://inta.gob.ar/sites/default/files/script-tmp-7\{\_\}prospectiva $\left\{\backslash \_\right\}$estrategia $\left\{\backslash \_\right\}$pevi.pdf.

Sadoff, C.W., J.W. Hall, D. Grey, J.C.J.H. Aerts, M. Ait-Kadi, C. Brown, A. Cox, S. Dadson, D. Garrick, J. Kelman, P. McCornick, C. Ringler, M. Rosegrant, D. Whittington, and D. Wilberg. 2015. "Securing water, sustaining growth: report of the GWP/OECD task force on water security and sustainable growth." University of Oxford. Available at: http://www.gwp.org/Global/About GWP/Publications/The Global Dialogue/SECURING WATER SUSTAINING GROWTH.PDF.

SAGyP - INTA. 2007. "Suelos de la República Argentina." Available at: http://www.geointa.inta. gob.ar/2013/05/26/suelos-de-la-republica-argentina/.

Salomón, M., C. Sánchez, and L. Santos Pereira. 2008. "Estimación del balance hídrico mediante aplicación del modelo ISAREG en el canal segundo Vistalba, Luján de Cuyo, Mendoza (Argentina)." In Aller internacional red de riegos cyted procisur epagri. Florianópolis. Santa Catarina. Brasil: Asociación Primera Zona Río Mendoza (ASIC). Available at: http://www.asicprimerazona.com.ar/asic/publicaciones/estimacion $\left\{\backslash \_\right\}$balance $\left\{\backslash \_\right\}$vistalba.pdf.

Scheierling, S., D.O. Treguer, and J.F. Booker. 2016. "Water productivity in agriculture: looking for water in the agricultural productivity and efficiency literature." Water Economics and Policy 2(3):1650007. Available at: http://www.worldscientific.com/doi/abs/10.1142/S2382624X16500077 http://www.worldscientific.com/doi/10.1142/S2382624X16500077.

Scheierling, S.M., J.B. Loomis, and R.a. Young. 2006. "Irrigation water demand: A meta-analysis of price elasticities." Water Resources Research 42(1):1-9.

Scott, C.A., S. Vicuña, I. Blanco-Gutiérrez, F. Meza, and C. Varela-Ortega. 2014. "Irrigation efficiency and water-policy implications for river basin resilience." Hydrology and Earth System Sciences 18(4):1339-1348.

Severino, S. 2016. "Entrevista con representativo de EMESA y EPRE."

Severino, S. 2005. "Tarifa eléctrica del riego agrícola en la provincia de Mendoza: Análisis de 
alternativas de su determinación." In XX congreso nacional del agua y iii simposia de recursos hídricos del cono sur. Mendoza, Argentina.

Shah, T., M. Giordano, and A. Mukherji. 2012. "Political economy of the energy-groundwater nexus in India: exploring issues and assessing policy options." Hydrogeology Journal 20(5):995-1006. Shephard, R.W. 1972. "Theory of Cost and Production Functions." The Economic Journal 82(327):1059. Available at: https://www.jstor.org/stable/10.2307/2230285? origin=crossref.

Silanes, R. 2013. Manuel Bermejo y la ley de aguas 1st ed. Mendoza, Argentina: Departamento General de Irrigación.

Speelman, S., M. D’Haese, J. Buysse, and L. D’Haese. 2008. "A measure for the efficiency of water use and its determinants, a case study of small-scale irrigation schemes in North-West Province, South Africa." Agricultural Systems 98(1):31-39.

SSPE. 2016. "Informes de cadenas de valor. Vitivinicultura." Informes de cadenas de valor Subsecretaría de Planificación Económica. Available at: https://goo.gl/Gj9LrC.

Stein, S. 2007. "Grape Wars." In Wine, society, and globalization. New York: Palgrave Macmillan US, pp. 99-117. Available at: http://link.springer.com/10.1057/9780230609907\{\_\}6.

Sun, S., J.P. Sesmero, and K. Schoengold. 2016. "The role of common pool problems in irrigation inefficiency: a case study in groundwater pumping in Mexico." Agricultural Economics 47(1):117-127. Available at: http://doi.wiley.com/10.1111/agec.12214.

Tamini, L.D., B. Larue, and G. West. 2012. "Technical and environmental efficiencies and best management practices in agriculture." Applied Economics 44(13):1659-1672. Available at: http://www.tandfonline.com/doi/abs/10.1080/00036846.2010.548789.

Theesfeld, I. 2010. "Institutional challenges for national groundwater governance: policies and issues." Groundwater 48(1):131-142. Available at: http://doi.wiley.com/10.1111/j.1745-6584.2009.00624.x.

Theesfeld, I., C. Schleyer, and O. Aznar. 2010. "The procedure for institutional compatibility assessment: ex-ante policy assessment from an institutional perspective." Journal of Institutional Economics 6(03):377-399.

Townsend, R.F., J. Kirsten, and N. Vink. 1998. "Farm size, productivity and returns to scale in agriculture revisited: a case study of wine producers in South Africa." Agricultural Economics 19(1-2):175-180. Available at: http://doi.wiley.com/10.1016/S0169-5150(98)00033-4.

Trentacoste, E.R., C.M. Puertas, and V.O. Sadras. 2015. "Effect of irrigation and tree density on vegetative growth, oil yield and water use efficiency in young olive orchard under arid conditions in Mendoza, Argentina." Irrigation Science 33(6):429-440. Available at: http://link.springer.com/10. 1007/s00271-015-0479-z.

Urso, A., G. Timpanaro, F. Caracciolo, and L. Cembalo. 2018. "Efficiency analysis of Italian wine producers." Wine Economics and Policy 7(1):3-12. Available at: https://linkinghub.elsevier.com/ 
retrieve/pii/S2212977417300492.

Van den Bosch, M.E. 2012. "Sustentabilidad económica comparativa de los principales modelos productivos de viñateros de uvas finas de la Provincia de Mendoza." In XLIII reunión anual de la aaea octubre. Corrientes, pp. 1-22.

Van den Bosch, M.E. 2008. Un modelo de desarrollo sustentable en las áreas bajo riego de los distritos Ugarteche y El Carrizal. Departamento de Luján de Cuyo. Provincia de Mendoza: Un aporte para el ordenamiento territorial rural. Master thesis. Universidad Nacional de Cuyo. Available at: http://www.bdigital.uncu.edu.ar/4631.

Wagner, L.S. 2010. Problemas ambientales y conflicto social en Argentina. Movimientos socioambientales en Mendoza. La defensa del agua y el rechazo a la megaminería en los inicios del siglo XXI. Doctoral thesis. Universidad Nacional de Quilmes.

Wang, H.J., and P. Schmidt. 2002. "One-step and two-step estimation of the effects of exogenous variables on technical efficiency levels." Journal of Productivity Analysis 18(2):129-144.

Wang, X.-y. 2010. "Irrigation Water Use Efficiency of Farmers and Its Determinants: Evidence from a Survey in Northwestern China." Agricultural Sciences in China 9(9):1326-1337. Available at: http://linkinghub.elsevier.com/retrieve/pii/S1671292709602236.

Ward, F.A., and M. Pulido-Velazquez. 2008. "Water conservation in irrigation can increase water use." Proceedings of the National Academy of Sciences 105(47):18215-18220. Available at: http://www.pnas.org/cgi/doi/10.1073/pnas.0805554105.

WEF. 2011a. "Agriculture." In Water security. Washington, DC: World Economic Forum; Island Press/Center for Resource Economics, pp. 17-43. Available at: http://link.springer.com/10.5822/9781-61091-026-2\{\_\}1.

WEF. 2011b. "Energy." In Water security. the water-food-energy-climate nexus. Washington, DC: World Economic Forum; Island Press/Center for Resource Economics, pp. 44-67. Available at: http://link.springer.com/10.5822/978-1-61091-026-2-2.

World Bank. 2017. "Implementation Completition Report. AR PROSAP2 2nd Provincial Agricultural Development." No. ICRR0020961, World Bank. Available at: http://documents.worldbank. org/curated/pt/957061516292814141/pdf/ICRR-Disclosable-P106684-01-18-2018-1516292791420. pdf.

World Bank. 2008. "The political economy of policy reform: Issues and implications for policy dialogue and development operations." No. 44288-GLB, The World Bank. Available at: www. worldbank.org.

WWAP/UN-Water. 2018. "The United Nations World Water Development Report 2018: NatureBased Solutions for Water." World Water Assessment Programme / United Nations-Water; UNESCO. Available at: http://www.unesco.org/new/en/natural-sciences/environment/water/wwap/wwdr/ 
2018-nature-based-solutions/.

Zhang, X., R.R. Walker, R.M. Stevens, and L.D. Prior. 2002. "Yield-salinity relationships of different grapevine (Vitis vinifera L.) scion-rootstock combinations." Australian Journal of Grape and Wine Research 8(3):150-156. Available at: http://doi.wiley.com/10.1111/j.1755-0238.2002.tb00250.x.

Zilberman, D., T. Sproul, D. Rajagopal, S. Sexton, and P. Hellegers. 2008. "Rising energy prices and the economics of water in agriculture." Water Policy 10(SUPPL. 1):11-21. 


\section{General appendix}

Trabajo de campo para tesis doctoral de Sebastian Riera Cátedra de Análisis de Mercados Agrícolas

Departamento de Economía Agrícola y Desarrollo Rural Universidad de Göttingen (Alemania)

Encuesta de Eficiencia Ambiental

Encuesta de Eficiencia Ambiental ................................. 1

1. Identificación encuesta......................................... 2

2. Informacion del informante...................................

3. Informacion del productor ................................... 2

4. Educación informante ........................................ 2

5. Educación productor .......................................... 2

6. Informacion de la explotación .............................2

7. Manejo y certificación.......................................... 2

8. Capital pregunta ............................................ 3

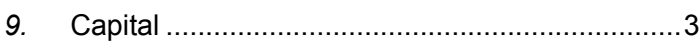

10. Galpón ................................................... 3

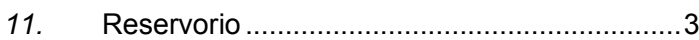

12. Tractor ................................................... 3

13. Infraestructura para elaborar vino .................... 3

14. (12.1) Establecimiento elaborador *** ............. 3

15. Capital \& Financiamiento ............................... 3

Preguntas sobre el riego ........................................... 4

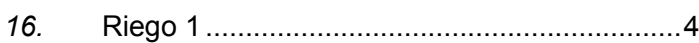

17. Riego 4. Aclare respecto a su(s) derechos de riego 4

18. Riego 5. Pozos en finca …............................... 4

19. Riego 6. Mantenimiento ................................. 4

20. Riego 6.1 Subsidio al riego agrícola ...............4

21. Riego 7. Calidad del agua y suelo ..................4

22. Riego 8 ¿Quiere medir la calidad del agua? ...4

23. Riego 9. Limitaciones del agua para riego......4

24. Riego 10. Decisiones de riego ........................4

25. Riego 11. Indique el tiempo de riego ..............4

26. Riego 13. Mantenimiento sistema de riego.....5

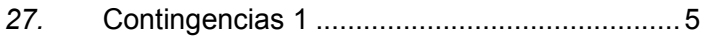

28. Contingencias 2 ......................................... 5

29. Asistencia técnica ........................................... 5

30. Agricultura de Precisión (AP) ......................... 5

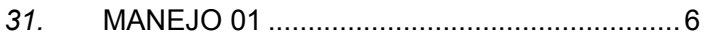

32. Manejo - Uso maquinaria $\rightarrow$ llena preg. 40 .... 6

33. Manejo del cultivo - Fertilizaciones .................. 6

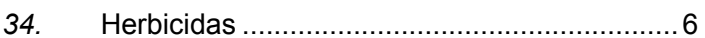

35. Curaciones - Manejo de la vid ........................ 7

36. Lobesia............................................................. 7

37. CUARTELES VID........................................ 7

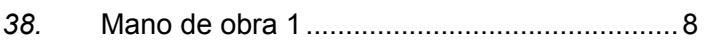

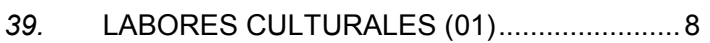

40. Labores culturales tercerizados ...................... 8

41. MAQUINARIA .............................................. 9

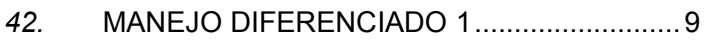

43. MANEJO DIFERENCIADO 2 (CUADRO)....9

44. MD - Fertilizantes sólidos ................................ 9

45. MD - Fertilizantes líquidos ............................. 9

46. Manejo diferenciado - Fertilización UREA .....9

47. MD - Fertilización ANIMAL ............................ 10

48. MD - Fertilizantes HIDROSOLUBLES .......... 10

49. MD-Curaciones FITOSANITARIAS adicional10

50. MD - Herbicidas. Costo adicional .................. 10

51. Manejo diferenciado - Otros ......................... 10

52. LCD - PODA ........................................... 10

53. LCD - DESBROTE ..................................... 10

54. LCD - DESPAMPANADO …...................... 10

55. LCD - Raleo (jj/ha) .................................... 10 

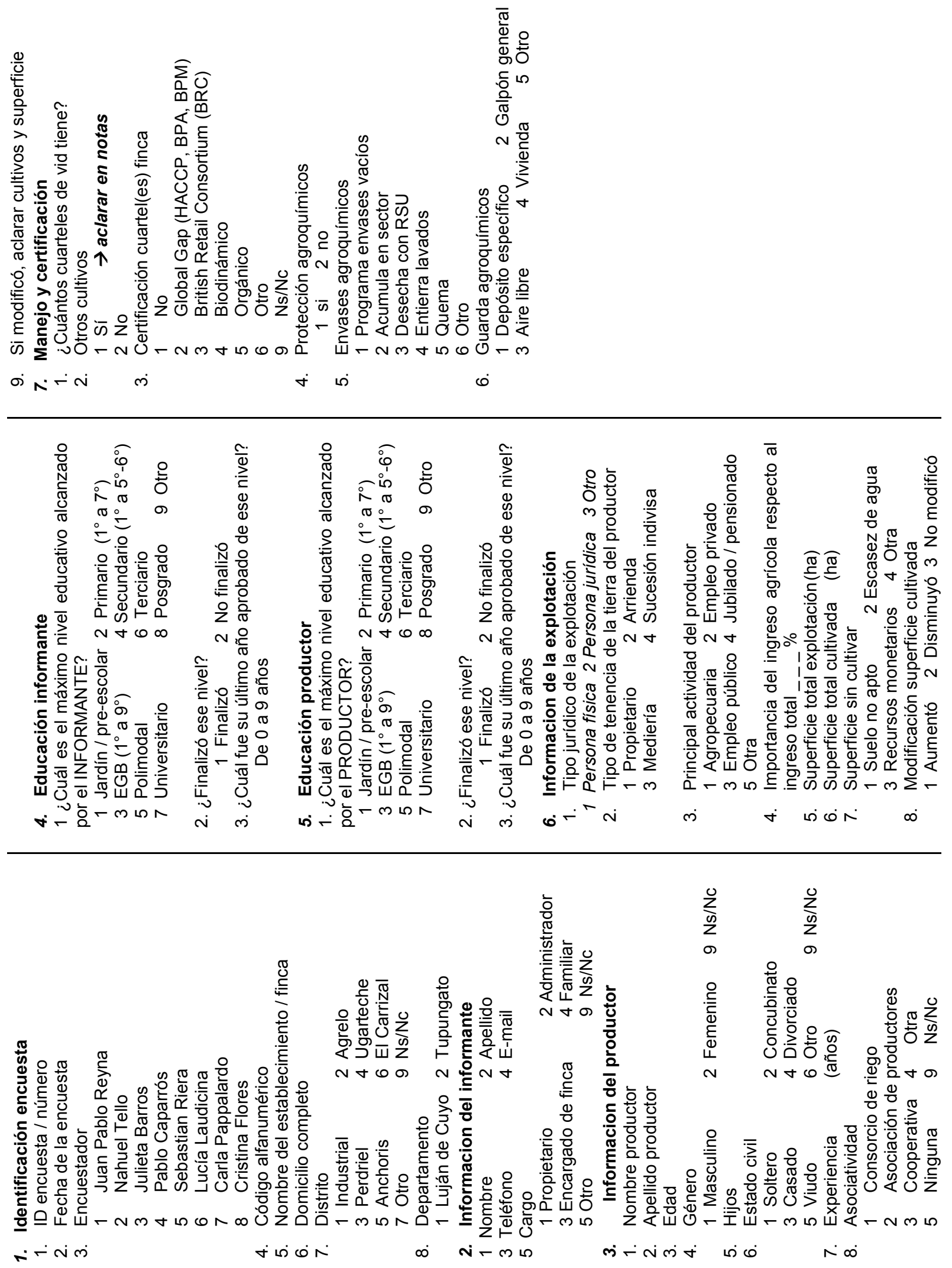
@

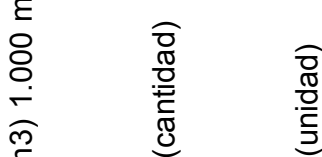

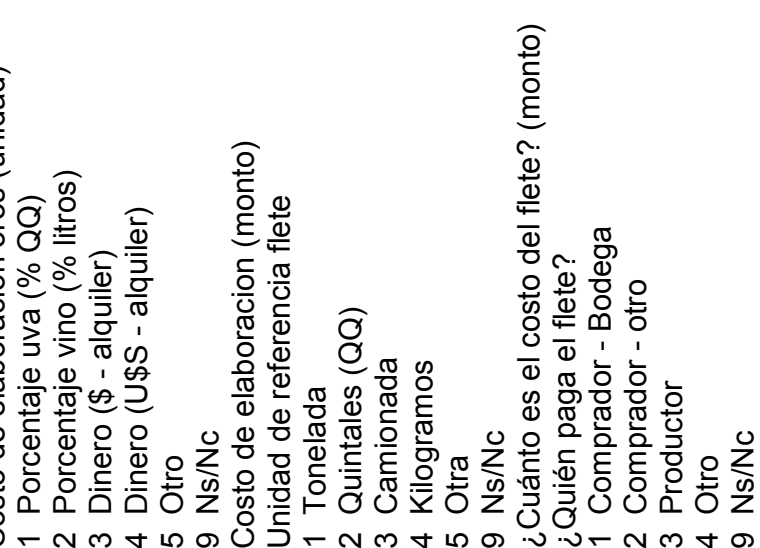

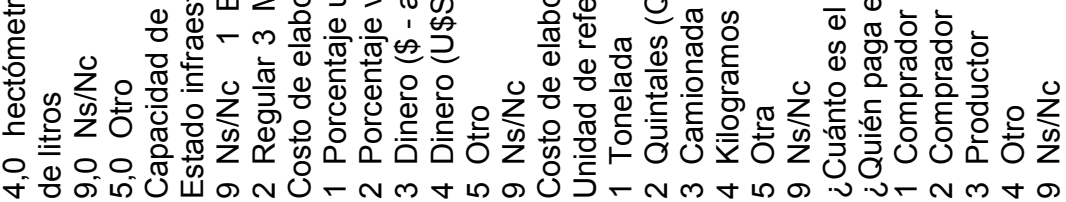

ن

$\wedge \infty$

क음

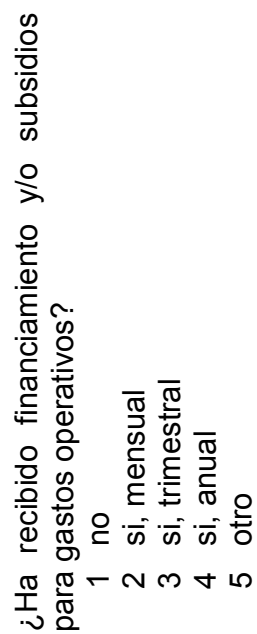

nं
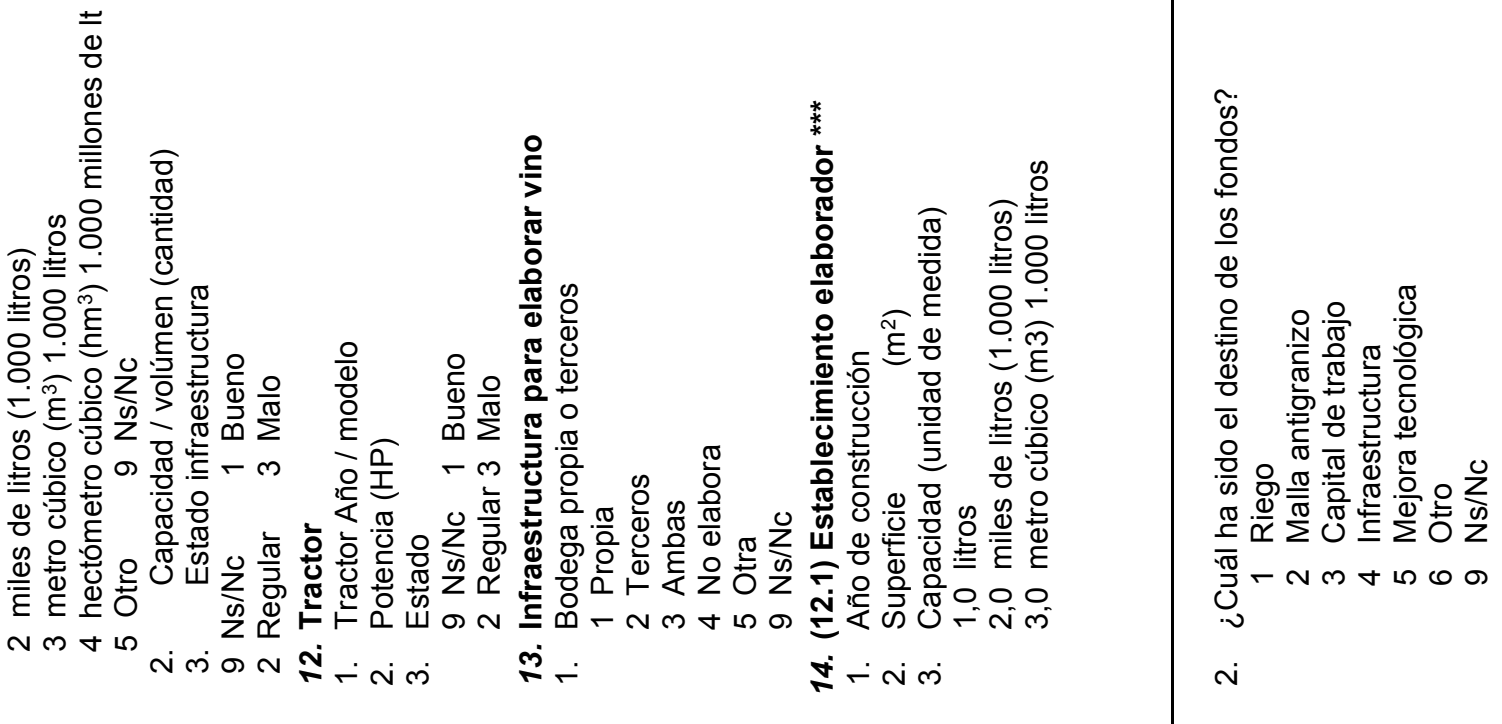

i

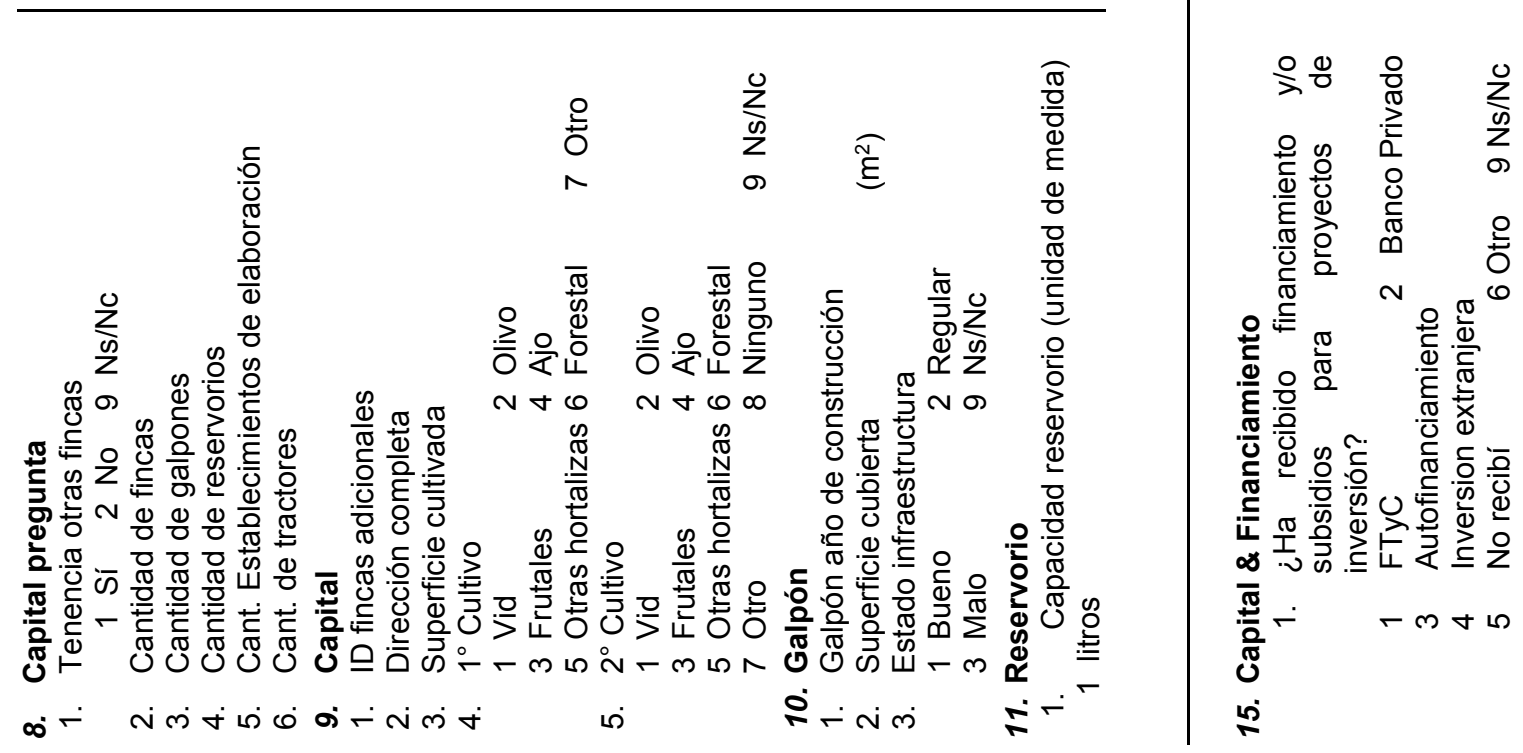



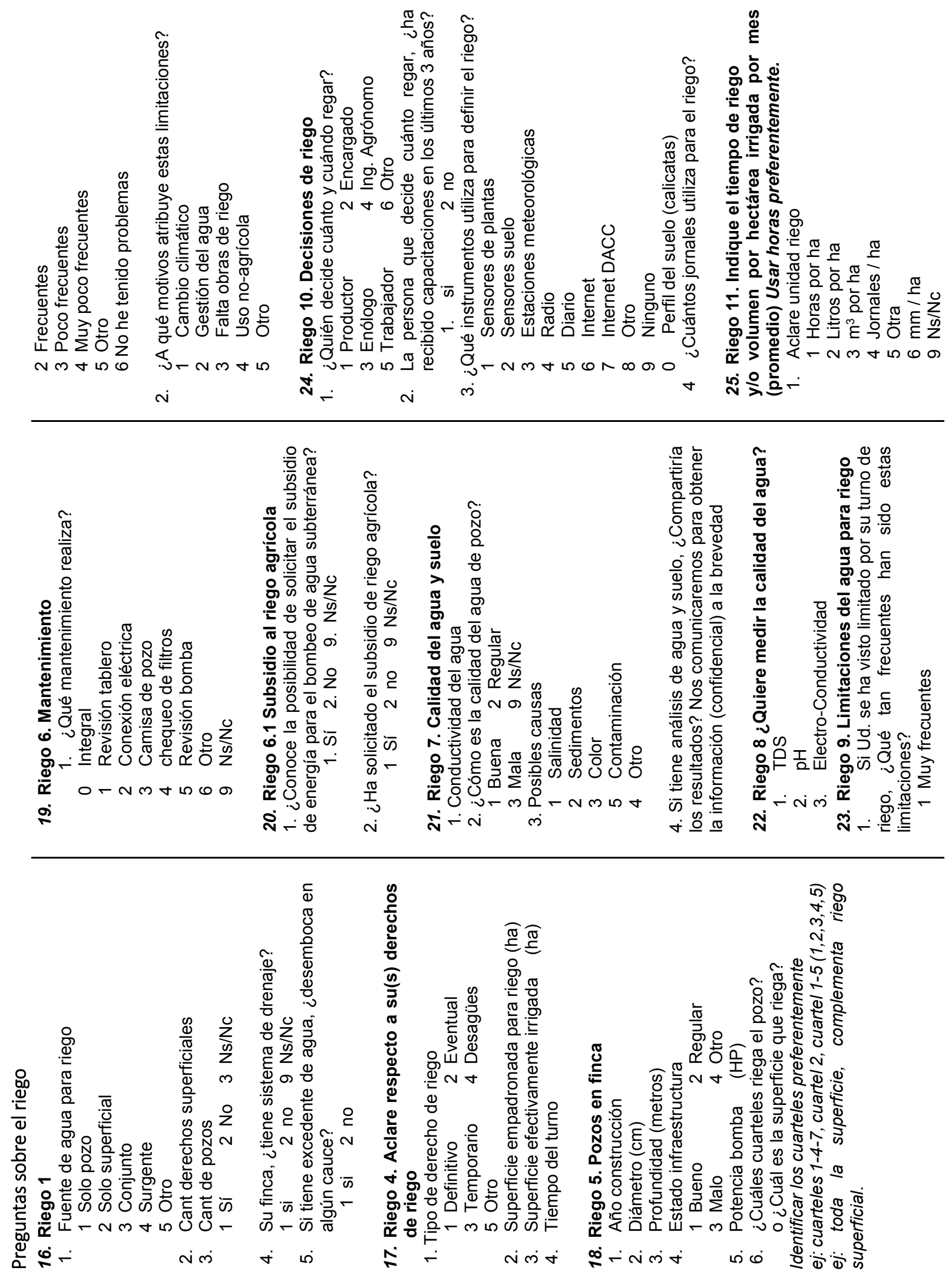

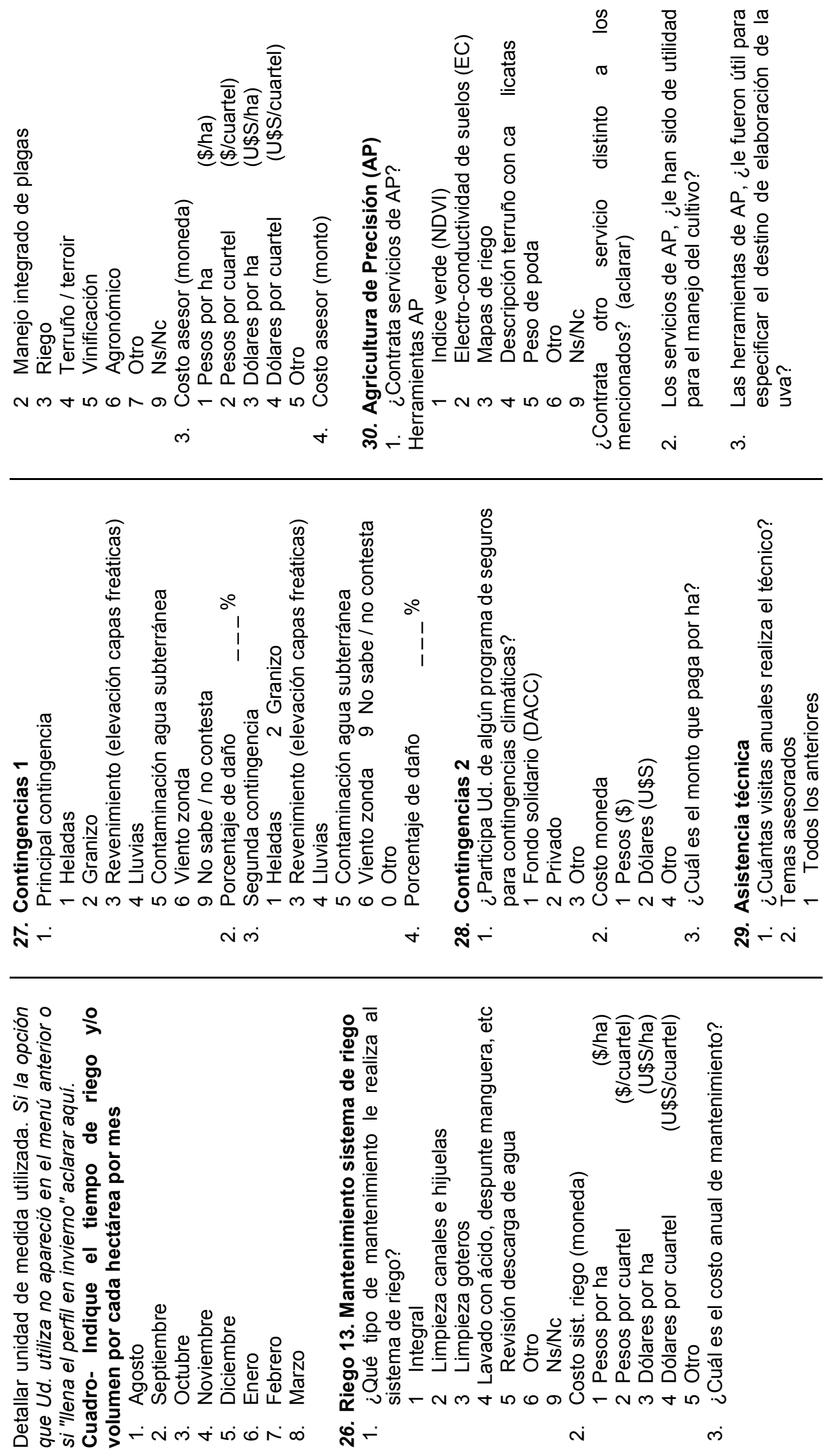

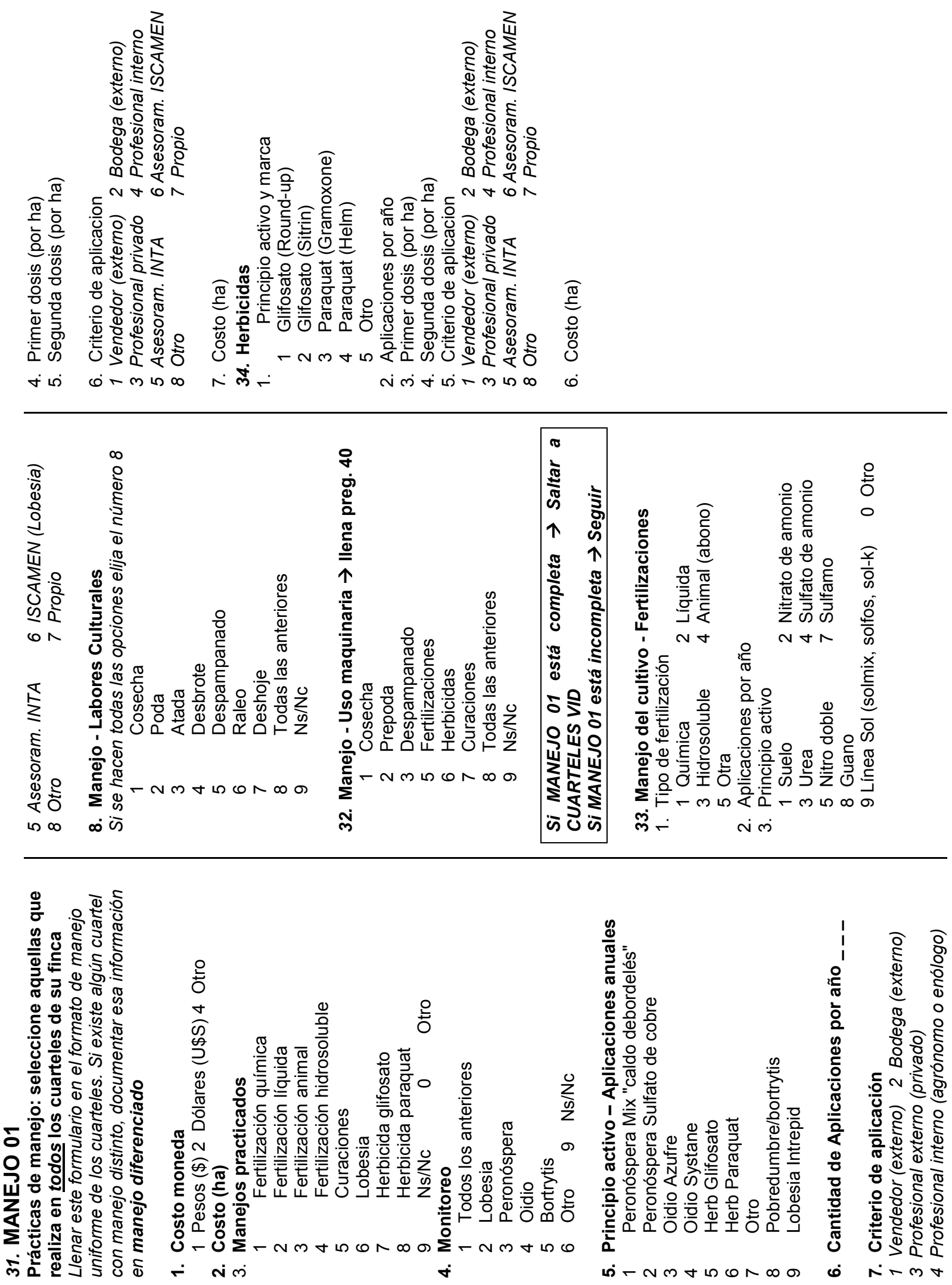

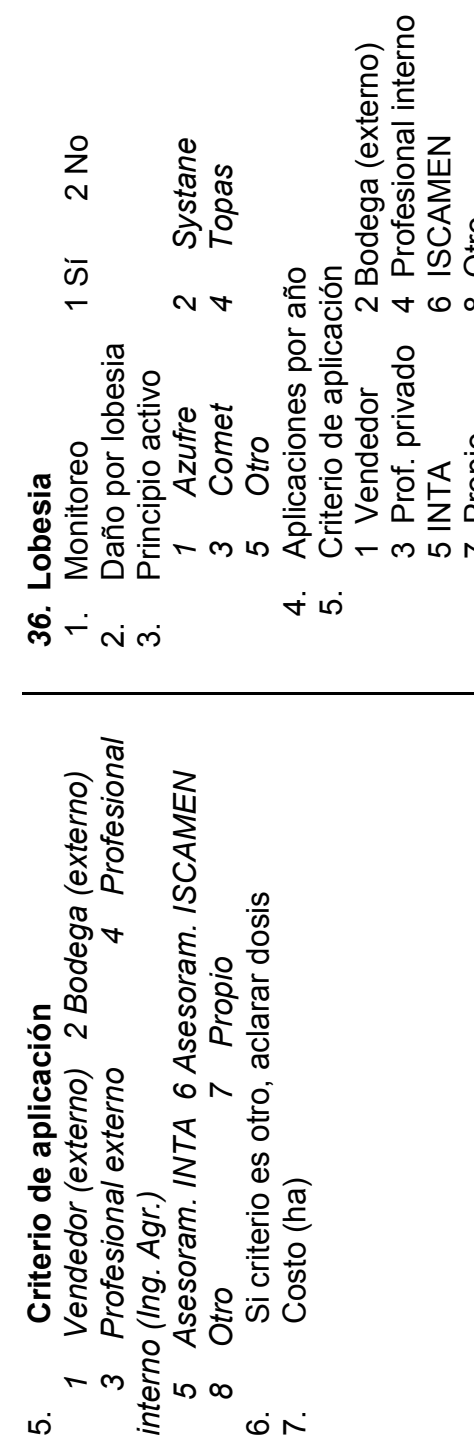

응으은

N $\forall$ 它 :은 $\sim * \infty$

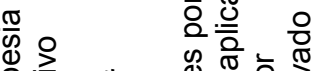

은

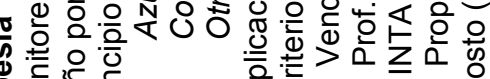

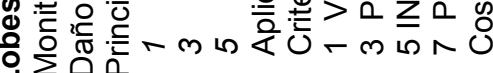
+ंi

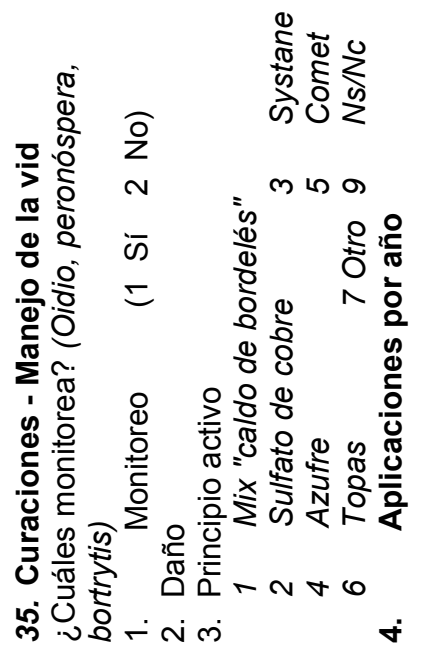

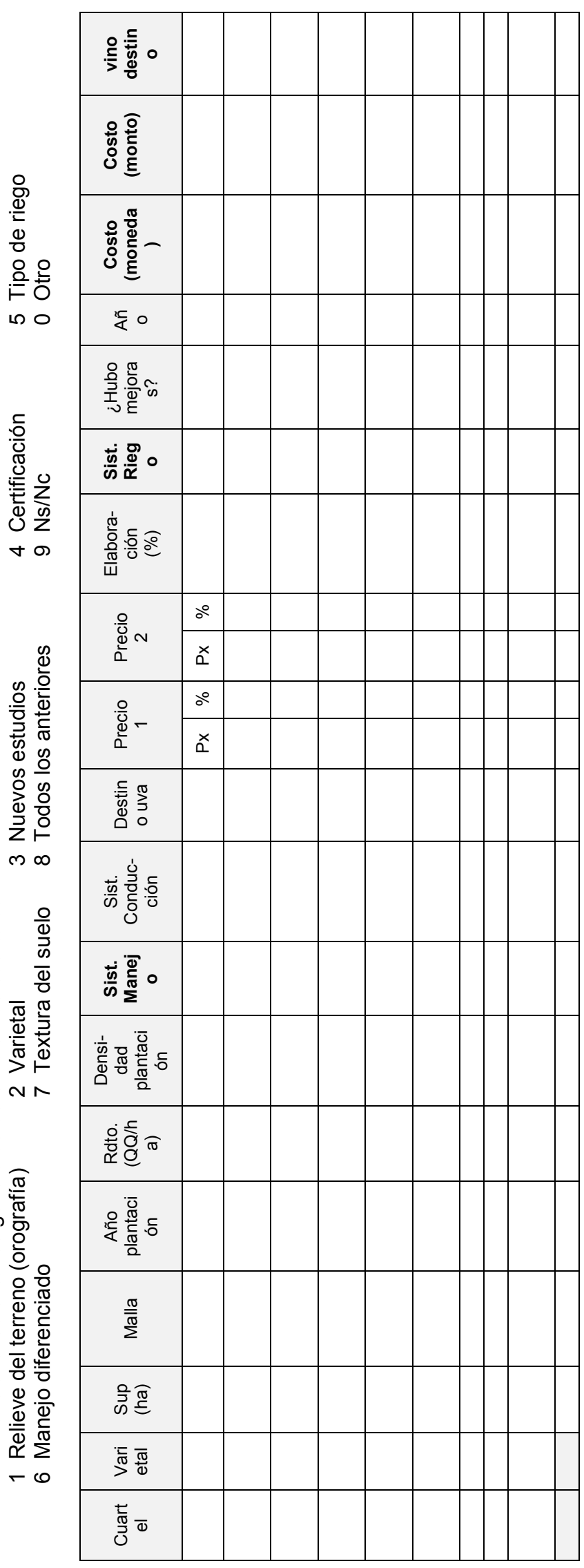



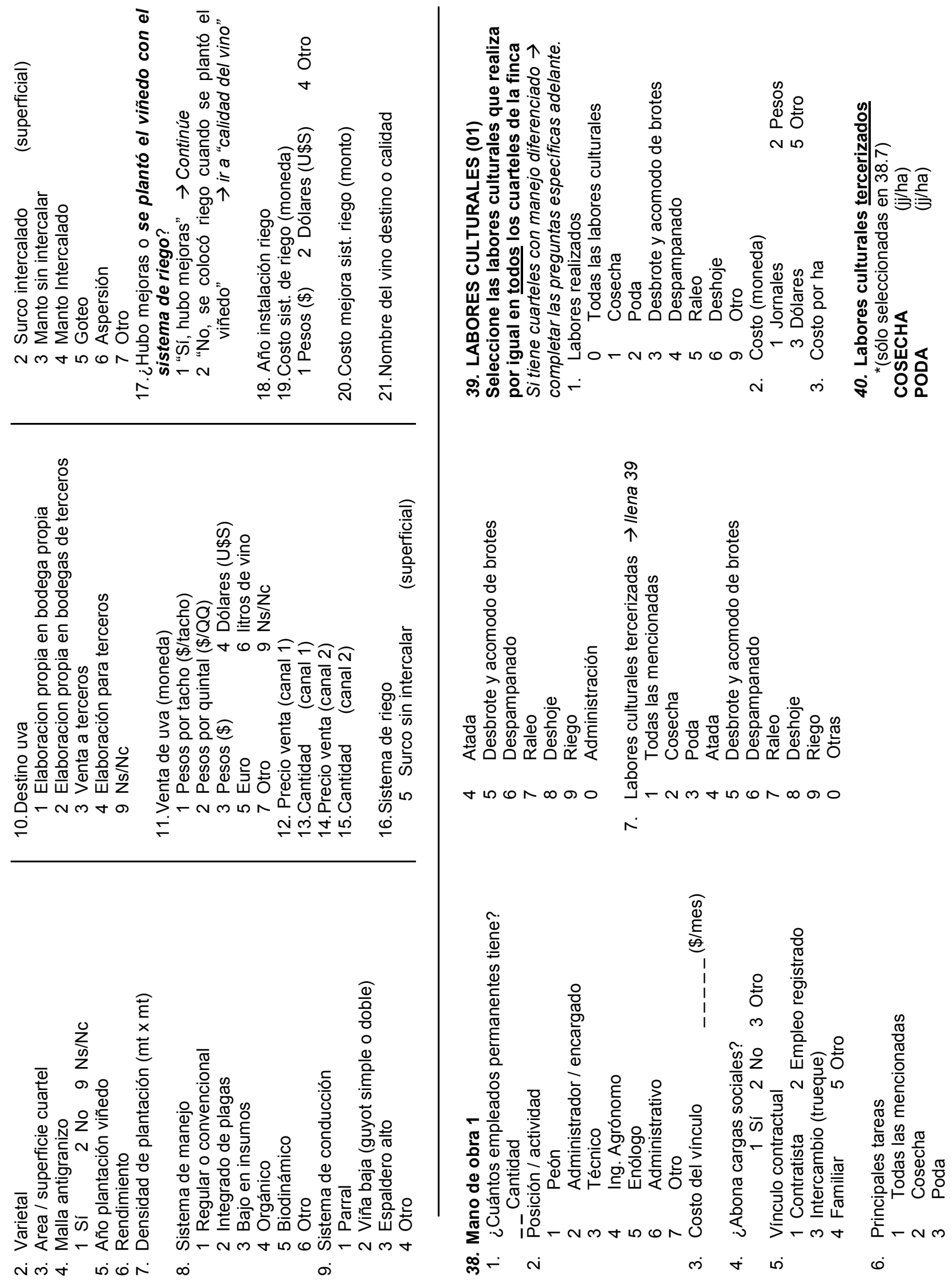

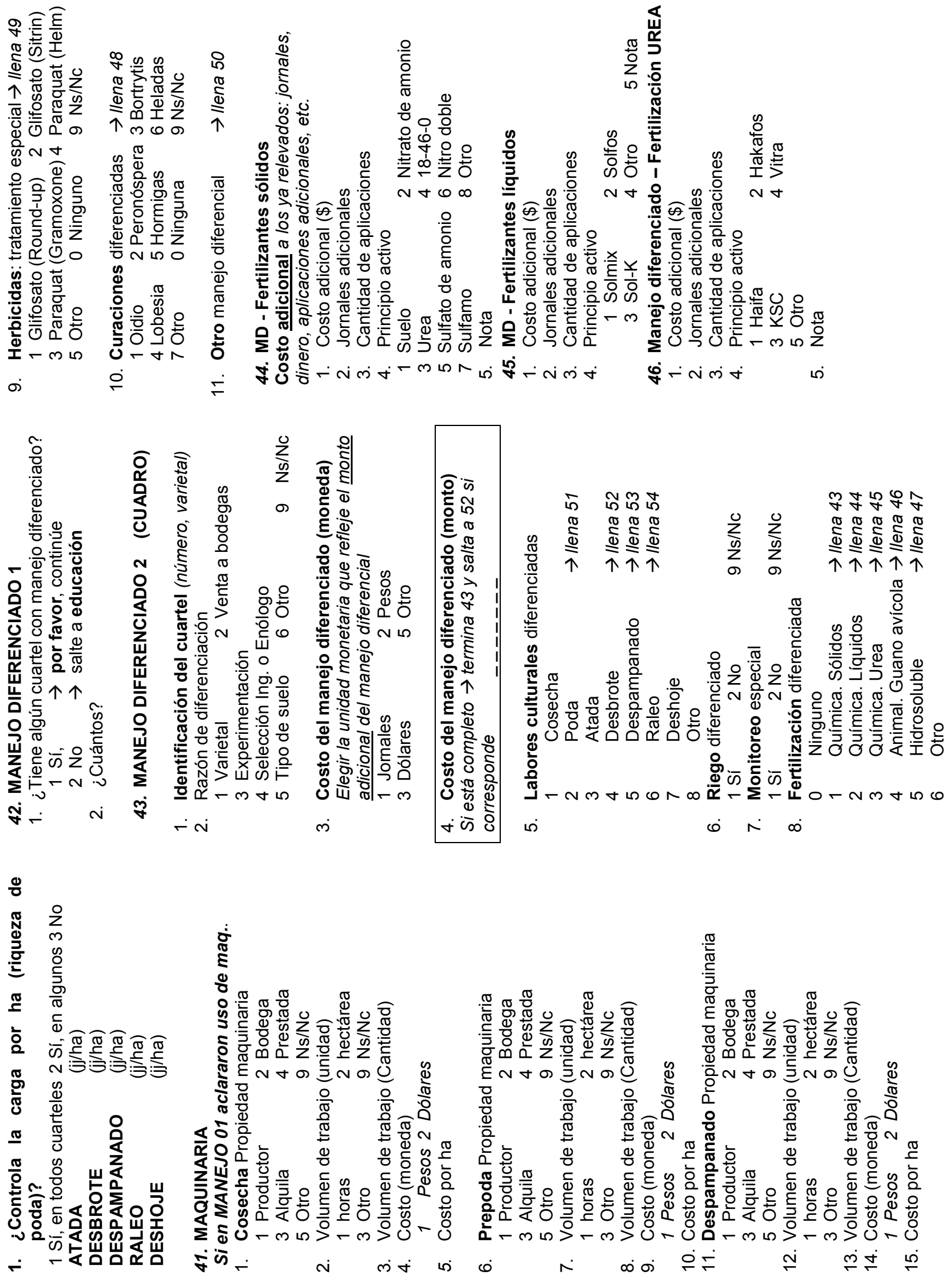

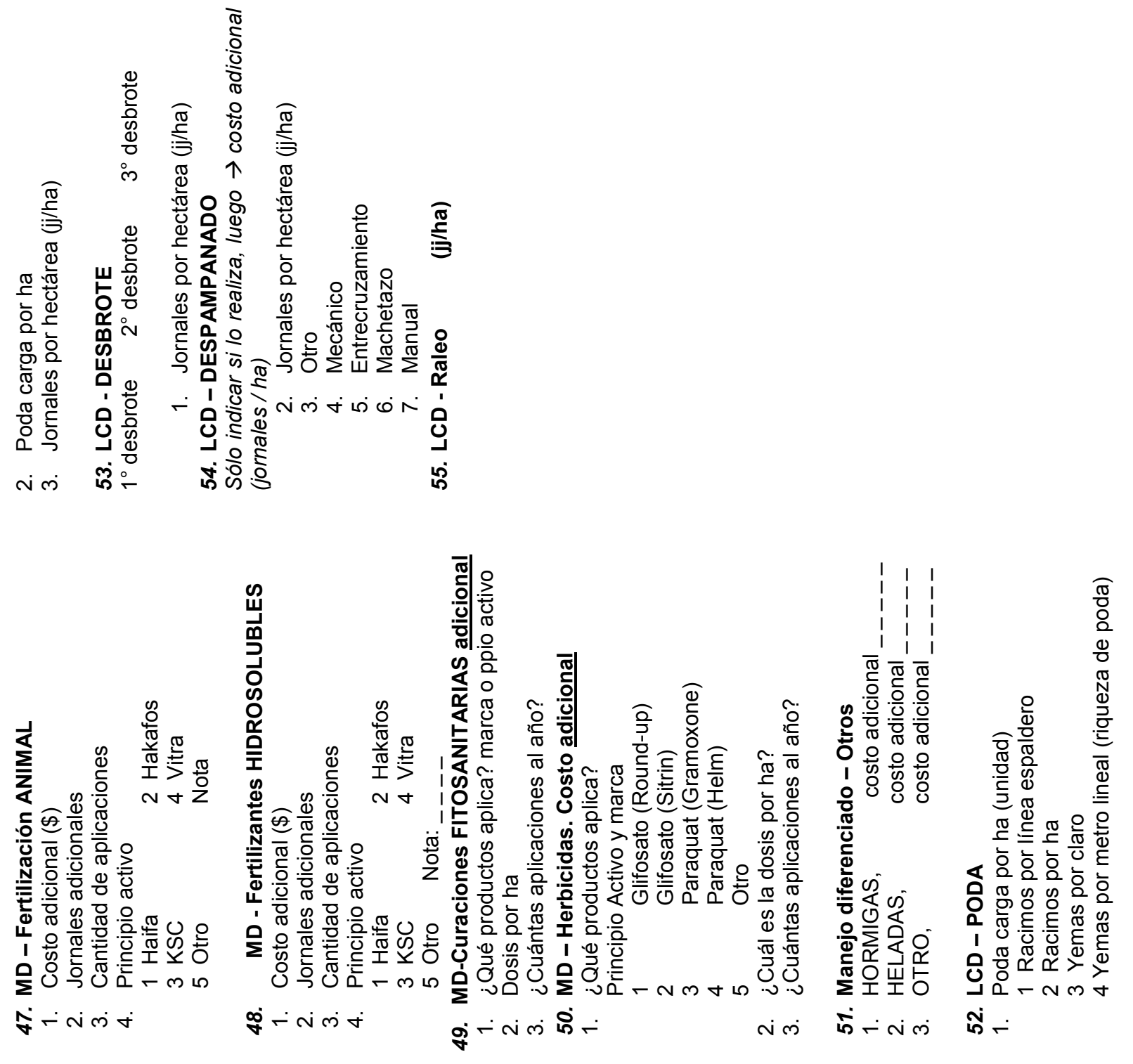


\author{
Sebastian Riera Yankeliovich \\ $\mathrm{PhD}$ candidate in Agricultural Economics. M.Sc. \\ + $4915226640612 \cdot$ sebary@gmail.com
}

Summary

Economist pursuing a Ph.D. in Agricultural Economics. Relevant experience in agriculture modelling, quantitative and qualitative analysis.

Professional Interest: Technical efficiency, environmental efficiency, water \& natural resources economics, agricultural policy analysis, renewable energies, socioeconomics, valuation of environmental externalities and Ecosystem Services (ES).

Communication and intercultural skills: Participation in international and multi-disciplinary groups, education centres and organizations.

Languages: English (D2), German (B1) and French (A2).

Academic Qualifications

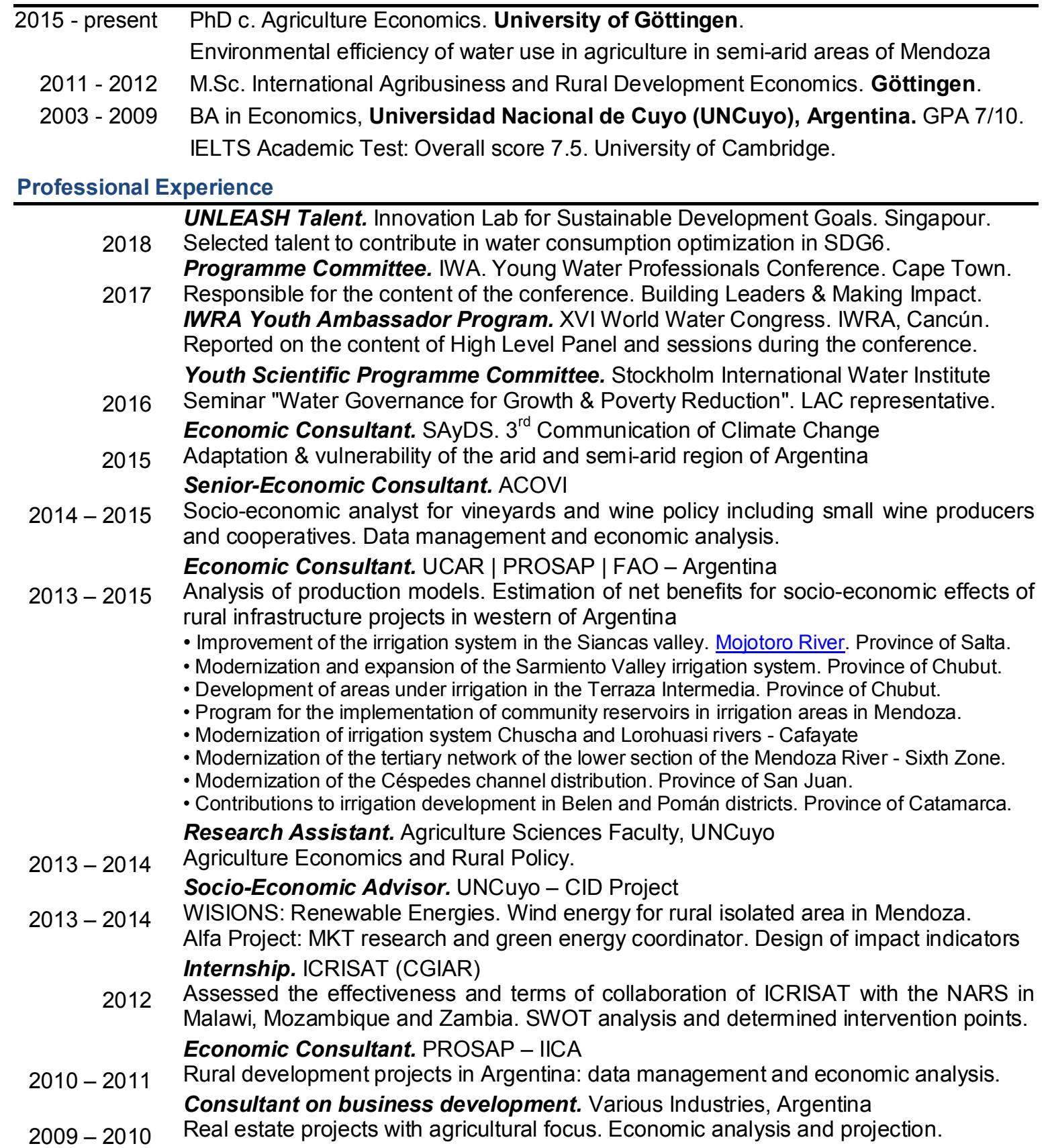






Teaching experience

2016-17 Universidad de Congreso. Puente Program. English taught lessons

Water Management in Semi-Arid Regions. Sustainable Development: LAC perspective.

Topics of Agribusiness \& Rural Development in the Cuyo Region.

2013-15 FCA - UNCuyo. Teacher assistant. Chair of Agricultural Economics and Policy.

Book chapters

2017 Económica de los Subsidios Energéticos para Riego con Agua Subterránea en Mendoza, Argentina. Riera, F. S.; Bruemmer, B.; Gennari, A. En Alvarez Goncalez, Cristina Viviana [et al.]. Agua y Sociedad $-1^{a}$ edición especial - CABA, Argentina: Lajouane, 2017. 493 p.

Política ISBN 978-950-9580-18-3 $\underline{\text { link }}$

Conference papers

2017 XI Annual American Association of Wine Economist Conference. Padua, Italia.

Political economy of energy subsidies for grapevine irrigation. link

Agri benchmark: an international network approach to the economic analysis of wine grape production systems. link

XVI World Water Conference. IWRA. Cancún, Mexico.

Political economy of energy subsidies for groundwater irrigation. link

Estimation of irrigation efficiency and economic value of environmental trade-offs in grapevine production. link

Dresden Nexus Conference. UNU-Flores. Dresden, Germany link

2016 IRFH 2016 - 3er. Encuentro de Investigadores en Formación en Recursos Hídricos:

Resúmenes / editado por Martín Sabarots Gerbec ... [et.al.]. - 1a ed. - Ezeiza: Instituto

Nacional del Agua, 2016. ISBN 978-978-45194-6-7 link

Water Policy for Food Security. World Food Center. UC Davis. California.

2015 ICBAE 2014. Retrieved Utility on Groundwater Exploitation for Agriculture Use. Talca.

2014 Tropentag: The Role of the NARS in Malawi, Mozambique and Zambia. Hohenheim link

2013 FAO | Rura-Invest: Economic Analysis of Terraza Intermedia Project. Rome

Critical Economics Conference. Political and Economic Effects of GMOs introduction.

Courses \& Seminars

2016 Climate Change \& Biodiversity in LatAm: Challenges of Agriculture. Talca, Chile.

2015 Modelling the Bioeconomy. Summer School. Universität Hohenheim

2015 Organic Agriculture \& Climate Change. Winter School. DAAD - Alumni. Hohenheim.

2012 Workshop 'Feed the World'. ICRISAT. Chitedze Agricultural Research Station, Malawi.

2010 Pyxis Gestion Coaching - Auto-leadership Coaching Course for Professionals (CCA).

\section{Other activities}

2016 - present Member of the Environmental Science Institute (ICA), UNCuyo

1997 - present Interested in sports, travel \& culture. Teamwork \& leadership values as a Rugby player.

2001 - 2002 Rotary International Exchange Student. Cultural Ambassador in Ludlow, VT. USA. 


\section{Appendix 4:}

\section{E C L A R A T I O N S}

1. I, hereby, declare that this Ph.D. dissertation has not been presented to any other examining body either in its present or a similar form.

Furthermore, I also affirm that I have not applied for a Ph.D. at any other higher school of education.

Göttingen,

(Signature)

(Name in block capitals)

2. I, hereby, solemnly declare that this dissertation was undertaken independently and without any unauthorised aid.

Göttingen,.

(Signature)

(Name in block capitals) 